Document downloaded from:

http://hdl.handle.net/10251/158949

This paper must be cited as:

Dhakshinamoorthy, A.; Navalón Oltra, S.; Asiri, AM.; García Gómez, H. (2020). Metal organic frameworks as solid catalysts for liquid-phase continuous flow reactions. Chemical Communications. 56(1):26-45. https://doi.org/10.1039/c9cc07953j

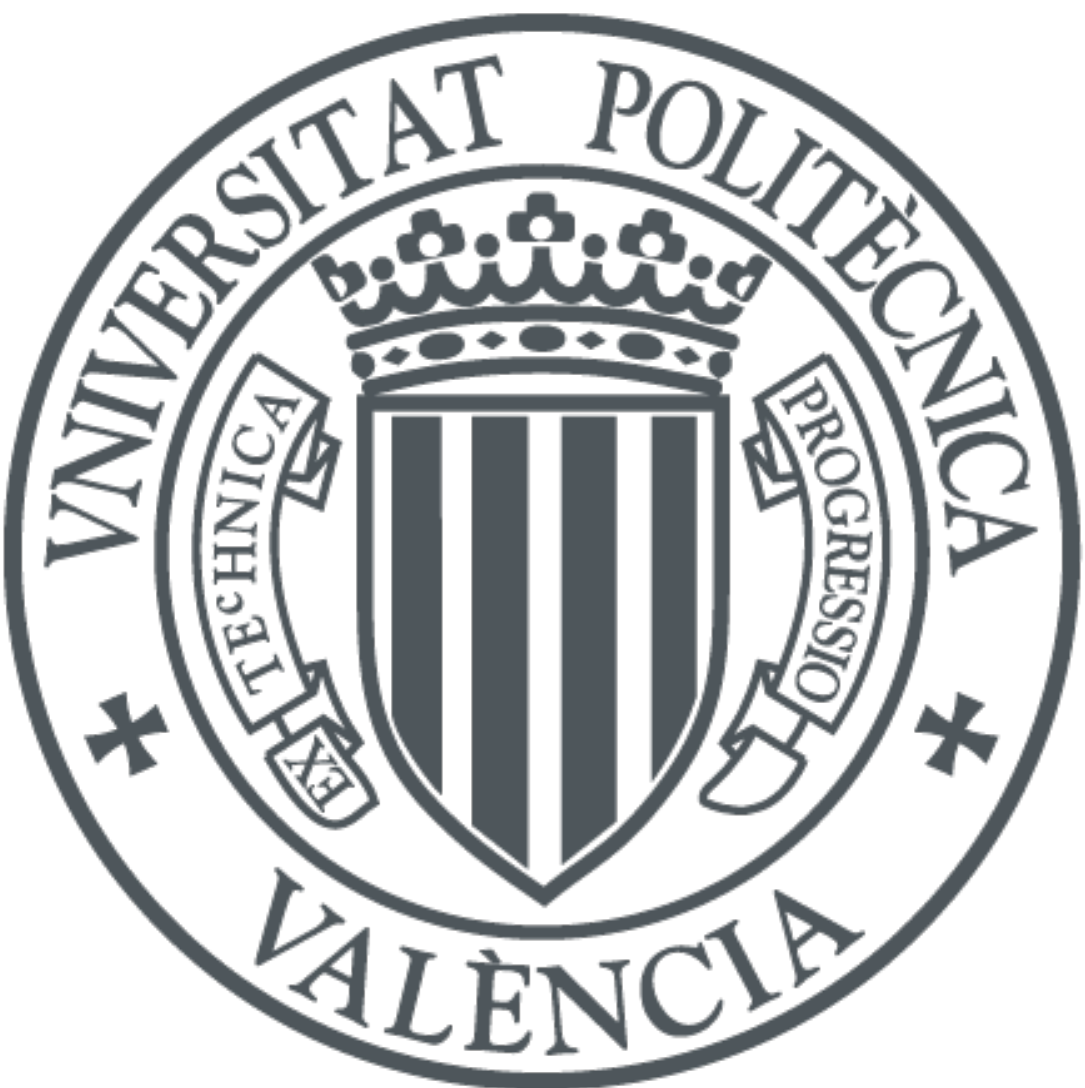

The final publication is available at

https://doi.org/10.1039/c9cc07953j

Copyright The Royal Society of Chemistry

Additional Information 


\title{
Metal organic frameworks as solid catalysts for liquid-phase continuous flow reactions
}

Amarajothi Dhakshinamoorthy, ${ }^{* a}$ Sergio Navalon, ${ }^{\mathrm{b}}$ Abdullah M. Asiri, ${ }^{\mathrm{c}}$ Hermenegildo $\operatorname{Garcia}^{* \mathrm{c}, \mathrm{d}}$

${ }^{a}$ School of Chemistry, Madurai Kamaraj University, Madurai-625 021, Tamil Nadu, India. E-mail:admguru@gmail.com

${ }^{b}$ Departamento de Quimica, Universitat Politecnica de Valencia, Av. De los Naranjos s $/ n$, 46022 Valencia, Spain.E-mail: hgarcia@qim.upv.es

${ }^{c}$ Center of Excellence for Advanced Materials Research, King Abdulaziz University, Saudi Arabia.

${ }^{d}$ Departamento de Quimica and Instituto Universitario de Tecnologia Quimica (CSIC-UPV), Universitat Politecnica de Valencia, Av. De los Naranjos s/n, 46022 Valencia, Spain. E-mail: hgarcia@qim.upv.es

\begin{abstract}
Metal organic frameworks (MOFs) are widely used as solid catalysts in the liquid phase under batch mode conditions. Moving towards the development of industrial processes, data of the performance of MOFs under continuous flow operation would be desirable. This feature article describes the state of the art regarding the use of MOFs as catalysts of continuous flow processes, paying special attention to the issue of catalyst stability. The review is organized according to the type of bond that is formed in the reaction from $\mathrm{C}-\mathrm{C}, \mathrm{C}$ $\mathrm{O}$ to $\mathrm{C}-\mathrm{N}$ bonds. Examples are presented of MOF catalysts that are stable under continuous flow operation, even for those structures that are not very stable such as $\mathrm{Cu}_{3}(\mathrm{BTC})_{2}$. It can be anticipated that there will be a growth in the percentage of studies carried out under continuous flow with the final goal of implementing a commercial chemical process using MOFs as catalyst.
\end{abstract}




\section{Introduction}

Metal organic frameworks (MOFs) in where metallic nodes of one or few metal cations are coordinated to rigid organic linkers are becoming increasingly used in heterogeneous catalysis for liquid phase reactions under moderate conditions. ${ }^{1-5}$ The main reason to explain why these porous crystalline materials have gained such large importance as solid catalysts include their large surface area and porosity, ${ }^{6,7}$ easy and reliable preparation, synthesis by $\operatorname{design}^{8,9}$ and a large proportion of transition metals in their composition. There are many examples of MOFs in where the metal nodes contain some coordination positions not compromised with the construction of the lattice. These coordination positions are typically occupied by solvent molecules or other exchangeable ligands that can be easily removed, upon activation, generally by thermal treatment under vacuum, resulting in coordinatively unsaturated positions ${ }^{10,11}$ around the metal clusters that can act as Lewis sites. ${ }^{12}$ In addition to exchangeable ligands, MOFs always contain a certain density of defects in which the metal ions are not well coordinated and these defects can behave also as catalytic sites. ${ }^{13-16}$

Compared to other porous solids used in heterogeneous catalysis, ${ }^{17-20}$ and zeolites ${ }^{21}$ in particular, MOFs offer considerable flexibility in design and the possibility of select structures with large pore dimension in the range of mesopores and low framework density. ${ }^{22,}$ ${ }^{23}$ MOFs are considered as the materials with the highest open porosity and the record of free empty space in the structure that often is over $50 \%$ volume. $^{24}$

Another especially important feature of MOFs is the large variety of transition metals and ligands that can be employed in their preparation. ${ }^{25-27}$ Moreover, by knowing the directionality of the coordination bonds around the metal clusters and the geometry and dimensions of the organic linkers, the topology of the voids in MOFs can be predicted. ${ }^{28,29}$ 
This possibility to anticipate pore size and pore geometry in MOFs has led to the concept of synthesis by design meaning that there is a considerable predictive understanding in the porosity in MOFs. ${ }^{30-32}$

For gas phase reactions, particularly in refining and petrochemical industry, zeolites and porous aluminosilicates are the preferable solid catalysts. ${ }^{33-35}$ However, due to the limited pore size of conventional zeolites the activity of these crystalline aluminosilicates in liquid phase reaction is considerably much lower ${ }^{19}$ and there was an interest in the development of other classes of porous solid catalysts for this type of reactions, particularly for the production of fine chemicals ${ }^{36,37}$ where the size of the molecules are larger than normal alkanes found in refining and petrochemistry. In this context, since the first reports of MOF synthesis, it was clear that these materials should be very promising as solid catalysts, complementing zeolites, particularly in the liquid phase. ${ }^{38}$

However, in spite of the previously commented positive structural features exhibited by MOF, one of the limiting factors that has hampered applications of MOFs at industrial scale has been the poor structural stability of many MOFs. ${ }^{5,39,40}$ In contrast to zeolites that can be reactivated by combustion of the organic matter at temperatures above $500{ }^{\circ} \mathrm{C}$ under air, ${ }^{41,}{ }^{42}$ MOFs cannot stand thermal treatments above $400{ }^{\circ} \mathrm{C}$ and in many cases, even at much lower temperature. Besides thermal stability, MOFs can also be unstable in the presence of certain acidic/basic conditions, aggressive reagents or even solvents. ${ }^{43}$ For instance, MOFs can stand aqueous solutions in a certain range of $\mathrm{pH}$ value and amines and even carboxylic acids can deteriorate the structure of MOFs.

However, although the lack of stability is well known in the area, there are certain structures that are remarkably robust and stable both upon heating and in the presence of chemical reagents. Examples of these stable MOFs include certain materials of the MIL 
series $^{44,45}$ (MIL: Materials Institute of Lavoisier) such as MIL-100(Cr), MIL-101(Cr) and different MOFs of Zr-based nodes, particularly UiO-66, 46, 47 (UiO: University of Oslo). In the last case, it is possible to heat at $400{ }^{\circ} \mathrm{C}$ causing a reversible dehydration of the $\mathrm{Zr}_{6} \mathrm{O}_{4}(\mathrm{OH})_{4}$ nodes, but without causing the collapse of the crystal structure. In the case of MIL-101, it is possible to perform harsh reactions at the organic linker such as sulfonation with highly corrosive chlorosulfonic acid without altering the crystallinity of the sample. The crystal structure of UiO-66 consists of a cubic framework of cationic $\mathrm{Zr}_{6} \mathrm{O}_{4}(\mathrm{OH})_{4}$ nodes and 1,4-benzenedicarboxylate (BDC) as linkers. ${ }^{48}$ UiO-66 is one of the most robust MOFs. UiO66 is often synthesised in the presence of modulators to introduce structural defects or increase crystallinity. ${ }^{49}$ Besides, it also can be subjected to post-synthetic modifications ${ }^{50}$ to tune further the active sites. The combination of these interesting properties together with high surface area and large pore size makes UiO-66 an attractive material for catalytic applications. $^{47,51}$ In many other cases, experimental evidence has shown that the crystal structure can stand the reaction conditions and they are acting as catalytically stable materials. ${ }^{52}$ Table 1 summarizes the most commonly used MOFs in catalysis indicating their metal ions/node, linkers, typical BET surface area and pore volume.

Table 1. Some of the most often used MOF catalysts with their structural properties.

\begin{tabular}{|l|l|l|l|l|}
\hline Catalyst & $\begin{array}{l}\text { Metal ion/ } \\
\text { node }\end{array}$ & Linker & $\begin{array}{l}\text { BET surface } \\
\text { area }\left(\mathrm{m}^{2} / \mathrm{g}\right)^{\mathrm{a}}\end{array}$ & $\begin{array}{l}\text { Pore volume } \\
\left(\mathrm{cm}^{3} / \mathrm{g}\right)^{\mathrm{a}}\end{array}$ \\
\hline MIL-101(Cr) & $\mathrm{Cr}^{3+}$ & $\begin{array}{l}1,4-\text {-benzenedicarboxylic } \\
\text { acid (BDC) }\end{array}$ & 2750 & 2.2 \\
\hline MIL-100(Fe) & $\mathrm{Fe}^{3+}$ & $\begin{array}{l}1,3,5- \\
\text { benzenetricarboxylic } \\
\text { acid (BTC) }\end{array}$ & 2000 & 1.2 \\
\hline $\mathrm{Cu}_{3}(\mathrm{BTC})_{2}$ & $\mathrm{Cu}^{2+}$ & BTC & 1200 & 0.7 \\
\hline $\mathrm{UiO}^{2} 66$ & $\mathrm{Zr}_{6} \mathrm{O}_{4}(\mathrm{OH})_{4}$ & BDC & 1250 & 0.5 \\
\hline
\end{tabular}


${ }^{a}$ These values are typical data reported in the literature and they may vary depending on the measurements.

However most of the data on catalyst stability reported so far are based on batch conditions, evaluating the performance of the material in a series of consecutive reuses of the same sample. ${ }^{53}$ Reusability tests typically consider the initial reaction rates, conversions and selectivity values of the same sample submitted to consecutive runs. Catalytic tests are combined with complimentary analytical and structural characterization of the used solid showing that the crystallinity is preserved upon successive reuses and that the metal content of the materials has remained unchanged.

In spite of the considerable information gathered for the activity of MOFs as solid catalysts in liquid phase reactions, application of these materials for large scale reactions in industry still remains elusive. Implementation of commercial processes using MOFs as catalysts for the production of fine chemicals in the liquid phase is a long sought goal pursued in this field that will serve to demonstrate the superiority of MOF solid catalysts in liquid phase reactions over other alternative solid catalysts.

Towards this final goal, one necessary step is to determine the catalytic behaviour of MOFs under continuous flow operation. Industrial processes typically prefer continuous flow operation versus batch reactions, since the former represents an intensive process, resulting in higher productivity. ${ }^{54-56}$ Compared to batch conditions, operation under continuous flow provides unique information about catalyst stability and the main deactivation pathways. In this context, it is remarkable that there is a paucity of information about the behaviour of MOFs as catalysts under continuous flow conditions in the liquid phase. Studies of the catalytic behaviour of MOFs under continuous flow can surely serve to demonstrate their stability under reaction conditions. 
Compared to batch reactions, continuous flow present significant advantages, including high ratio of surface-to-volume, enhanced heat transfer and precise temperature control, higher reaction rates, operation under extreme conditions, safer handling of highly exothermic, explosive, or toxic reagents, good control of the residence time, easy automation and scale-up and cost effectiveness.

Considering these beneficial advantages of continuous flow reactions compared to batch processes, many industrial process including pharmaceutical products are being manufactured under continuous flow mainly due to the easy recovery of products from catalysts and the remarkable process intensification in terms of production per unit of time. On other hand, efficient separation of the reaction mixture from the solid catalyst presents he two-fold advantages of isolating the final product in high purity and minimizing catalyst deactivation by poisoning. Furthermore, selectivity can be higher under continuous flow conditions by arresting consecutive reactions that could occur in the primary products.

Solid catalyst stability in batch reactions is commonly ascertained by recovering the solid after the reaction and reusing in a subsequent run, measuring initial reaction rates and final conversions at a certain time. Although it is considered as the most convenient way to study catalyst stability in batch reaction, this method suffers from several disadvantages including unavoidable catalyst loss and tedious and time consuming workup. On other hand, the stability of a solid catalyst can easily be monitored under continuous flow operation by measuring the decay in conversion over the time on stream. Chart 1 shows examples of continuous flow reactors namely, capillary, packed-bed, honeycomb and monolithic reactors. These reactors are classified based on the dimension of the inner diameter varying between micro $(10-500 \mu \mathrm{m})$ or mesofluidic $(500 \mu \mathrm{m}$ up to few $\mathrm{mm})$ reactors and on the arrangement of the reactor channels. ${ }^{57,58}$ It should be noted at this point that the previous classification is has been often employed for continuous flow process with solid catalysts and that the number 
of reports using MOFs as solid catalysts for liquid-phase continuous flow is still very limited, particularly compared to the use of MOFs under batch conditions.

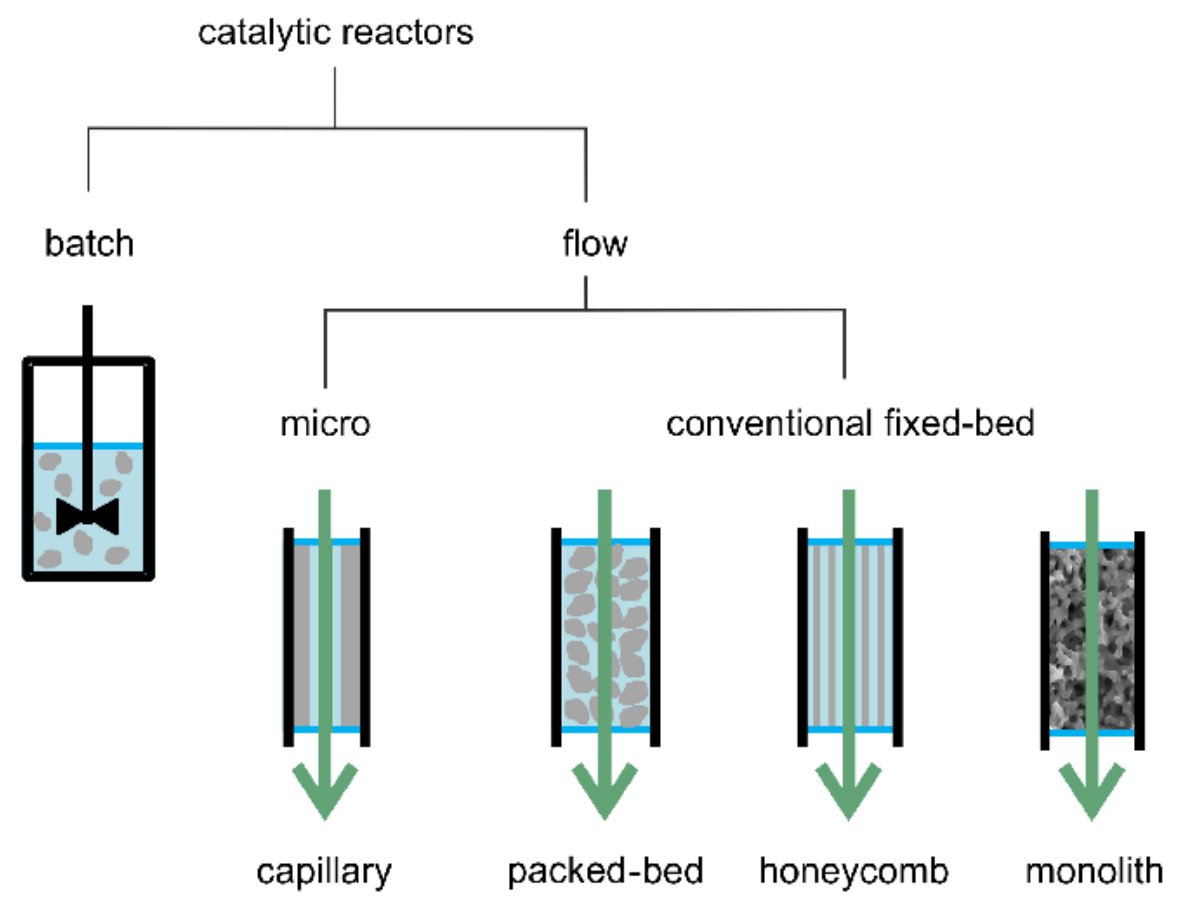

Chart 1. A representation of most common reactor types for batch and continuous-flow reactions. Particles, layer or body of the catalyst are shown in grey.

Development of continuous flow reactors is an important technological aspect for both synthetic chemists and process engineering. ${ }^{57,59-67}$ Interestingly, various continuous flow reactors and processes have been reported for the synthesis of drug molecules through cross coupling reactions, including Suzuki-Miyaura, Sonogashira and Heck, ${ }^{68,69}$ as well as for hydrogenation of alkynes ${ }^{70}$ and aerobic oxidations. ${ }^{71}$ Recently, Pd@MIL-101-NH $\mathrm{NH}_{2}$ was packed in a micro-flow reactor and employed as catalyst for the preparation of series of biaryls of commercial importance under continuous flow, exhibiting a remarkable stability up to $54 \mathrm{~h}^{72}$

Very recently, the main achievements, challenges and limitations regarding the synthesis of fine chemicals, pharmaceuticals and bulk chemicals under continuous flow has 
been reviewed and readers are encouraged to refer this article for a detailed overview. ${ }^{73}$ In another review article, the use of MOFs and covalent organic frameworks packed in columns as stationary phase in chromatographic separation as well as continuous flow synthesis was discussed. ${ }^{74}$ In this context, the main objective of the present article is to show the relevance and opportunity for developing liquid-phase continuous flow reactions using MOFs as catalysts to achieve the final goal of implementing commercial synthetic processes based on these porous materials.

Due to the significant advances in the field of micro- and mesoreactors, several examples of the synthesis of drugs and fine chemicals using continuous flow processes have recently been described. Some of the main reasons that make continuous flow preferable to batch processes include higher productivity for a given period of time, but also better yields or selectivity and safer process together with less environmental impact. Although batch reactions are more versatile and flexible being adequate for the first stages of catalytic studies at laboratory scale, they are less adequate than continuous flow processes for scaling up and present practical complications to implement adequate heat and mass transfer, which may heavily hinder productivity. Continuous flow processes are also better suited for automation and requires lesser manpower. Thus, continuous flow systems are characterised by reduced costs and maximize the economic viability of new drugs and products. ${ }^{75-78}$ For these reasons, studies under continuous flow conditions for liquid phase reaction generally correspond to reactions of potential industrial interest and are based on stable catalysts.

The purpose of the present review is to cover the existing literature on the use of MOFs as catalysts under continuous flow operation in liquid phase reactions. The existing literature has been reviewed paying particular emphasis in the most recent achievements, especially in the use of MOFs in enantioselective continuous flow processes. ${ }^{79}$ It will be shown that in several cases, remarkably stable MOFs catalysts for certain reactions under 
continuous flow such as acetalization, cyclocondensations, $\mathrm{CO}_{2}$ insertion and alcohol oxidation have been reported, illustrating the possibility to go one step further towards the implementation of MOFs as catalysts for large scale processes. Recently, Lin and co-workers have published a perspective on the various strategies employed in gas-phase reactions using MOFs as solid catalysts, discussing the various limiting factors in this type of processes. ${ }^{80}$ Hence, the present review is exclusively focussed on the use of MOFs as catalysts in continuous flow reactions in the liquid phase, focussing mainly on activity and stability. Emphasis will be made in comparing the performance of MOFs as catalysts with other solid catalysts. Unfortunately, given the incipient development level of MOFs in continuous flow, the current lack of information makes not possible to provide a fair comparison for every reaction.

The following sections are organized based the type of bond formed in the final product. Emphases are given on the structural aspects of the MOF catalysts employed for the continuous flow processes, reactant conversion level, product selectivities, productivity data and catalyst stability based on catalytic data and on characterization of the catalyst after extensive use by analytical or microscopic techniques. Table 2 provides an overview of reactions that have been screened up to now under continuous flow in the liquid phase using MOFs as solid catalysts, the reactor type employed and the activity and stability reached.

Table 2. List of liquid-phase continuous flow reactions using MOFs as heterogeneous catalysts.

\begin{tabular}{|l|l|l|l|l|l|}
\hline Catalyst & Reactor type & Reaction & Activity & Stability & Ref. \\
\hline $\begin{array}{l}{\left[\mathrm{Me}_{2} \mathrm{NH}_{2}\right]\left[\mathrm{Mn}_{2}\left(\mathrm{~L}^{1}\right)\right.} \\
\left.\left(\mathrm{H}_{2} \mathrm{O}\right)_{2}\right] \cdot 2 \mathrm{H}_{2} \mathrm{O} \cdot 2 \mathrm{D} \\
\mathrm{MA}^{\mathrm{a}}\end{array}$ & $\begin{array}{l}\text { stainless steel } \\
\text { column filled } \\
\text { with finely } \\
\text { grounded solid }\end{array}$ & $\begin{array}{l}\text { Friedel- } \\
\text { Crafts } \\
\text { reaction }\end{array}$ & $\begin{array}{l}89-92 \% \text { yield } \\
\text { with 91-94 \% ee } \\
\text { after 12 h time on } \\
\text { stream (TOS) }\end{array}$ & $\begin{array}{l}\text { Reused } \\
\text { seven times }\end{array}$ & 81 \\
\hline nano-BIT-58 film & 70 wt\% nano & Knoevena & $100 \%$ conversion & Reused & 82 \\
\hline
\end{tabular}




\begin{tabular}{|c|c|c|c|c|c|}
\hline & $\begin{array}{l}\text { BIT-58 in } \\
\text { polyacrylonitrile } \\
\text { fabricated } \\
\text { by } \\
\text { electrospinning }\end{array}$ & $\begin{array}{l}\text { gel } \\
\text { condensati } \\
\text { on }\end{array}$ & & three times & \\
\hline $\mathrm{Cu}_{3}(\mathrm{BTC})_{2}{ }^{\mathrm{c}}$ & $\begin{array}{l}\text { mixed matrix } \\
\text { membranes of } \\
\mathrm{Cu}_{3}(\mathrm{BTC})_{2} \text { and } \\
\text { cellulose acetate }\end{array}$ & $\begin{array}{l}\text { Acetalizati } \\
\text { on }\end{array}$ & $\begin{array}{l}0.59 \mathrm{mmol} \mathrm{min}^{-1} \mathrm{~g} \\
\mathrm{Cu}_{3}(\mathrm{BTC})_{2}{ }^{-1}\end{array}$ & $\begin{array}{l}\text { TOS of } 24 \\
h\end{array}$ & 83 \\
\hline $\mathrm{Cu}_{3}(\mathrm{BTC})_{2}$ & packed-bed & $\begin{array}{l}\text { Acetalizati } \\
\text { on }\end{array}$ & $3.12 \mathrm{~h}^{-1}$ & $\begin{array}{l}\text { Reuse, } \\
\text { XRD, BET }\end{array}$ & 84 \\
\hline $\begin{array}{l}\text { copper } \\
\text { hydroxysulfate@C } \\
\mathrm{u}_{3}(\mathrm{BTC})_{2}\end{array}$ & flow & $\begin{array}{l}\text { Acetalizati } \\
\text { on }\end{array}$ & $\begin{array}{l}87 \% \text { yield and } 99 \\
\% \text { selectivity }\end{array}$ & - & 85 \\
\hline MIL-101(Sc) & packed-bed & $\begin{array}{l}\mathrm{CO}_{2} \\
\text { cycloaddit } \\
\text { ion to } \\
\text { propylene } \\
\text { oxide }\end{array}$ & $\begin{array}{l}\text { Turnover } \\
\text { frequency (TOF) } \\
87 \mathrm{~h}^{-1}\end{array}$ & $\begin{array}{l}\text { Stable up to } \\
5 \mathrm{~h}, \mathrm{XRD}\end{array}$ & 86 \\
\hline $\begin{array}{l}\mathrm{Co}(\mathrm{CO})_{4} \subset \mathrm{MIL}- \\
101(\mathrm{Cr})\end{array}$ & packed-bed & $\begin{array}{l}\text { carbonylat } \\
\text { ion of } \\
\beta \text {-lactones }\end{array}$ & $\begin{array}{l}1300 \\
\mathrm{~mol}_{\text {Anhydride }} \cdot \mathrm{mol}_{\mathrm{Co}}- \\
{ }^{\text {after }} 6 \mathrm{~h}\end{array}$ & - & 87 \\
\hline $\mathrm{UiO}-66(\mathrm{Zr})$ & packed-bed & $\begin{array}{l}\text { methyl } \\
\text { levulinate } \\
\text { to } \gamma \text { - } \\
\text { valerolact } \\
\text { one }\end{array}$ & $\begin{array}{l}92.3 \\
\operatorname{mmol}_{\mathrm{GVL}} \mathrm{g}^{-1} \mathrm{~h}^{-1}\end{array}$ & $\begin{array}{l}\text { TOS = } 1 \mathrm{~h} \\
\text { BET, TEM }\end{array}$ & 88 \\
\hline $\begin{array}{l}\mathrm{Cu}_{3}(\mathrm{BTC})_{2^{-}} \\
\text {MonoSil }^{\mathrm{d}}\end{array}$ & $\begin{array}{l}\text { packed-bed }(2 \\
\mathrm{cm} \text { length } \times 6 \\
\mathrm{~cm} \text { diameter })\end{array}$ & $\begin{array}{l}\text { Friedlande } \\
\mathrm{r} \\
\text { reaction }\end{array}$ & $\begin{array}{l}826 \mathrm{~g} \text { of the } \\
\text { desired product } \\
\text { per } \\
\mathrm{g} \text { of } \mathrm{Cu}_{3}(\mathrm{BTC})_{2} \\
\text { per day }\end{array}$ & - & 89 \\
\hline $\begin{array}{l}\mathrm{Pd} @ \mathrm{MIL}-88 \mathrm{~B}- \\
\mathrm{NH}_{2} @ \text { nano-SiO }_{2}\end{array}$ & packed-bed & $\begin{array}{l}\text { alcohol } \\
\text { oxidation }\end{array}$ & $\begin{array}{ll}\text { conversion } & \text { at } \\
\text { around } 80 \% & \end{array}$ & $\begin{array}{l}\text { Conversion } \\
\text { almost } \\
\text { stable for } 7 \\
\text { days }\end{array}$ & 90 \\
\hline UiO-66(Zr,Ti) & $\begin{array}{l}\text { tubular glass } \\
\text { column }\end{array}$ & $\begin{array}{l}\text { oxidative } \\
\text { desulfuriz } \\
\text { ation of } \\
\text { thioanisole }\end{array}$ & $\begin{array}{l}<1 \quad \text { ppm of } \\
\text { sulphur }\end{array}$ & - & 91 \\
\hline $\begin{array}{l}\text { OPH@MIL- } \\
100(\mathrm{Fe})^{\mathrm{e}}\end{array}$ & plug-flow & $\begin{array}{l}\text { cascade } \\
\text { degradatio }\end{array}$ & $\begin{array}{l}\text { retained more } \\
\text { than } 50 \% \text { of the }\end{array}$ & $\begin{array}{l}\text { retained } \\
\text { more }\end{array}$ & 92 \\
\hline
\end{tabular}




\begin{tabular}{|l|l|l|l|l|l|}
\hline & $\begin{array}{l}\mathrm{n} \text { of } \\
\text { organopho } \\
\text { sphate } \\
\text { nerve } \\
\text { agents to } \\
4- \\
\text { aminophe } \\
\text { nol }\end{array}$ & & $\begin{array}{l}\text { after nine cycles } \\
\text { of } \\
\text { initial the } \\
\text { activity } \\
\text { after nine } \\
\text { cycles }\end{array}$ \\
\hline
\end{tabular}

${ }^{a} L^{1}$ structure in Scheme 1; DMA: N,N-dimethylacetamide. ${ }^{b}$ BIT: Beijing Institute of Technology. ${ }^{\mathrm{c}} \mathrm{BTC}$ : 1,3,5-benzenetricarboxylate. ${ }^{\mathrm{d}}$ silica monolith. ${ }^{\mathrm{e}} \mathrm{OPH}$ : organophosphorous hydrolase.

\section{C-C bond formation}

One of the fundamental challenges in heterogeneous catalysis is the appropriate design of an efficient catalyst featuring high activity and recyclability without deactivation exhibiting an exquisite selectivity. In this regard, stereoselective and enantioselective reactions correspond to the most challenging case, due to the structural similarity of the products. In a study of catalytic asymmetric induction, Cui and co-workers have recently developed high-performance heterogeneous asymmetric catalysts using a ligand design strategy. Three porous chiral MOFs with the general formula $\left[\mathrm{Me}_{2} \mathrm{NH}_{2}\right]\left[\mathrm{Mn}_{2}\left(\mathrm{~L}^{\mathrm{i}}\right)\left(\mathrm{H}_{2} \mathrm{O}\right)_{2}\right] \cdot 2 \mathrm{H}_{2} \mathrm{O} \cdot \mathrm{nDMA}$ (for $\mathrm{L}^{\mathrm{i}}$ see structure in Figure $1, \mathrm{n}=2$ or 3 ) were prepared from enantiopure phosphono-carboxylate ligands of 1,1'-biphenol that are functionalized with 3,5-bis(trifluoromethyl)-, bismethyl-, and bisperfluorophenyl substituents at the $3,3^{\prime}$-position. ${ }^{81}$ The carboxylate and phosphonate groups were coordinated to metal ions to form crystalline porous networks in where the metal nodes act as Lewis acids, while the 3,3'-substituents generate a chiral environment that dictates the stereochemical and electronic control over the organic reactions. TGA indicated that these solids are stable up to $380{ }^{\circ} \mathrm{C}$. Chemical stability experiments with acids and bases revealed that the stability increases in the order of $\left[\mathrm{Me}_{2} \mathrm{NH}_{2}\right]\left[\mathrm{Mn}_{2}\left(\mathrm{~L}^{1}\right)\left(\mathrm{H}_{2} \mathrm{O}\right)_{2}\right] \cdot 2 \mathrm{H}_{2} \mathrm{O} \cdot 2 \mathrm{DMA}>$ $\left[\mathrm{Me}_{2} \mathrm{NH}_{2}\right]\left[\mathrm{Mn}_{2}\left(\mathrm{~L}^{2}\right)\left(\mathrm{H}_{2} \mathrm{O}\right)_{2}\right] \cdot 2 \mathrm{H}_{2} \mathrm{O} \cdot 3 \mathrm{DMA}>\left[\mathrm{Me}_{2} \mathrm{NH}_{2}\right]\left[\mathrm{Mn}_{2}\left(\mathrm{~L}^{3}\right)\left(\mathrm{H}_{2} \mathrm{O}\right)_{2}\right] \cdot 2 \mathrm{H}_{2} \mathrm{O} \cdot 3 \mathrm{DMA}$ which 
follows the same order as the increase in the size of the bulky phenyl substituent at the 3,3'position of the 1,1'-biphenyl ligands.

The activity of these chiral solid catalysts was studied in the Friedel-Crafts reaction of N-methylindole with methyl(E)-2-oxo-4-phenylbut-3-enoate (Scheme 1). The experimental results have shown that $\left[\mathrm{Me}_{2} \mathrm{NH}_{2}\right]\left[\mathrm{Mn}_{2}\left(\mathrm{~L}^{1}\right)\left(\mathrm{H}_{2} \mathrm{O}\right)_{2}\right] \cdot 2 \mathrm{H}_{2} \mathrm{O} \cdot 2 \mathrm{DMA}$ exhibits much higher activity and stereoselectivity induction ability than the other two solids. $\left[\mathrm{Me}_{2} \mathrm{NH}_{2}\right]\left[\mathrm{Mn}_{2}\left(\mathrm{~L}^{1}\right)\left(\mathrm{H}_{2} \mathrm{O}\right)_{2}\right] \cdot 2 \mathrm{H}_{2} \mathrm{O} \cdot 2 \mathrm{DMA}$ gave in chloroform at $30{ }^{\circ} \mathrm{C}$ the 1,4 -addition product in $91 \%$ yield with $96 \%$ ee. Analogously, a wide range of $\beta, \gamma$-unsaturated $\alpha$-keto esters with various electronic properties and different ring sizes were reacted with $\mathrm{N}$-methyl or N-benzylindole, achieving the expected products in 84-95\% yields with $91-99.9 \%$ ee. The 1,4-addition product was the only product observed in all substrates studied, 1,2-addition isomer being not formed. In comparison, the addition of $\mathrm{N}$-methylindole to $\alpha$-keto esters in the presence of $\left[\mathrm{Me}_{2} \mathrm{NH}_{2}\right]\left[\mathrm{Mn}_{2}\left(\mathrm{~L}^{2}\right)\left(\mathrm{H}_{2} \mathrm{O}\right)_{2}\right] \cdot 2 \mathrm{H}_{2} \mathrm{O} \cdot 3 \mathrm{DMA} \quad$ and $\left[\mathrm{Me}_{2} \mathrm{NH}_{2}\right]\left[\mathrm{Mn}_{2}\left(\mathrm{~L}^{3}\right)\left(\mathrm{H}_{2} \mathrm{O}\right)_{2}\right] \cdot 2 \mathrm{H}_{2} \mathrm{O} \cdot 3 \mathrm{DMA}$ resulted in 73-82 \% and 79-84 \% yield and 55-74 $\%$ and $71-85 \%$ ee of the products, respectively, which are lower values than with $\left[\mathrm{Me}_{2} \mathrm{NH}_{2}\right]\left[\mathrm{Mn}_{2}\left(\mathrm{~L}^{1}\right)\left(\mathrm{H}_{2} \mathrm{O}\right)_{2}\right] \cdot 2 \mathrm{H}_{2} \mathrm{O} \cdot 2 \mathrm{DMA}$ under identical conditions. The enhanced activity of $\left[\mathrm{Me}_{2} \mathrm{NH}_{2}\right]\left[\mathrm{Mn}_{2}\left(\mathrm{~L}^{1}\right)\left(\mathrm{H}_{2} \mathrm{O}\right)_{2}\right] \cdot 2 \mathrm{H}_{2} \mathrm{O} \cdot 2 \mathrm{DMA}$ is proposed to arise from the $o$-disubstitution of the aromatic ring with strong electron withdrawing $-\mathrm{CF}_{3}$ groups which should favour the increase of both the steric encumbrance around the sites and the Lewis acidity of metal ions, thereby resulting in a notable enhancement of the reaction rate and the ee values. In contrast, the activity of the ligand as well as the metal nodes in solution was lower in terms of yield and ee values under identical conditions. In addition, $\left[\mathrm{Me}_{2} \mathrm{NH}_{2}\right]\left[\mathrm{Mn}_{2}\left(\mathrm{~L}^{1}\right)\left(\mathrm{H}_{2} \mathrm{O}\right)_{2}\right] \cdot 2 \mathrm{H}_{2} \mathrm{O} \cdot 2 \mathrm{DMA}$ was reused for ten cycles without any decrease in its activity, regioselectivity and enantioselectivity. Powder XRD pattern and BET surface area of the ten-times reused solid remained unchanged compared to the fresh solid. Hot 
filtration experiments showed also the absence of leaching of $\mathrm{Mn}$ ions. All these characterization data indicate the stability of the catalyst under reaction conditions. Further, the Friedel-Crafts reaction of trans- $\beta$-nitrostyrene with pyrrole (Scheme 1) was also catalyzed by $\left[\mathrm{Me}_{2} \mathrm{NH}_{2}\right]\left[\mathrm{Mn}_{2}\left(\mathrm{~L}^{1}\right)\left(\mathrm{H}_{2} \mathrm{O}\right)_{2}\right] \cdot 2 \mathrm{H}_{2} \mathrm{O} \cdot 2 \mathrm{DMA}$ solid affording $87 \%$ yield with $97 \%$ ee in chloroform at $0{ }^{\circ} \mathrm{C}$. The substrate scope of this solid catalyst was further exploited with other aryl-substituted nitroalkenes possessing electron-donating and electron-withdrawing groups on the aromatic rings, achieving excellent to high yields (79-93\%) and high enantioselectivities (62-97\%). $\left[\mathrm{Me}_{2} \mathrm{NH}_{2}\right]\left[\mathrm{Mn}_{2}\left(\mathrm{~L}^{1}\right)\left(\mathrm{H}_{2} \mathrm{O}\right)_{2}\right] \cdot 2 \mathrm{H}_{2} \mathrm{O} \cdot 2 \mathrm{DMA}$ MOF promoted pyrrole alkylation with stereoselectivities close to the values reached with other homogeneous and heterogeneous catalysts based on binaphthyl derived phosphoric acids (Table 3).

Table 3. Comparison of the activity of $\left[\mathrm{Me}_{2} \mathrm{NH}_{2}\right]\left[\mathrm{Mn}_{2}\left(\mathrm{~L}^{1}\right)\left(\mathrm{H}_{2} \mathrm{O}\right)_{2}\right] \cdot 2 \mathrm{H}_{2} \mathrm{O} \cdot 2 \mathrm{DMA}$ in Friedel Crafts alkylation reaction between pyrrole and t- $\beta$-nitrostyrene with other catalysts at room temperature.

\begin{tabular}{|l|l|l|l|}
\hline Catalyst & Yield (\%) & ee (\%) & Ref. \\
\hline $\begin{array}{l}\text { Binol derived phosphoric acid } \\
\text { chloride (heterogeneous) }\end{array}$ & 91 & 96 & 93 \\
\hline $\begin{array}{l}\text { Tridendate Schiff base+Cu } \\
\text { (homogeneous) }\end{array}$ & $>99$ conv. & 93 & 94 \\
\hline $\begin{array}{l}\text { Tridendate Schiff base+Cu } \\
\text { (homogeneous) }\end{array}$ & 86 & 92 & 95 \\
\hline Anthryl-Binol PA (homogeneous) & 93 & 88 & 96 \\
\hline
\end{tabular}


a)
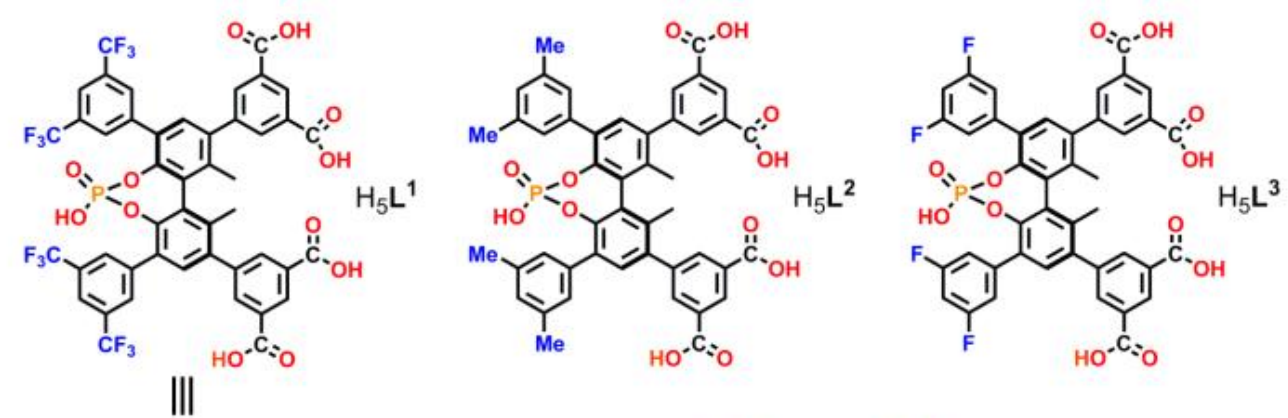

b)
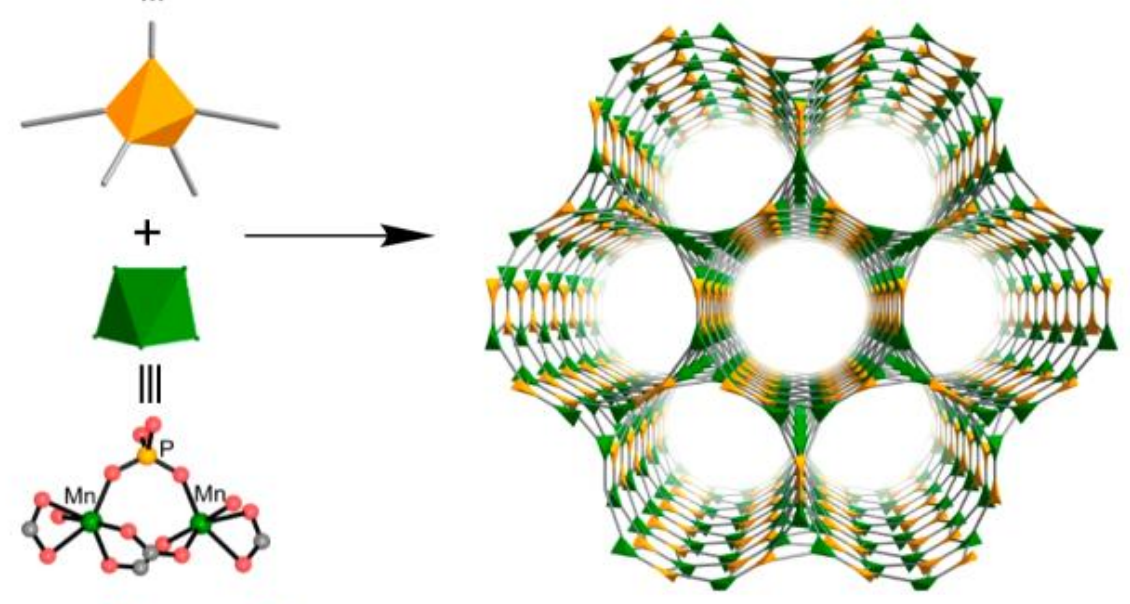

c)
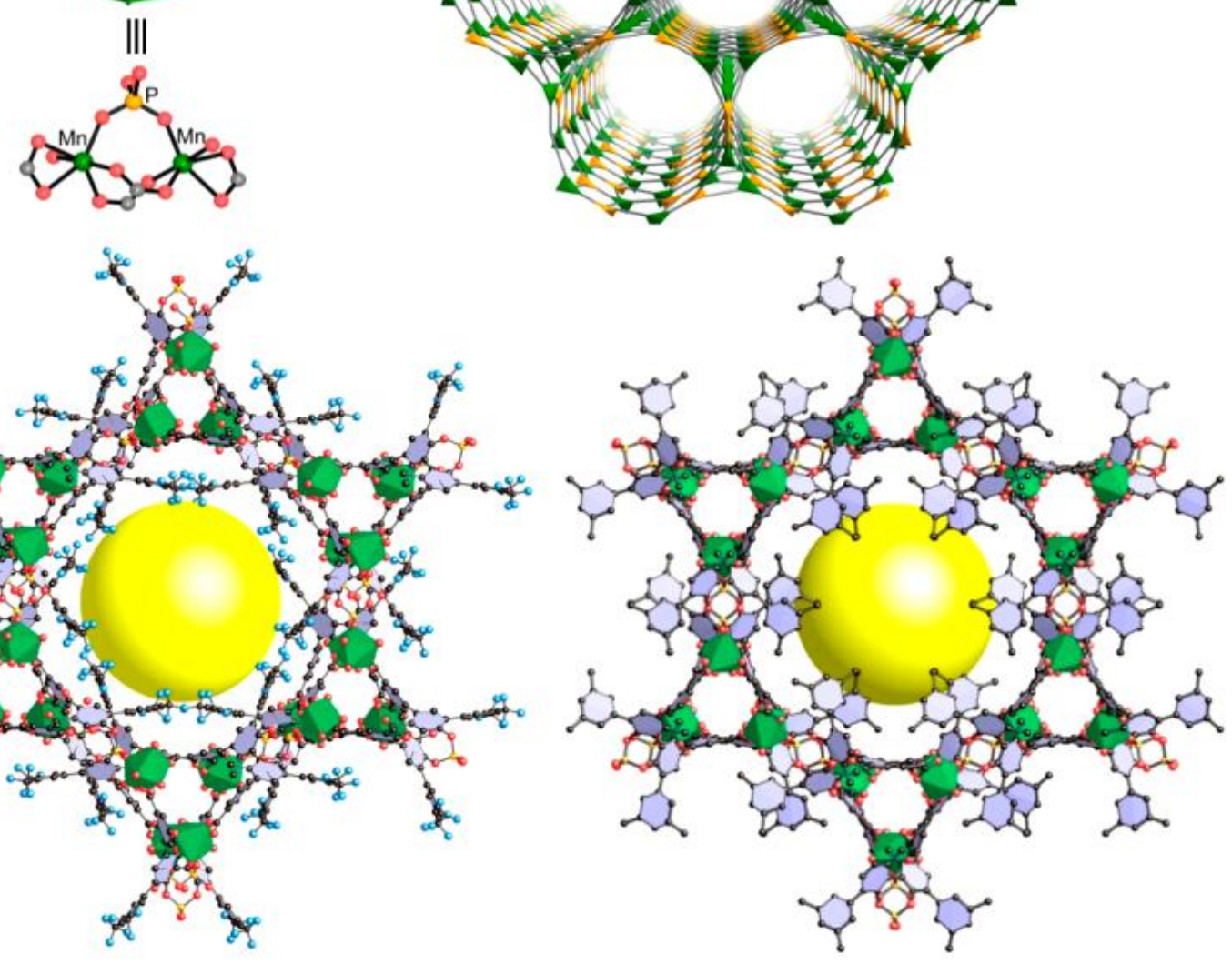

Figure 1. (a) Structure of the organic ligands $\mathrm{H}_{5} \mathrm{~L}^{1}-\mathrm{H}_{5} \mathrm{~L}^{3}$ employed in the synthesis of chiral MOFs; (b) Construction of enantioselectively pure MOFs from dimeric $\left[\mathrm{Mn}_{2}\left(\mathrm{CO}_{2}\right)_{4}\left(\mathrm{PO}_{4}\right)\left(\mathrm{H}_{2} \mathrm{O}\right)_{2}\right]$ linked by $\mathrm{H}_{5} \mathrm{~L}$ to give 3D networks with fns topology; (c) Framework structures of the resulting chiral Mn MOFs with channel diameters of $\sim 2.5 \times 2.5$ 
$\mathrm{nm}^{2}$ and $\sim 0.68 \times 0.68 \mathrm{~nm}^{2}$ along the $\mathrm{c}$-axis $(\mathrm{Mn}$, green polyhedra; $\mathrm{O}$, red; $\mathrm{P}$, yellow; $\mathrm{C}$, black; F, light blue. $\mathrm{H}$ atoms are omitted for clarity). Reproduced with permission from ref. ${ }^{81}$

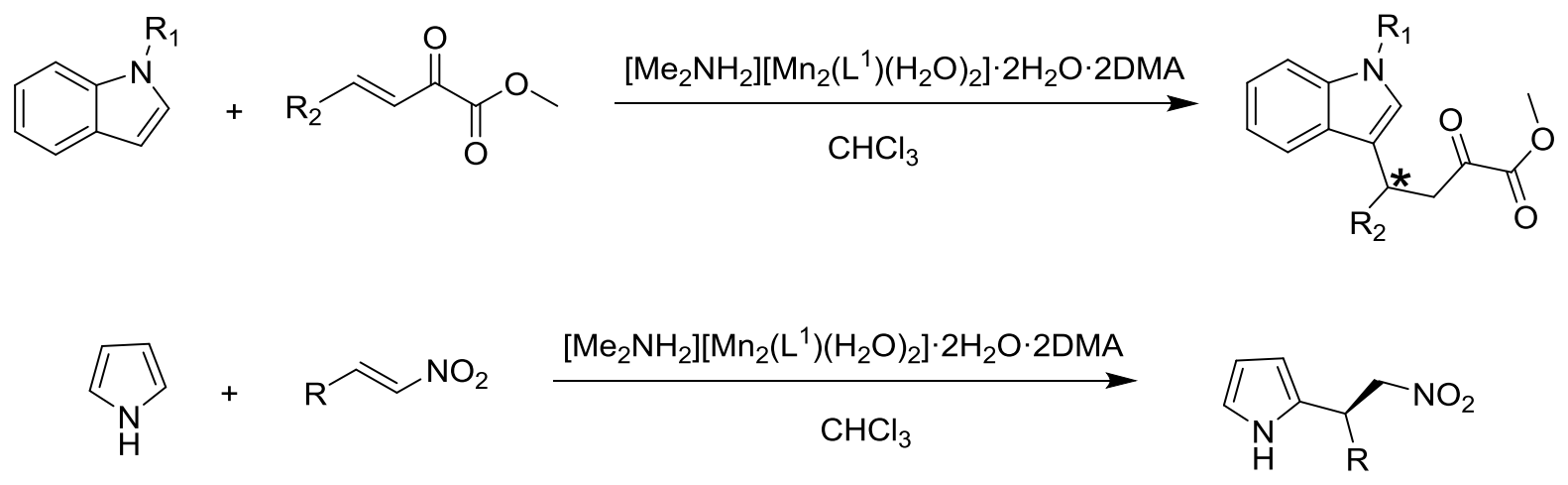

Scheme 1. Enantioselective Friedel-Crafts alkylation reactions catalyzed by chiral $\left[\mathrm{Me}_{2} \mathrm{NH}_{2}\right]\left[\mathrm{Mn}_{2}\left(\mathrm{~L}^{1}\right)\left(\mathrm{H}_{2} \mathrm{O}\right)_{2}\right] \cdot 2 \mathrm{H}_{2} \mathrm{O} \cdot 2 \mathrm{DMA}$.

The performance of $\left[\mathrm{Me}_{2} \mathrm{NH}_{2}\right]\left[\mathrm{Mn}_{2}\left(\mathrm{~L}^{1}\right)\left(\mathrm{H}_{2} \mathrm{O}\right)_{2}\right] \cdot 2 \mathrm{H}_{2} \mathrm{O} \cdot 2 \mathrm{DMA}$ was also evaluated under continuous flow set up as shown in Figure 2. The continuous flow reaction of Nmethylindole with $\alpha$-keto esters was performed in a stainless steel column filled with finely grounded $\left[\mathrm{Me}_{2} \mathrm{NH}_{2}\right]\left[\mathrm{Mn}_{2}\left(\mathrm{~L}^{1}\right)\left(\mathrm{H}_{2} \mathrm{O}\right)_{2}\right] \cdot 2 \mathrm{H}_{2} \mathrm{O} \cdot 2 \mathrm{DMA}(0.4-5 \mu \mathrm{m})$ mixed with quartz sand. Under optimized flow conditions, a complete conversion of $\alpha$-keto esters towards the formation of 1,4-addition product in 89-92\% yield with 91-94 \% ee after a residence time of $12 \mathrm{~h}$ was achieved. The comparison of the batch and flow processes shows that the flow process afforded a slight increase in the yield, but a slight decrease in enantioselectivity. This lower ee values for the continuous flow process were ascribed to the negative effect of the silica needed for packing the catalyst bed in the reactor that introduces adventitious sites deteriorating the enantioselectivity. 


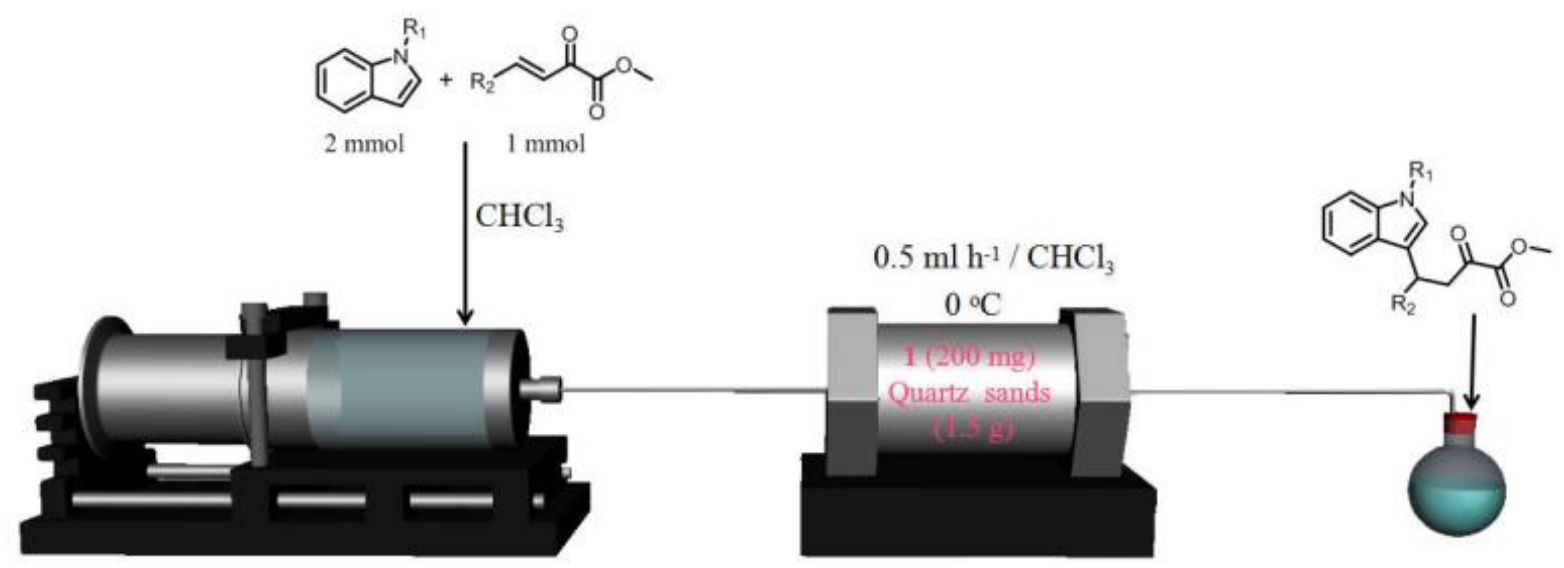

Figure 2. The experimental set up for the fixed bed reactor used for the enantioselective Friedel-Crafts reactions between $\mathrm{N}$-methylindole with $\beta, \gamma$-unsaturated $\alpha$-ketoesters under continuous flow conditions using $\left[\mathrm{Me}_{2} \mathrm{NH}_{2}\right]\left[\mathrm{Mn}_{2}\left(\mathrm{~L}^{1}\right)\left(\mathrm{H}_{2} \mathrm{O}\right)_{2}\right] \cdot 2 \mathrm{H}_{2} \mathrm{O} \cdot 2 \mathrm{DMA}$ as catalyst. Yields of $89,91,92 \%$ with $94,91,94 \%$ ee was obtained for $\mathrm{R}_{2}$ with 4-MePh, 4-BrPh and 4thienyl, respectively.

One of the key findings in this study is the proposal that the availability of large pore size in MOF catalyst assists the distribution of the heat generated during the reaction, avoiding coke formation generated by local over heating as observed with zeolites. ${ }^{97}$ This is one of the beneficial advantages of using MOFs as heterogeneous catalysts compared to other porous solids with smaller pore size and lower thermal conductivity like zeolites.

The catalyst of the flow system was reused for seven cycles (each a $24 \mathrm{~h}$ cycle) without any decrease in activity and selectivity. This is one of the first reports of MOF-based heterogeneous asymmetric catalysts for continuous-flow reactions and illustrates the vast potential that MOFs offer in this area.

Knoevenagel condensation between aldehyde and an active methylene compound is a very versatile reaction widely used in organic synthesis. In this context, a coordination modulation method was developed for the synthesis of nano-sized Ce-MOF through defect 
engineering and electrospinning process (Figure 3). The nano-szied Ce-MOF was used as catalyst in Knoevenagel condensation. ${ }^{82}$ The Ce-BTB MOF (BIT-58; BIT: Beijing Institute of Technology) was obtained by coordination between $\mathrm{Ce}^{3+}$ as the metal center and 1,3,5tris(4-carboxyphenyl)benzene (BTB) as ligand. The crystal size and defects of BIT-58 were controlled by the presence of various nitrogen heterocycles such as 1-methylimidazole acting as modulator during the synthesis of the material. ${ }^{98}$ BIT-58 possesses a one-dimensional channel system with pore diameters of about $1 \mathrm{~nm}$. Ce exists in BIT-58 structure as trivalent ion as revealed by XPS and coordinates to nine oxygen atoms as $\mathrm{CeO}_{9}$ cluster. BIT-58 showed very high chemical and thermal stability. BIT-58 was stable at temperatures as high as $490{ }^{\circ} \mathrm{C}$ under $\mathrm{N}_{2}$ and $400{ }^{\circ} \mathrm{C}$ under air. The crystallite size of BIT-58 powders was adjusted by treating with 1-methylimidazole as modulator as well as monodendate ligand that competes with the coordination sites and controls the growth of MOF crystals. ${ }^{99}$ The average particle size of BIT-58 was greatly reduced from $25 \mu \mathrm{m}$ to $30 \mathrm{~nm}$, while preserving the crystallinity, rendering nano-BIT-58 samples.

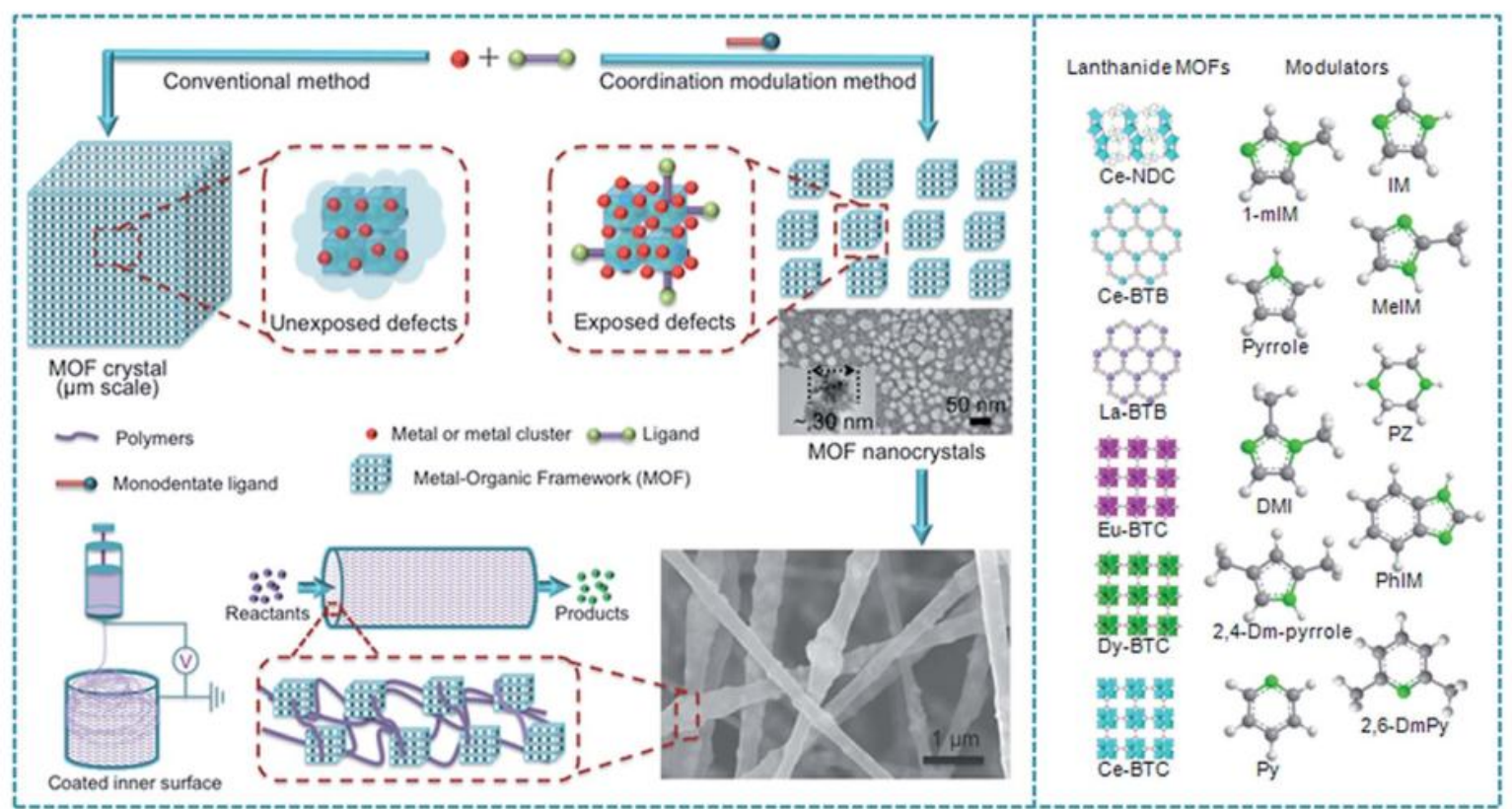


Figure 3. Representation of the coordination modulation concept for lanthanide MOF synthesis of NPs and fabrication of a catalyst film by electrospinning. Reproduced with permission from ref. ${ }^{82}$

Gas adsorption measurements indicated that nano-BIT-58 showed a slightly higher BET surface area of $1169 \mathrm{~m}^{2} \mathrm{~g}^{-1}$ than BIT-58 $\left(1075 \mathrm{~m}^{2} \mathrm{~g}^{-1}\right)$. Although, the micropore volume of nano-BIT-58 $\left(0.39 \mathrm{~cm}^{3} \mathrm{~g}^{-1},<2 \mathrm{~nm}\right)$ is similar as that BIT-58 $\left(0.40 \mathrm{~cm}^{3} \mathrm{~g}^{-1},<2 \mathrm{~nm}\right)$, the mesopore volume of nano-BIT-58 $\left(0.35 \mathrm{~cm}^{3} \mathrm{~g}^{-1}, 2-40 \mathrm{~nm}\right)$ was around seven times bigger than that of BIT-58 $\left(0.05 \mathrm{~cm}^{3} \mathrm{~g}^{-1}, 2-40 \mathrm{~nm}\right)$. This higher mesopore volume derives from the assembly of the nanoparticles (NPs) and is highly beneficial to avoid mass transport limitation of substrates to the active sites. Furthermore, $\mathrm{NH}_{3}$-TPD titration curves revealed that nano-BIT-58 contains a total acid site amount of 7.06 sites per gram which is 10.5 times higher than the micrometric BIT-58 sample (0.67 sites per gram). This enhancement is due to the higher density of Lewis acid sites arising from defects (e.g., unsaturated metal sites) and higher population of Brönsted acid sites (e.g. uncoordinated carboxy groups) present in the crystal structure upon treatment with 1-methylimidazole. It is unclear, however, what exactly the number of 7.06 sites per gram correspond in terms of mmols of acid sites per gram.

The activity of BIT-58 was tested in the Knoevenagel condensation reaction under continuous flow conditions. The conversion efficiency for the reaction between benzaldehyde and malononitrile of nano-BIT-58 was $100 \%$, while the activity of BIT-58 was only $78 \%$ which clearly indicates the superior activity of the former catalyst due to its higher acidity derived from defects. A similar reactivity trend was observed for the other substrates tested. Particularly, the conversion of 1-naphthaldehyde was under similar reaction conditions 31 and $90 \%$ with BIT-58 and nano-BIT-58, whereas the conversion of 9-anthraldehyde was 3 and $42 \%$ for BIT-58 and nano-BIT-58, respectively. These experimental results nicely agree 
with lesser diffusion limitations for nano-BIT-58 compared to BIT-58, resulting in a higher activity of the former.

A nano-BIT-58 film (70 wt\% nanoBIT-58 in polyacrylonitrile (PAN)) was fabricated by electrospinning with intact internal topology of the nano MOF (Figure 4). This film displayed nanofiber-interweaved network, where nano-BIT-58 particles are uniformly dispersed. The porosity of nano-BIT-58 film was $409 \mathrm{~m}^{2} \mathrm{~g}^{-1}$ as evidenced by BET analysis. The catalytic efficiency of this film was studied under continuous flow, observing $100 \%$ conversion for the Knoevenagel condensation of benzaldehyde and malononitrile after $6 \mathrm{~h}$. The catalytic film was recycled at least three times without any decay in activity.

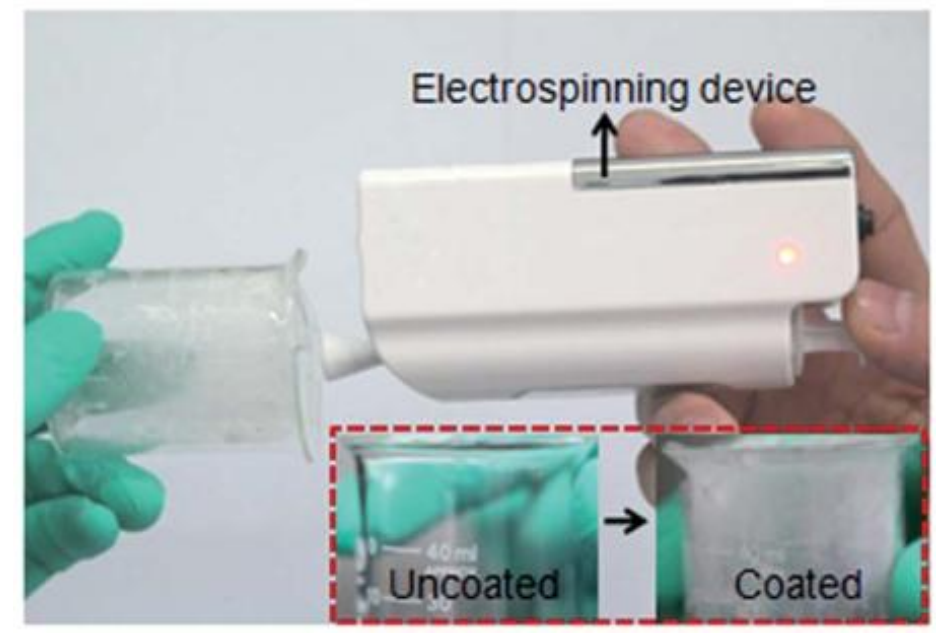

Figure 4. The experimental set up a beaker before and after treating with the coating of nanoBIT-58 film for Knoevenagel condensation between benzaldehyde and malononitrile at $60{ }^{\circ} \mathrm{C}$ for a residence time of $6 \mathrm{~h}$.

In this context, it is worth commenting that besides the importance in organic synthesis to form $\mathrm{C}-\mathrm{C}$ bonds, the Knoevenagel condensation is one of the favourite probe reactions that has also been carried out with many other solid catalysts under continuous flow reaction, such as amino groups immobilized on mesoporous silicas, ${ }^{100}$ zeolites $^{101}$ and organic 
polymers, ${ }^{102}$ among others, ${ }^{103}$ and the present data do not allowed to have a clear picture of the possible advantages of the use of MOFs as solid catalysts for this process.

\section{C-O bond formation}

Polymer membranes have been extensively employed in continuous flow catalytic processes. ${ }^{104}$ Although these organic membranes have high fluxes, they generally suffer from short lifetime, low stability and insufficient selectivity. ${ }^{105}$ On other hand, mixed matrix membranes (MMMs) have been reported to overcome some of the limitations of polymeric membranes by introducing inorganic or organic fillers in the polymer matrix. ${ }^{106}$ MOFs have been identified as one of the possible fillers for polymeric membranes due to their large surface area, high porosity and tunable structures. ${ }^{107}$ One example of these MMMs containing MOF is the combination of $\mathrm{Cu}_{3}(\mathrm{BTC})_{2}$ (BTC: 1,3,5-benzenetricarboxylate) and cellulose acetate (CA) that exhibits catalytic activity for the continuous production of acetals through acetalization of benzaldehyde. ${ }^{83} \mathrm{CA}$ served as the matrix and $\mathrm{Cu}_{3}(\mathrm{BTC})_{2}$ as the filler with catalytic activity. In this study, a series of catalytic membranes with different $\mathrm{Cu}_{3}(\mathrm{BTC})_{2}$ loading were prepared. SEM images revealed that CA fibres are twisted in the membrane and that the size of $\mathrm{Cu}_{3}(\mathrm{BTC})_{2}$ particles are around $15-20 \mu \mathrm{m}$. It was proved that the MOF component was uniformly distributed on the $\mathrm{CA}$ membrane. Furthermore, $\mathrm{Cu}_{3}(\mathrm{BTC})_{2}$-based MMMs exhibit the characteristic XRD peaks corresponding to CA and to $\mathrm{Cu} M O F$.

Acetalization of benzaldehyde was performed under continuous flow for $2 \mathrm{~h}$ as shown in Figure 5, reaching a benzaldehyde conversion of $94 \%$ and an acetal selectivity of $99 \%$, with a productivity value of $0.59 \mathrm{mmol} \mathrm{min}^{-1} \mathrm{~g}_{\mathrm{Cu} 3(\mathrm{BTC}) 2}{ }^{-1}$ in the steady state regime. These values were maintained for $24 \mathrm{~h}$, indicating the long-term stability of the catalytic membrane (Figure 6). Furthermore, upon increasing of benzaldehyde flow rate, the yields of benzaldehyde diethyl acetal were also increased. For example, the conversion of 
benzaldehyde was found to be 79,87 and $94 \%$ for flow rates of $0.8,1.6$ and $3.2 \mu \mathrm{L} \mathrm{min}{ }^{-1}$, respectively. No conversion of benzaldehyde was observed with CA. Under the same conditions, using $3.2 \mu \mathrm{L} \mathrm{min}{ }^{-1}$ of benzaldehyde, the conversion of benzaldehyde was $78 \%$ with $99 \%$ selectivity and $99 \%$ conversion with $82 \%$ selectivity using methanol and ethylene glycol, respectively. Under identical conditions, $\mathrm{Cu}_{3}(\mathrm{BTC})_{2}$ catalyst showed $16 \%$ conversion with $99 \%$ selectivity towards diethyl acetal, revealing the advantages of the MMM. This protocol was also extended to the synthesis of a series of acetals, reaching 68 to $94 \%$ conversion values at a selectivity of $99 \%$.

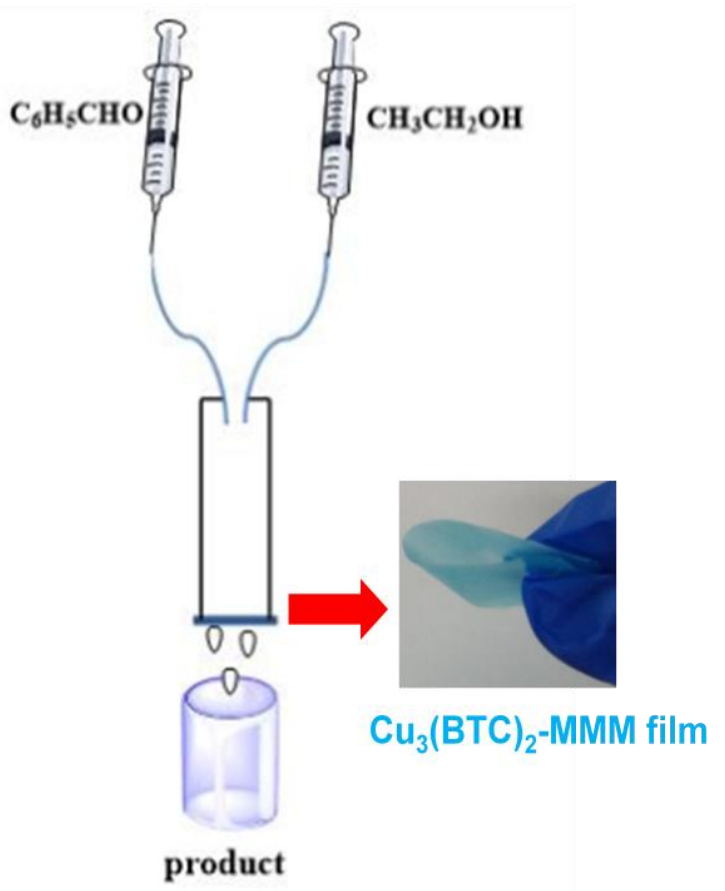

Figure 5. The experimental set-up used for continuous flow experiment for the acetalization of benzaldehyde.

Shape-selective acetalization could also be performed with $\mathrm{Cu}_{3}(\mathrm{BTC})_{2} \mathrm{MMM}$, providing an indirect evidence that the reaction takes place inside the pores of the $\mathrm{Cu}$ MOF. Thus, acetalization of benzaldehyde $\left(0.53 \times 0.66 \mathrm{~nm}^{2}\right)$ was $94 \%$ since its dimensions were smaller than the pore size of $\mathrm{Cu}_{3}(\mathrm{BTC})_{2}$. In contrast, acetalization of 2-naphthaldehyde $(0.77$ 
$\left.\times 0.66 \mathrm{~nm}^{2}\right)$ gave $56 \%$ yield, while the yield of 9 -anthraldehyde $\left(1.03 \times 0.66 \mathrm{~nm}^{2}\right)$ was only $18 \%$ under identical conditions.

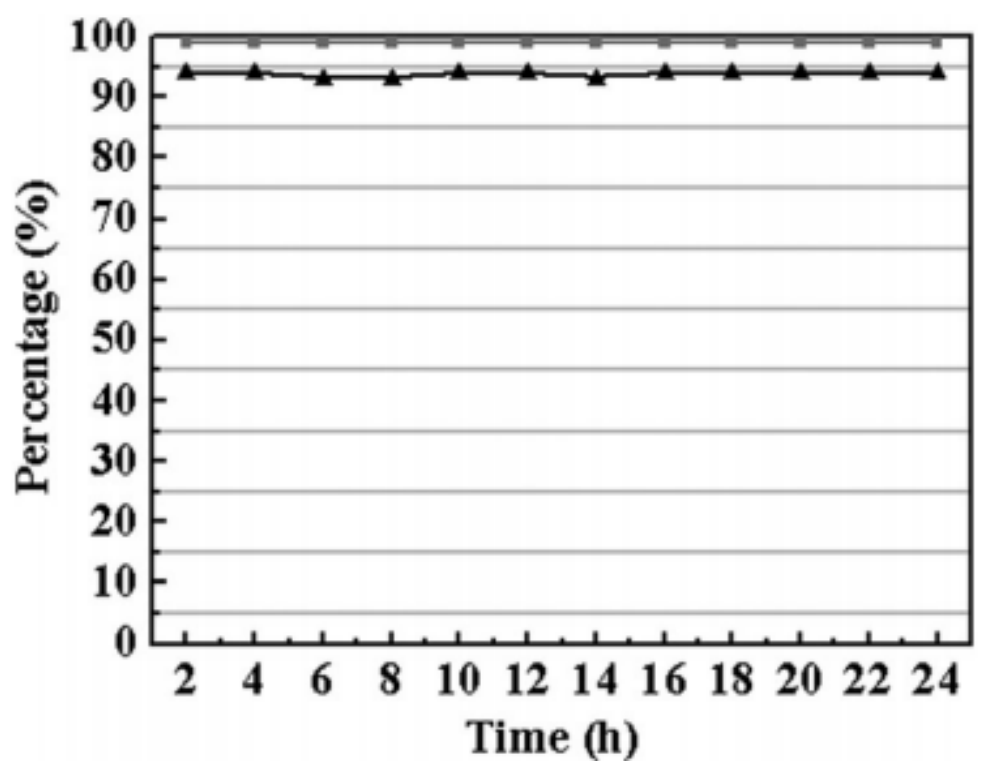

Figure 6. Time on stream conversion (triangle) and selectivity (square) for acetalization of benzaldehyde with ethanol on the $\mathrm{Cu}_{3}(\mathrm{BTC})_{2}$. Reproduced with permission from ref. ${ }^{83}$

In another precedent, acetalization of benzaldehyde with methanol was reported using $\mathrm{Cu}_{3}(\mathrm{BTC})_{2}$ as heterogeneous catalyst, both under batch as well as continuous flow conditions (Figure 7). ${ }^{84}$ The focus of this study was to investigate catalyst stability during batch and continuous flow conditions. The productivity rate for benzaldehyde dimethyl acetal using $\mathrm{Cu}_{3}(\mathrm{BTC})_{2}$ was $5.85 \times 10^{-2} \mathrm{~h}^{-1}$ at room temperature after $24 \mathrm{~h}$, while the rate was $6.83 \times 10^{-1} \mathrm{~h}^{-1}$ after $10 \mathrm{~h}$ at $70{ }^{\circ} \mathrm{C}$. Besides temperature, the productivity rate could be enhanced to $3.12 \mathrm{~h}^{-1}$ at $70{ }^{\circ} \mathrm{C}$ after $10 \mathrm{~h}$ by using ground fine particles of $\mathrm{Cu}_{3}(\mathrm{BTC})_{2}$. A significant decay in the catalytic activity was observed after recycling the solid catalyst in repeated batch reactions. Under continuous flow tests a sudden deactivation occurs in the first minutes of time on stream, but after this period the catalytic activity grows moderately. Powder XRD and BET surface area analysis revealed the occurrence of structural as well as morphological changes, decreasing the intensities of the peaks and diminishing the surface area and pore volume, 
respectively. Interestingly, fine particles of $\mathrm{Cu}_{3}(\mathrm{BTC})_{2}$ exhibits the highest continuous flow activity and also presents the increase in the catalytic activity over the time on stream after the initial deactivation (Figure 8).

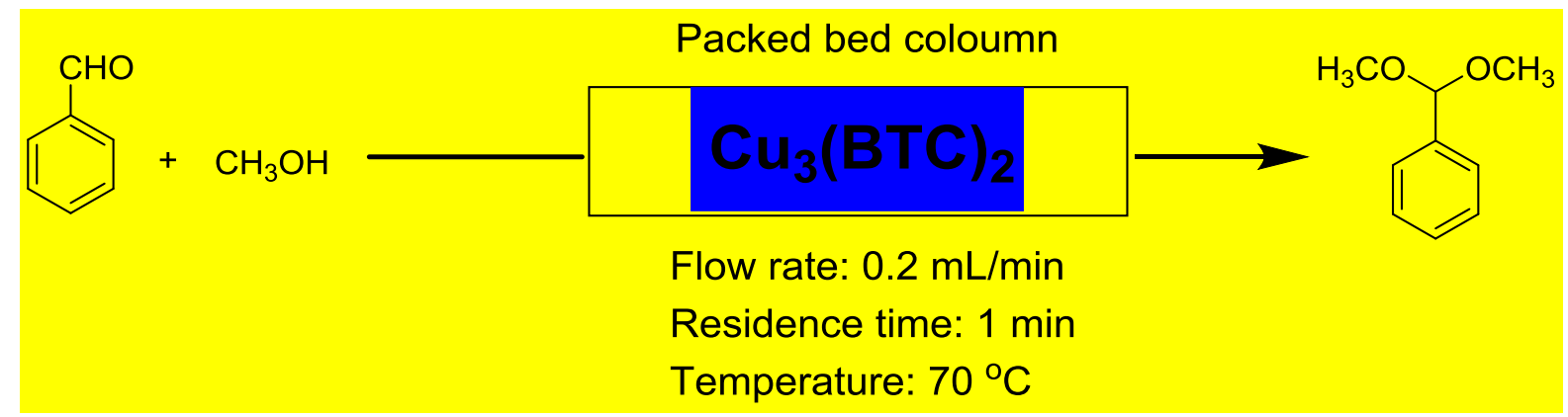

Figure 7. Acetalization of benzaldehyde with methanol using $\mathrm{Cu}_{3}(\mathrm{BTC})_{2}$ as solid catalyst under continuous flow conditions.

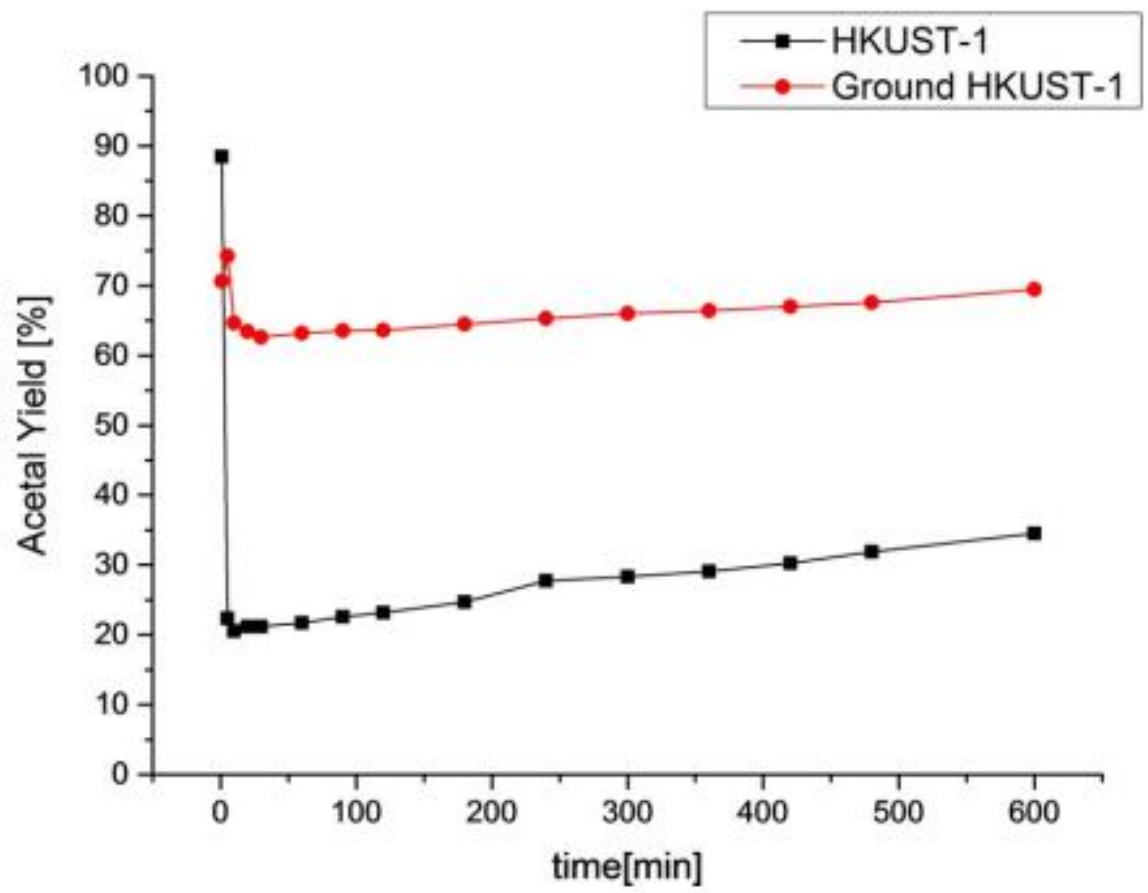

Figure 8. Yield of benzaldehyde dimethyl acetal versus time for the continuous flow tests. Reproduced with permission from ref. ${ }^{84}$ 
A hierarchical yolk/shell copper hydroxysulfate@ $\mathrm{Cu}_{3}(\mathrm{BTC})_{2}\left(\mathrm{CHS} @ \mathrm{Cu}_{3}(\mathrm{BTC})_{2}\right)$ was obtained at room temperature starting from a homogeneous yolk/shell copper hydroxysulfate (CHS) template composed of a reactive shell and a stabilized core. ${ }^{85}$ The active shell contributed as the source of $\mathrm{Cu}^{2+}$ ions that were in situ transformed to a well-defined MOF crystal shell upon reacting with 1,3,5-benzenetricarboxylate present in the solution. As result, the stabilized core retained during the formation of the MOF shell its own CHS nature. The process is illustrated in Figure 9. In the resulting CHS@ $\mathrm{Cu}_{3}(\mathrm{BTC})_{2}$, the core was constructed of tiny nanoplatelets with a thickness of $\sim 10 \mathrm{~nm}$, and the outer shell is assembled of closely packed nanosheets, each with a thickness of $\sim 100 \mathrm{~nm}$. The activity of $\mathrm{CHS} @ \mathrm{Cu}_{3}(\mathrm{BTC})_{2}$ was tested in the room temperature acetalization of benzaldehyde with ethanol. Benzaldehyde was converted to benzaldehyde diethyl acetal in $88 \%$ yield with $99 \%$ selectivity. A blank in the absence of catalyst showed under identical conditions no benzaldehyde conversion, while the use of either pure CHS template or pure $\mathrm{Cu}_{3}(\mathrm{BTC})_{2}$ as catalyst reaches a benzaldehyde conversion of 80 and $17 \%$, respectively. The superior activity of yolk/shell CHS@ $\mathrm{Cu}_{3}(\mathrm{BTC})_{2}$ has been attributed to the CHS core that primarily promotes benzaldehyde acetalization, while the $\mathrm{Cu}_{3}(\mathrm{BTC})_{2}$ shell with large surface area behaves as a reactor impeding further agglomeration of CHS core and provides multiple access channels for the reactants to reach the active $\mathrm{CHS}$ surface. The $\mathrm{CHS} @ \mathrm{Cu}_{3}(\mathrm{BTC})_{2}$ core-shell provides a close intimacy of reactants that should accelerate the reaction rate. $\mathrm{CHS} @ \mathrm{Cu}_{3}(\mathrm{BTC})_{2}$ was reused five times without observing any notable change in its efficiency and selectivity. In contrast, the activity of CHS catalyst drastically decreased to $28 \%$. Since the morphology and crystal structure of the used CHS and $\mathrm{CHS} @ \mathrm{Cu}_{3}(\mathrm{BTC})_{2}$ remained unchanged, the significant deactivation of CHS was attributed to benzaldehyde adsorption on its surface. This proposal was supported by GC-MS analysis. Powder XRD indicated that the phase of the three-months stored CHS was transformed from $\mathrm{Cu}_{2.5} \mathrm{SO}_{4}(\mathrm{OH})_{3} \cdot 2 \mathrm{H}_{2} \mathrm{O}$ to $\mathrm{Cu}_{4} \mathrm{SO}_{4}(\mathrm{OH})_{6}$ and the 
morphology is transformed from yolk/shell microsphere to stacked microsheets. On the other hand, the phase and morphology of three months stored $\mathrm{CHS} @ \mathrm{Cu}_{3}(\mathrm{BTC})_{2}$ were retained without any change, thus indicating its stability.

A flow reactor was developed using CHS@ $\mathrm{Cu}_{3}(\mathrm{BTC})_{2}$ as immobilized stationaryphase catalyst (Figure 10). The reactant solution was injected into the reactor and the product was recovered at the exit. Under the continuous flow conditions, benzaldehyde was effectively converted to benzaldehyde diethyl acetal in $87 \%$ yield and $99 \%$ selectivity in a single pass, however, no details on residence time is provided. However, the catalyst stability under continuous flow conditions (time on stream) and its activity in terms of TOF remain to be determined.

As in the case of the Knoevenagel reaction, there is a large variety of solid acids that have been reported as solid catalysts for the continuous flow acetalization of aldehydes in the liquid phase, particularly for their application as biofuels using including sulfonic acid resins, ${ }^{108,}{ }^{109}$ zeolites ${ }^{110}$ and mesoporous silicas having grafted sulfonic acid groups. ${ }^{111}$ Some of the reported materials do not undergo deactivation upon time on stream and, therefore, there is still a need to find stable MOF that do not undergo the initial strong decline in its catalytic activity.

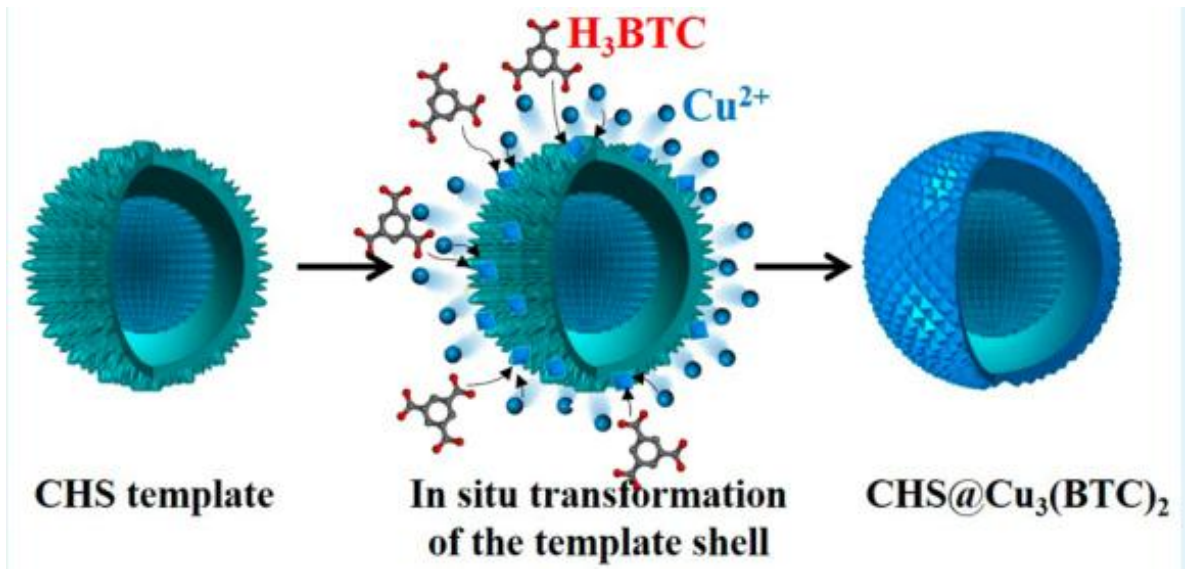

Figure 9. Preparation of yolk/shell CHS@ $\mathrm{Cu}_{3}(\mathrm{BTC})_{2}$ catalyst. $^{85}$ 


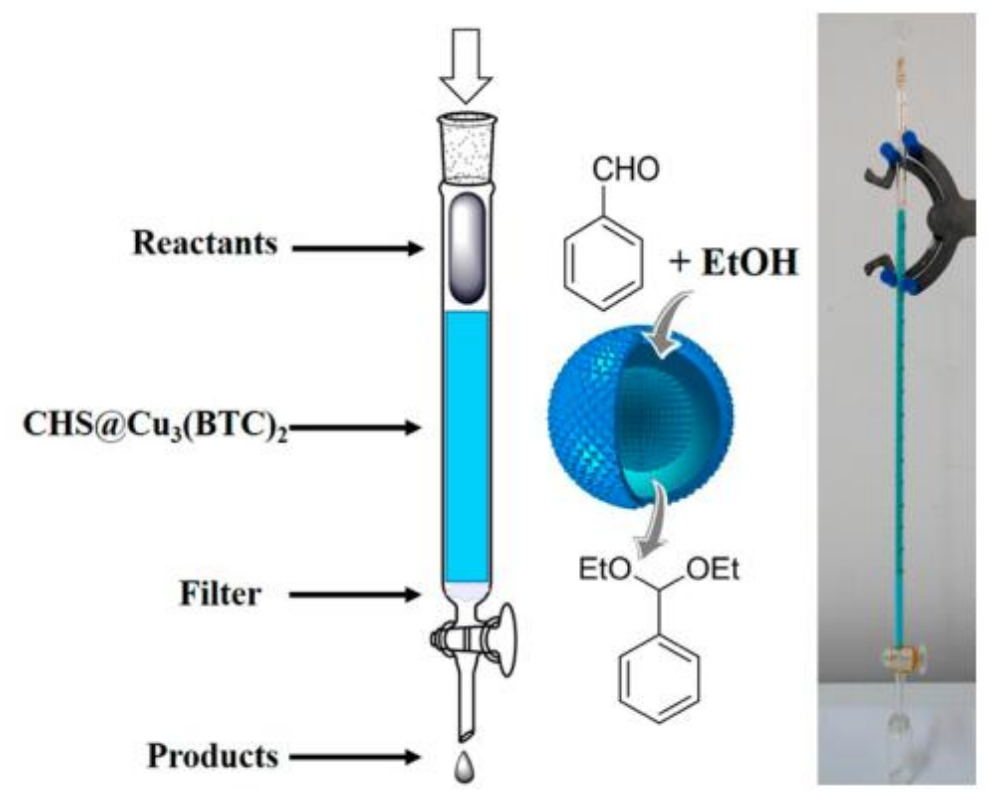

Figure 10. Schematic representation and photograph of the flow reactor using self-supported CHS@ $\mathrm{Cu}_{3}(\mathrm{BTC})_{2}$ catalyst with aldehyde and ethanol molar ratio of 1:80 at a flow rate of $0.05 \mathrm{~mL} / \mathrm{min}$ at $25^{\circ} \mathrm{C}$. Reproduced with permission from ref. ${ }^{85}$

Cyclic carbonates are valuable commodity chemicals that find application as solvents for Li-ion batteries (propylene carbonate), as well as monomers for polycarbonate synthesis. ${ }^{112}$ One of the conventional synthesis of cyclic carbonates is the reaction of phosgene with the corresponding diol (Scheme 2). ${ }^{113}$ An attractive alternative strategy for the synthesis of these compounds is the cycloaddition of $\mathrm{CO}_{2}$ to epoxides to yield the corresponding cyclic carbonate (Scheme 2), ${ }^{114}$ a reaction with complete atom economy, and the use of inexpensive and convenient substrates, avoiding phosgene as reagent. ${ }^{115}$ Recently, MIL-101(Cr) has been reported as an effective catalyst for the $\mathrm{CO}_{2}$ cycloaddition to propylene oxide to give propylene carbonate under flow conditions without the need of halide co-catalyst (Figure 11). ${ }^{86}$ Under steady-state operation after $1 \mathrm{~h}$, the propylene carbonate was obtained with a TOF of $20 \mathrm{~h}^{-1}$ using TBAB as co-catalyst. This TOF value is equivalent to $0.033 \mathrm{mmol} \mathrm{min} \mathrm{m}^{-1}$ of propylene carbonate in a single pass, corresponding to $80 \%$ yield 
(Figure 12). Later, the reaction was performed without TBAB under identical flow conditions, reaching under these conditions $54 \%$ yield in a single pass, which is a remarkable activity in the absence of bromide co-catalyst. Although these results are promising, the residence time is not provided which is very crucial to determine the activity of a solid under flow conditions. The effect of synthesis conditions on the catalytic performance of the resulting MIL-101(Cr) was studied by preparing MIL-101(Cr) using a series of acids, including hydrochloric acid, hydrofluoric acid, acetic acid and also under acid-free conditions. These four MIL-101(Cr) samples showed similar catalytic activity with single pass yield ranging between 33-41\%. In addition to MIL-101(Cr), analogous isostructural Feand Sc-based MOFs were also prepared and their activity under identical flow conditions tested. MIL-101(Cr) MOF prepared under acid free conditions afforded $41 \%$ yield at steady state operation with a TOF of $21 \mathrm{~h}^{-1}$. In comparison, MIL-101(Fe) showed a very low activity of only 1-2\% yield under analogous conditions. In contrast, the more oxophilic Sc-based catalyst, MIL-101(Sc) exhibited higher initial activity than MIL-101(Cr), with $53 \%$ yield of propylene carbonate and TOF value of $87 \mathrm{~h}^{-1}$ for MIL-101(Sc) after $1 \mathrm{~h}$. Unfortunately, the activity of MIL-101(Sc) decreased rapidly to $<10 \%$ in $3 \mathrm{~h}$. This result indicates catalyst deactivation under flow conditions. This was confirmed by recording the powder XRD pattern of the spent MIL-101(Sc) catalyst that showed a notable crystallinity loss after $3 \mathrm{~h}$ under the reaction conditions. In contrast, a minimal loss of crystallinity was seen for MIL$101(\mathrm{Cr})$ under analogous conditions, thus showing superior stability of MIL-101(Cr) with time on stream. Interestingly, in contrast to the performance of MIL-101(Sc), the activity of MIL-100(Sc) was found to be superior than MIL-101(Cr) by affording a product yield of 57 $\%$ and a TOF of $28 \mathrm{~h}^{-1}$ at steady state operation under the standard conditions. Furthermore, the activity of MIL-100(Sc) was maintained up to $5 \mathrm{~h}$ without any decay in its activity. 
Figure 11 shows the experimental set-up for the packed bed-flow reactor. HPLC pump high-pressure mass flow controller was used to supply epoxide stock solution of $\mathrm{CO}_{2}$ gas respectively. A four-way dynamic mixer was used for homogeneous mixing of reactants. The oven was constructed from copper pipe covered in silicone-wrapped heating tape connected to a temperature controller. The catalyst bed was made up of a glass tube fitted with Vespel/graphite ferrules and packed with a catalyst. A thermocouple was connected to the outside surface of the bed for regulating the temperature. Ice bath was attached to control the evaporation of solvent.

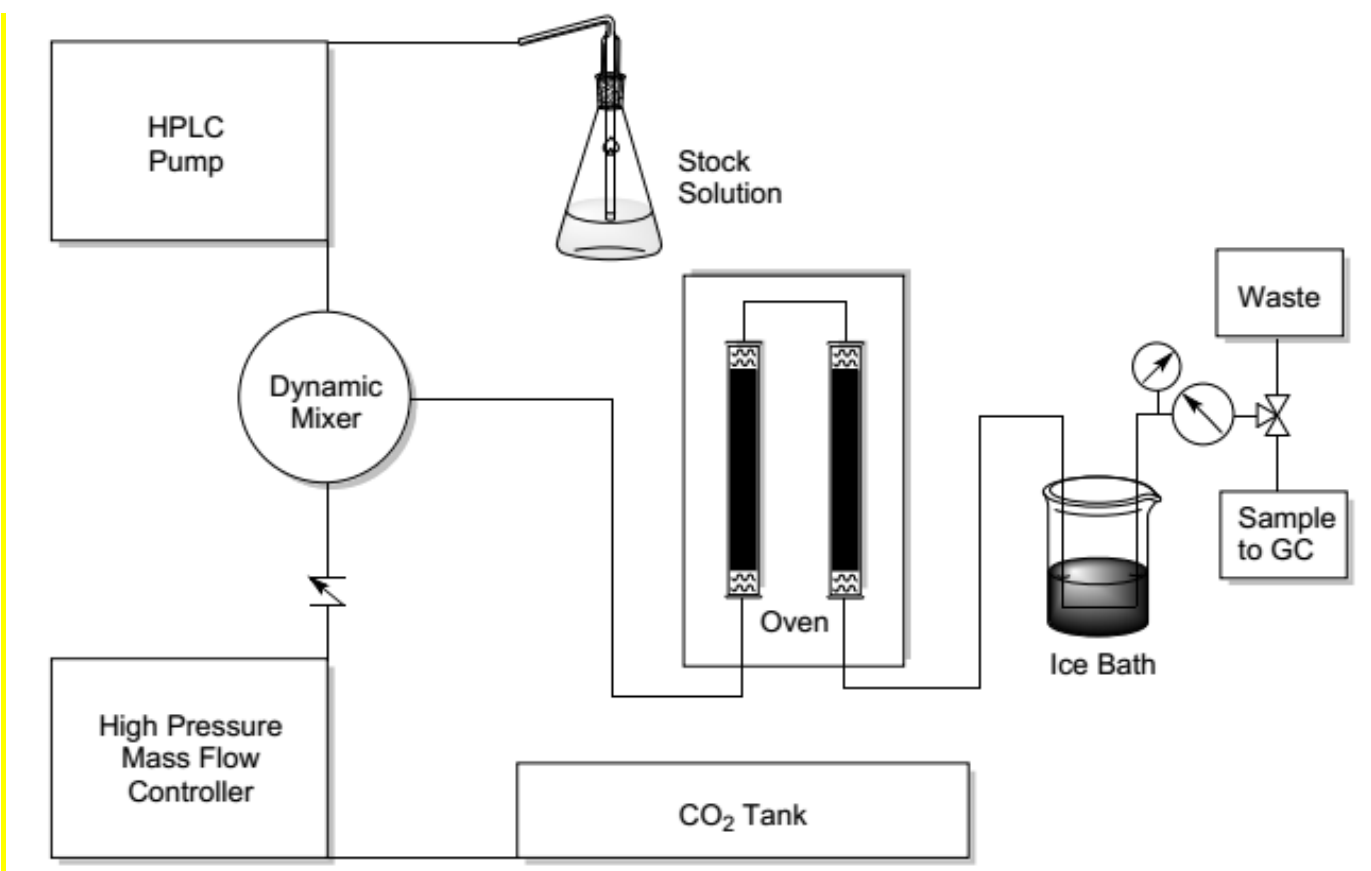

Figure 11. Schematic representation of packed-bed flow reactor used for the cycloaddition of $\mathrm{CO}_{2}$ to epoxides.

The structure activity relationship in Sc-based MOFs was studied by preparing several analogues with different crystal structures and node geometries which include MIL-88D(Sc) and MIL-68(Sc). MIL-88D(Sc) exhibit a yield of $11 \%$ and TOF value of $12 \mathrm{~h}^{-1}$. Furthermore, the activity of MIL-68(Sc) was even lower, affording < $1 \%$ yield of propylene carbonate under similar conditions. These results indicate that the presence of accessible Lewis acidic 
sites on the metal nodes in these MOF-based catalysts is a key requirement for exhibiting activity.

(a)
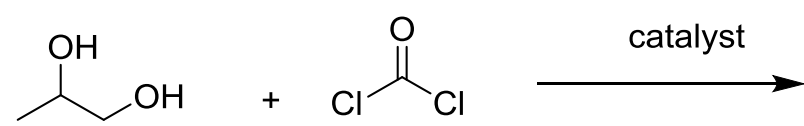<smiles>CC1COC(=O)O1</smiles>

(b)

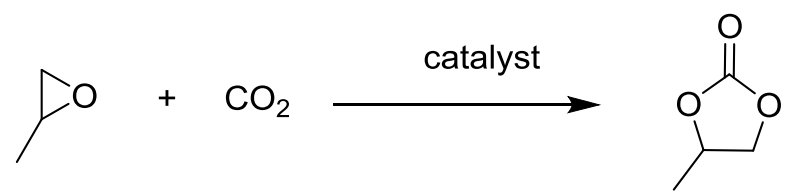

Scheme 2. Phosgene/diol (a) and $\mathrm{CO}_{2} /$ epoxide (b) routes to propylene carbonate.

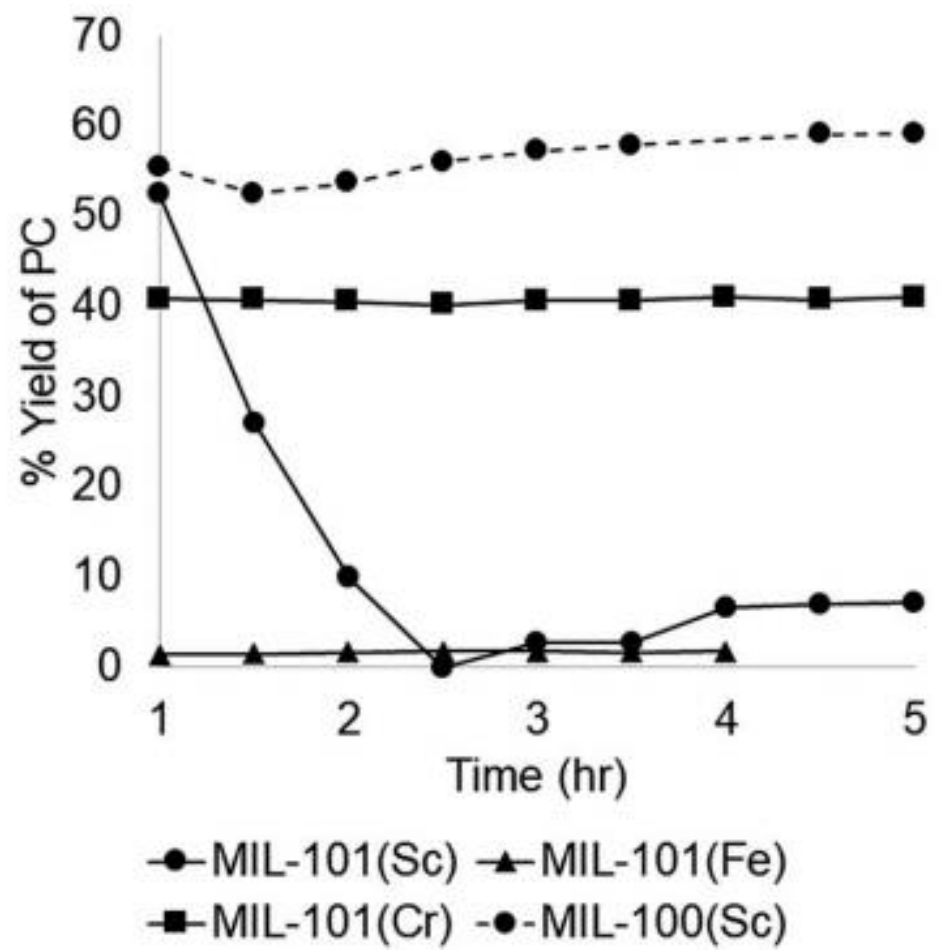

Figure 12. Contrasting catalytic activity of different MOFs for the conversion of propylene oxide to propylene carbonate. Reproduced with permission from ref. ${ }^{86}$

Recently, $\mathrm{NaCo}(\mathrm{CO})_{4}$-incorporated on $\mathrm{MIL}-101(\mathrm{Cr})\left[\mathrm{Co}(\mathrm{CO})_{4} \subset \mathrm{MIL}-101(\mathrm{Cr})\right]$ was reported as the first heterogeneous catalyst for the selective ring-expansion carbonylation of $\beta$-lactones to succinic anhydrides. ${ }^{87}$ The main reasons to select MIL-101(Cr) as solid support for the deposition of $\mathrm{Co}(\mathrm{CO})_{4}{ }^{-}$were its high surface area, large pore openings (12 and $16 \AA$ ) and pore diameters ( 29 and $34 \AA$ ) that should allow diffusion of reagents to the active sites. 
Besides porosity, high chemical and thermal stability were other factors for the selection of this material. ${ }^{116}$ Initially, the catalytic activity of $\mathrm{Co}(\mathrm{CO})_{4} \subset \mathrm{MIL}-101(\mathrm{Cr})$ was tested in the carbonylation of $\beta$-butyrolactone at $80{ }^{\circ} \mathrm{C}$ in toluene with 15 bar of $\mathrm{CO}$ for $24 \mathrm{~h}$, reaching full conversion. A similar reactivity was also observed for a homogeneous catalyst [(salph)Al(THF) $\left.)_{2}\right]\left[\mathrm{Co}(\mathrm{CO})_{4}\right]$ (salph: N,N'-o-phenylenebis(3,5-di-tert-butylsalicylideneimine); THF: tetrahydrofuran). ${ }^{117}$ Unfortunately, product analysis indicated the formation of the desired product methylsuccinic anhydride together with unwanted poly(3-hydroxybutyrate) as a major side product.

Later, the carbonylation activity of $\mathrm{Co}(\mathrm{CO})_{4} \subset \mathrm{MIL}-101(\mathrm{Cr})$ was studied for $\beta$ propiolactone (Scheme 3), targeting the synthesis of the commercially desirable unsubstituted succinic anhydride. Gratifyingly, $\mathrm{Co}(\mathrm{CO})_{4} \subset \mathrm{MIL}-101(\mathrm{Cr})$ efficiently promoted the carbonylation of $\beta$-propiolactone at room temperature in toluene with 15 bar of $\mathrm{CO}$ to give exclusively succinic anhydride in $92 \%$ yield without observing the formation of the poly(3hydroxypropionate) byproduct. This activity corresponds to an overall site time yield (the number of molecules of a specified product made per catalytic site and per unit time) of $16 \mathrm{~h}^{-}$ ${ }^{1}$ which is higher than the value provided by the homogeneous $\left[(\mathrm{salph}) \mathrm{Al}(\mathrm{THF})_{2}\right]\left[\mathrm{Co}(\mathrm{CO})_{4}\right]$ catalyst $\left(12 \mathrm{~h}^{-1}\right)$ under analogous conditions. MIL-101(Cr) and $\mathrm{Na}\left[\mathrm{Co}(\mathrm{CO})_{4}\right]$ exhibited 0 and $12 \%$ yields, respectively. This poorer catalytic performance of the individual components was attributed to the lack of $\mathrm{Co}(\mathrm{CO})_{4}{ }^{-}$active species required for $\mathrm{CO}$ insertion in one case and to the absence of strong Lewis acids to activate the lactone in the other one (Figure 13). Further, an equimolar mixture of MIL-101(Cr) and $\mathrm{Na}\left[\mathrm{Co}(\mathrm{CO})_{4}\right]$ as catalysts gave $43 \%$ yield, which is, also, higher compared to the use of either precursor individually. In any case, the activity of the physical mixture was much inferior to that of $\operatorname{Co}(\mathrm{CO})_{4} \subset \mathrm{MIL}-101(\mathrm{Cr})$ with well-defined $\mathrm{Cr} / \mathrm{Co}$ sites which can efficiently activate both substrate and $\mathrm{CO}$ that become inserted into the lactone. Hot filtration experiment verified the heterogeneity of the process. 
Powder XRD of the spent $\mathrm{Co}(\mathrm{CO})_{4} \subset \mathrm{MIL}-101(\mathrm{Cr})$ showed identical crystalline structure as that of the fresh solid, thus confirming the stability under the reaction conditions.

A laboratory-scale packed-bed reactor was designed to examine the activity of $\mathrm{Co}(\mathrm{CO})_{4} \subset \mathrm{MIL}-101(\mathrm{Cr})$ under continuous flow conditions (Figure 14). Using $\mathrm{Co}(\mathrm{CO})_{4} \subset \mathrm{MIL}-101(\mathrm{Cr})$ as solid catalyst operating at $0.1 \mathrm{~mL} / \mathrm{min}$ flow of $0.1 \mathrm{M} \beta$ propiolactone in $\mathrm{CH}_{2} \mathrm{Cl}_{2}$, equivalent to a weight hourly space velocity of $1200 \mathrm{~h}^{-1}$, with an excess $\mathrm{CO}$ flow of $30 \mathrm{~mL} / \mathrm{min}$ at 45 bar renders succinic anhydride as the sole product reaching at room temperature a productivity of $1300 \mathrm{~mol}_{\text {Anhydride }} \cdot \mathrm{mol}_{\mathrm{Co}}{ }^{-1}$ after $6 \mathrm{~h}$ on stream (Figure 15). Among all catalysts reported, the activity reached by $\mathrm{Co}(\mathrm{CO})_{4} \subset \mathrm{MIL}-101(\mathrm{Cr})$ is one of the best values achieved for $\beta$-carbonylation. Similarly, $\mathrm{Co}(\mathrm{CO})_{4} \subset \mathrm{MIL}-101(\mathrm{Cr})$ was also efficient to carbonylate $\beta$-butyrolactone to the desired methylsuccinic anhydride as the only product with an activity at $40{ }^{\circ} \mathrm{C}$ of $360 \mathrm{~mol}_{\text {Anhydride }} \cdot \mathrm{mol}_{\mathrm{Co}}{ }^{-1}$ after $60 \mathrm{~h}$ on stream (Figure 15). One of the main advantages of the packed-bed reactor is that solvent evaporation affords succinic anhydride crystals of very high purity. This process based on $\operatorname{Co}(\mathrm{CO})_{4} \subset \mathrm{MIL}-$ $101(\mathrm{Cr})$ greatly contrasts with alternative procedures consisting on poorly-selective hydrocarbon oxidation or microbial fermentation processes that require $\mathrm{NH}_{3} / \mathrm{H}_{2} \mathrm{SO}_{4}$-assisted succinate precipitation or $\mathrm{NaOH}$-assisted electrodialysis or amine-assisted reactive extraction. $^{118}$

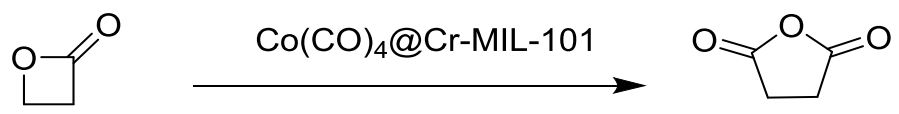

Scheme 3. Carbonylation of $\beta$-propiolactone. 
A<smiles>[R]C1CC(=O)OC1=O</smiles>

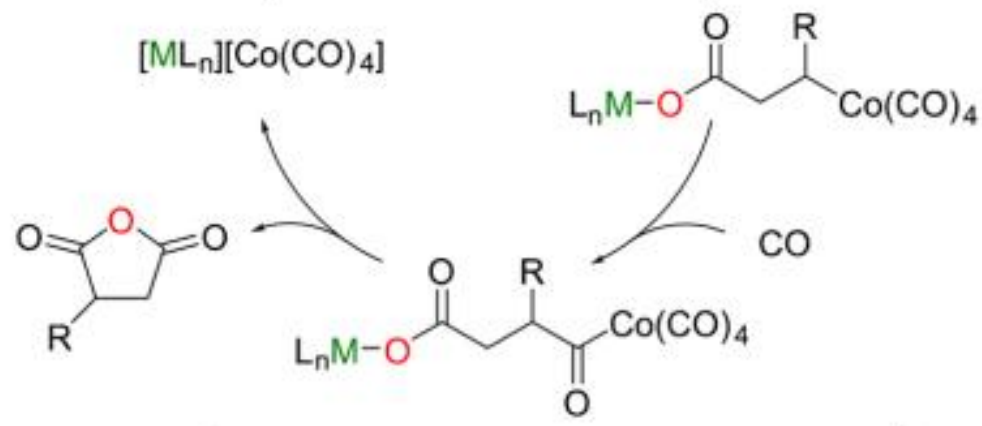

B

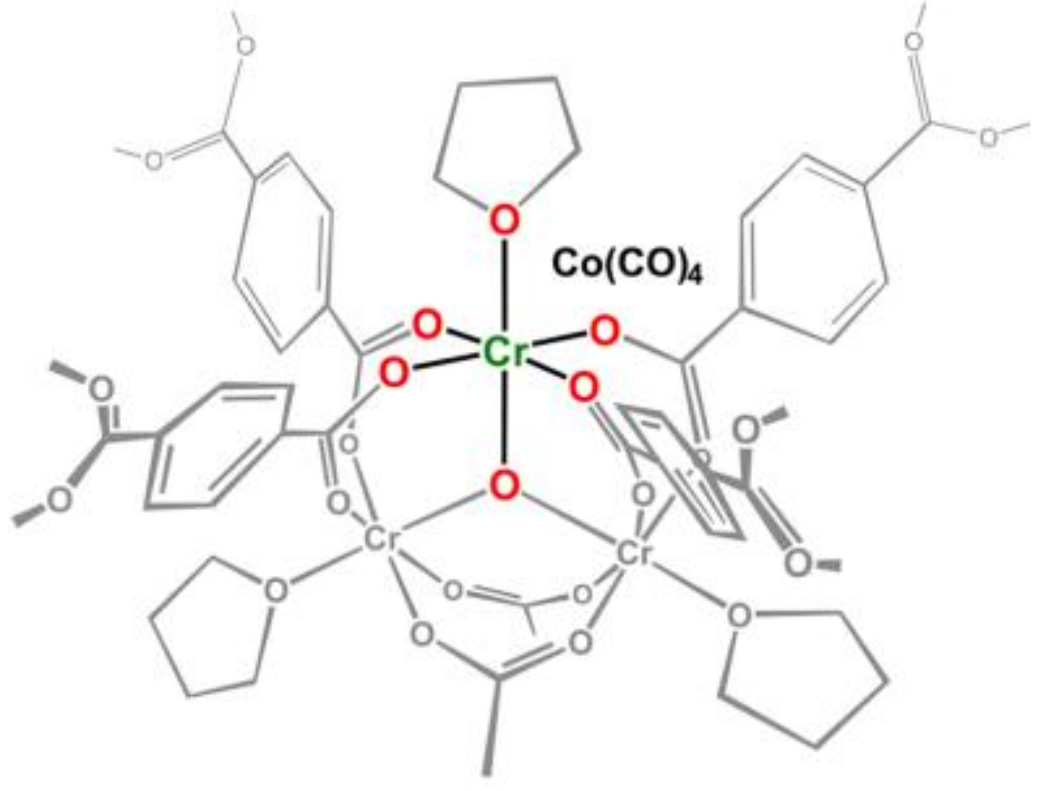

Figure 13. (A) Proposed mechanism for the ring-expansion carbonylation of $\beta$-lactones requiring the combination of [Lewis acid] and $\left[\mathrm{Co}(\mathrm{CO})_{4}\right]^{-}$; (B) Proposed active sites in $\mathrm{Co}(\mathrm{CO})_{4} \subset \mathrm{MIL}-101(\mathrm{Cr})$ with coordinated tetrahydrofuran molecules. Reproduced with permission from ref. ${ }^{87}$ 


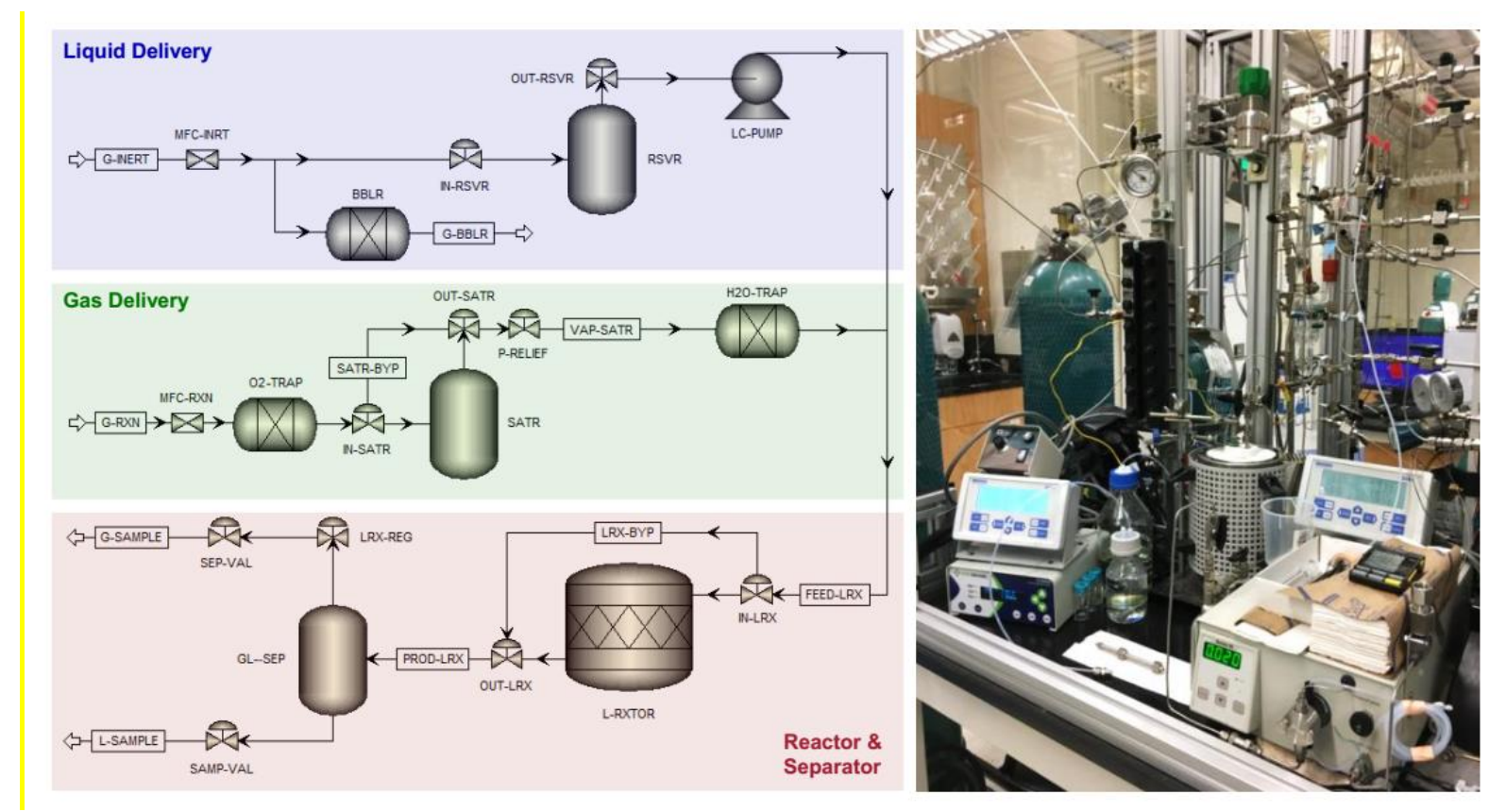

Figure 14. Process flow diagram and experimental setup of the packed bed reactor process for continuous-flow $\beta$-lactone carbonylation. 

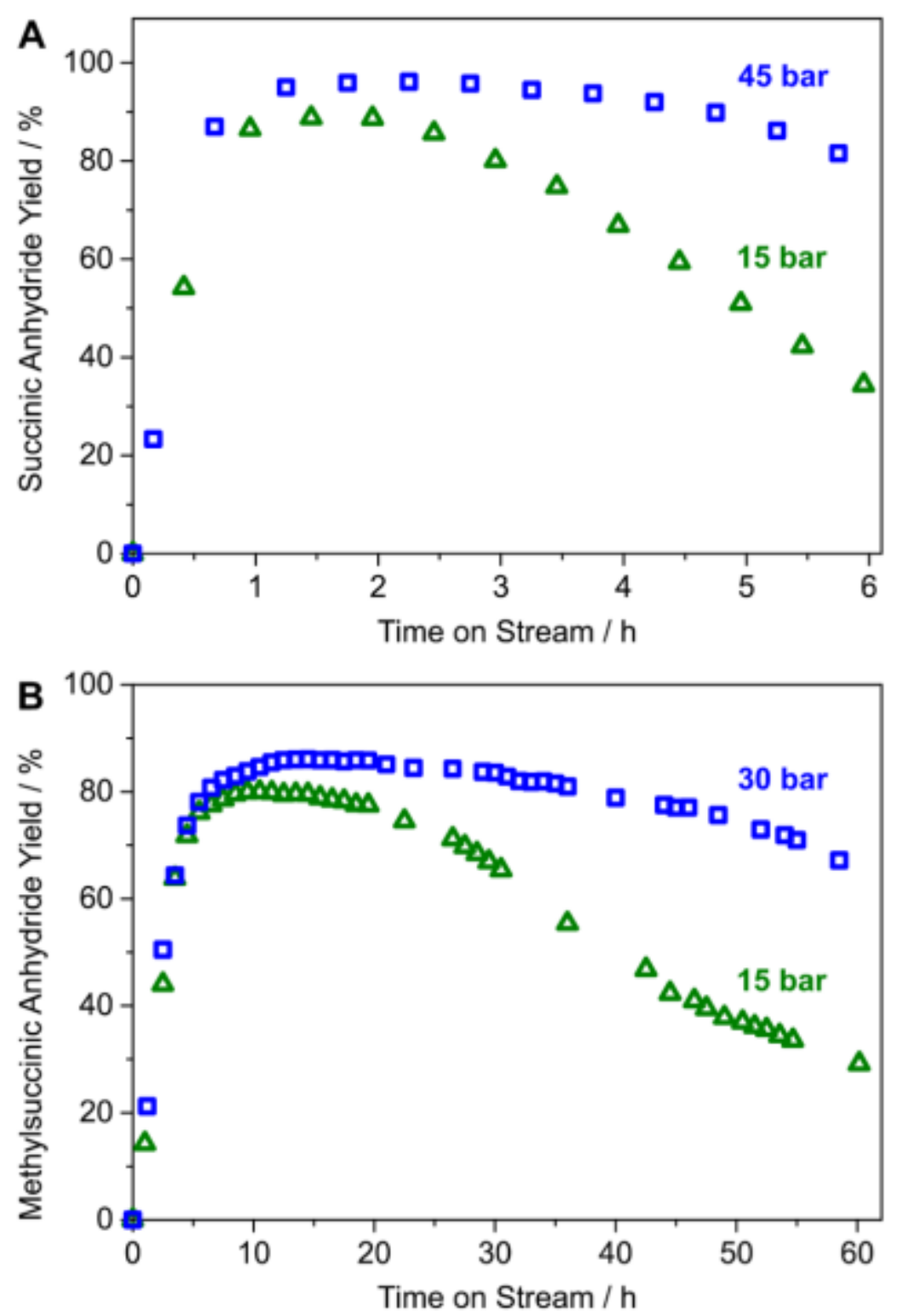

Figure 15. (A) Yield-time on stream plot for continuous-flow carbonylation of $\beta$ propiolactone by $\mathrm{Co}(\mathrm{CO})_{4} \subset \mathrm{MIL}-101(\mathrm{Cr})$ and (B) continuous flow carbonylation of $\beta$ butyrolactone by $\mathrm{Co}(\mathrm{CO})_{4} \subset \mathrm{MIL}-101(\mathrm{Cr})$. Reproduced with permission from ref. ${ }^{87}$

A UiO-66(Zr) sample with $1147 \mathrm{~m}^{2} / \mathrm{g}$ and a total pore volume of $0.58 \mathrm{~cm}^{3} / \mathrm{g}$ was tested as heterogeneous catalyst for the conversion of methyl levulinate (ML) to $\gamma$ valerolactone (GVL) through catalytic transfer hydrogenation under continuous flow conditions. ${ }^{88}$ The conversion of ML to GVL under batch reaction was optimized employing 
$0.23 \mathrm{~g}$ of $\mathrm{UiO}-66(\mathrm{Zr})$ as catalyst and $2.4 \mathrm{M}$ of $\mathrm{ML}$ in isopropanol at $240{ }^{\circ} \mathrm{C}$ under 35 bar. This study was also extended by performing continuous flow reaction as shown in Figure 16. The results obtained are given in Figure 17. The catalytic activity of UiO-66(Zr) was considerably stable up to $9 \mathrm{~h}$ on stream, observing a slight decrease of ML conversion at longer times. ML conversion reached to $56 \%$ after $30 \mathrm{~h}$ time on stream with GVL productivity of $58.94 \mathrm{mmol}_{\mathrm{GVL}} \mathrm{g}^{-1} \mathrm{~h}^{-1}$ and very high selectivity to GVL. The initial GVL productivity using $\mathrm{UiO}-66(\mathrm{Zr})$ was $92.3 \mathrm{mmol}_{\mathrm{GVL}} \mathrm{g}^{-1} \mathrm{~h}^{-1}(\mathrm{TOS}=1 \mathrm{~h})$, while it decreased to $58.9 \mathrm{mmol}_{\mathrm{GVL}} \mathrm{g}^{-1} \mathrm{~h}^{-1}$ after $30 \mathrm{~h}$ on stream. These values are much superior than with UiO$66(\mathrm{Zr})$ as catalyst under batch conditions $\left(1 \mathrm{mmol}_{\mathrm{GVL}} \mathrm{g}^{-1} \mathrm{~h}^{-1}\right)$ as well as with other earlier mixed oxide $\mathrm{Zr}-\mathrm{FeO}$ (1:1)-300 catalyst (39.2 mmol $_{\mathrm{GVL}} \mathrm{g}^{-1} \mathrm{~h}^{-1}$ ) (Table 4). ${ }^{119}$ Further, the catalytic performance of $\mathrm{UiO}-66(\mathrm{Zr})$ for the production of GVL under continuous flow was also compared with series of heterogeneous solid catalysts under batch conditions and these catalytic data clearly indicate that $\mathrm{UiO}-66(\mathrm{Zr})$ exhibits better performance under continuous flow than under batch conditions. These results clearly reveal the efficiency of UiO-66(Zr) as catalyst under continuous flow providing very high productivity of GVL. The decrease in the conversion of ML was due to catalyst decomposition, a proposal that was based on the detection of diisopropyl terephthalate by GC-MS analysis. Furthermore, the BET surface area of the catalyst recovered after continuous flow reaction decreased considerably to $109 \mathrm{~m}^{2} / \mathrm{g}$ compared to the value of the fresh sample. This low surface area value suggests the collapse of the crystalline framework, this being compatible with the detection of BDC ester derivative. TEM images of fresh and used UiO-66(Zr) indicated that the surface of fresh UiO-66(Zr) becomes transformed from smooth to rough after continuous flow operation which can be due to the loss of organic linkers and possibly formation of amorphous $\mathrm{ZrO}_{2}$ phase. These results indicate that further modification of $\mathrm{UiO}-66(\mathrm{Zr})$ is still necessary, 
together with milder reaction conditions to develop a continuous flow process in which UiO66(Zr) can enjoy stability.

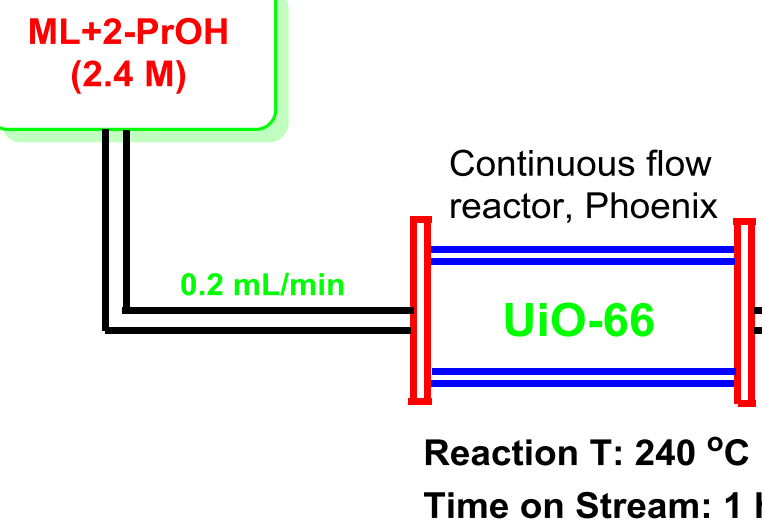

Figure 16. Experimental set up for the conversion of ML to GVL using UiO-66 as catalyst under continuous flow conditions.

Table 4. Comparison of UiO-66 (Zr) activity of with other catalysts for GVL synthesis.

\begin{tabular}{|c|c|c|c|c|c|}
\hline catalyst & Conditions & $\begin{array}{l}\text { Conversio } \\
\mathrm{n}(\%)\end{array}$ & $\begin{array}{l}\text { Selectivity } \\
(\%)\end{array}$ & $\begin{array}{l}\text { GVL } \\
\text { productivity } \\
\left(\operatorname{mmolg}^{-1} \mathrm{~h}^{-1}\right)\end{array}$ & Ref. \\
\hline UiO-66(Zr) & $\begin{array}{l}0.23 \mathrm{~g} \text { of catalysts, } 2.4 \mathrm{M} \\
\mathrm{ML} \text { in isopropanol, flow } \\
\text { rate }=0.2 \mathrm{~mL} / \mathrm{min}, 240^{\circ} \mathrm{C} \text {, } \\
35 \mathrm{bar}, \mathrm{TOS}=1 \mathrm{~h}\end{array}$ & 83 & 89 & 92.3 & 88 \\
\hline UiO-66(Zr) & $\begin{array}{l}0.22 \mathrm{~g} \text { of catalysts, } 4 \mathrm{mmol} \\
\text { of } \mathrm{EE}^{\mathrm{b}} \text { in } 400 \mathrm{mmol} \text { of } \\
\text { isopropanol, } 130^{\circ} \mathrm{C}, \mathrm{t}=3 \mathrm{~h} \\
\text { (batch reaction) }\end{array}$ & 43.3 & 18.5 & 0.534 & 120 \\
\hline MOF-808 & $\begin{array}{l}0.22 \mathrm{~g} \text { of catalysts, } 4 \mathrm{mmol} \\
\text { of } \mathrm{EE}^{\mathrm{b}} \text { in } 400 \mathrm{mmol} \text { of } \\
\text { isopropanol, } 130{ }^{\circ} \mathrm{C}, \mathrm{t}=3 \mathrm{~h} \\
\text { (batch reaction) }\end{array}$ & 100 & 85 & 5.66 & 120 \\
\hline UiO-66(Zr) & $\begin{array}{l}0.1 \mathrm{~g} \text { of catalysts, } 1 \mathrm{mmol} \\
\text { of } \mathrm{ML} \text { in } 5 \mathrm{~mL} \text { of } 2 \text {-butanol, } \\
140{ }^{\circ} \mathrm{C}, \mathrm{Ar}, 0.5 \mathrm{MPa}, \mathrm{t}=9 \mathrm{~h} \\
\text { (batch reaction) }\end{array}$ & 70 & 51 & 0.4 & 121 \\
\hline UiO-66-S ${ }_{60}^{a}$ & $\begin{array}{l}0.1 \mathrm{~g} \text { of catalysts, } 1 \mathrm{mmol} \\
\text { of } \mathrm{ML} \text { in } 5 \mathrm{~mL} \text { of } 2 \text {-butanol, }\end{array}$ & 98 & 82 & 0.889 & 121 \\
\hline
\end{tabular}




\begin{tabular}{|c|c|c|c|c|c|}
\hline & $\begin{array}{l}140{ }^{\circ} \mathrm{C}, \mathrm{Ar}, 0.5 \mathrm{MPa}, \mathrm{t}=9 \mathrm{~h} \\
\text { (batch reaction) }\end{array}$ & & & & \\
\hline $\begin{array}{l}\mathrm{Al} \\
{ }_{7} \mathrm{Zr}_{3}-300^{\mathrm{b}}\end{array}$ & $\begin{array}{l}0.072 \mathrm{~g} \text { of catalysts, } 1 \mathrm{mmol} \\
\text { of } \mathrm{EE}^{\mathrm{b}} \text { in } 5 \mathrm{~mL} \text { of } \\
\text { isopropanol, } 220^{\circ} \mathrm{C}, \mathrm{t}=4 \mathrm{~h} \\
\text { (batch reaction) }\end{array}$ & 95.5 & 87.1 & 2.89 & 122 \\
\hline $\mathrm{Zr}(\mathrm{OH})_{4}$ & $\begin{array}{l}1 \mathrm{~g} \text { of catalysts, } 2 \mathrm{~g} \text { of } \mathrm{EE}^{\mathrm{b}} \\
\text { in } 38 \mathrm{~g} \text { ethanol, } 240^{\circ} \mathrm{C}, \mathrm{t}= \\
1 \mathrm{~h} \\
\text { (batch reaction) }\end{array}$ & 89.1 & 84.5 & 10.7 & 123 \\
\hline $\begin{array}{l}\mathrm{ZrFeO}(1: 1)- \\
300^{\mathrm{c}}\end{array}$ & $\begin{array}{l}0.2 \mathrm{~g} \text { of catalysts, } 0.65 \mathrm{~g} \text { of } \\
\mathrm{EE}^{\mathrm{b}} \text { in } 11.8 \mathrm{~g} \text { of } \\
\text { isopropanol, } \\
230^{\circ} \mathrm{C}, \mathrm{t}=0.5 \mathrm{~h} \text { (batch } \\
\text { reaction) }\end{array}$ & 94.2 & 92 & 39.2 & 119 \\
\hline
\end{tabular}

${ }^{\mathrm{a}} \mathrm{S}_{60}$ represents $60 \mathrm{~mol} \%$ sulfonated ligand; ${ }^{b}$ molar ratio $\mathrm{Al} / \mathrm{Zr}$ is7:3 and the sample was calcined at $300{ }^{\circ} \mathrm{C}$; ${ }^{c}$ molar ratio $\mathrm{Zr} / \mathrm{Fe}$ is $1: 1$ and the sample was calcined at $300{ }^{\circ} \mathrm{C}$. ${ }^{\mathrm{b}} \mathrm{EE}$ : ethyl levulinate
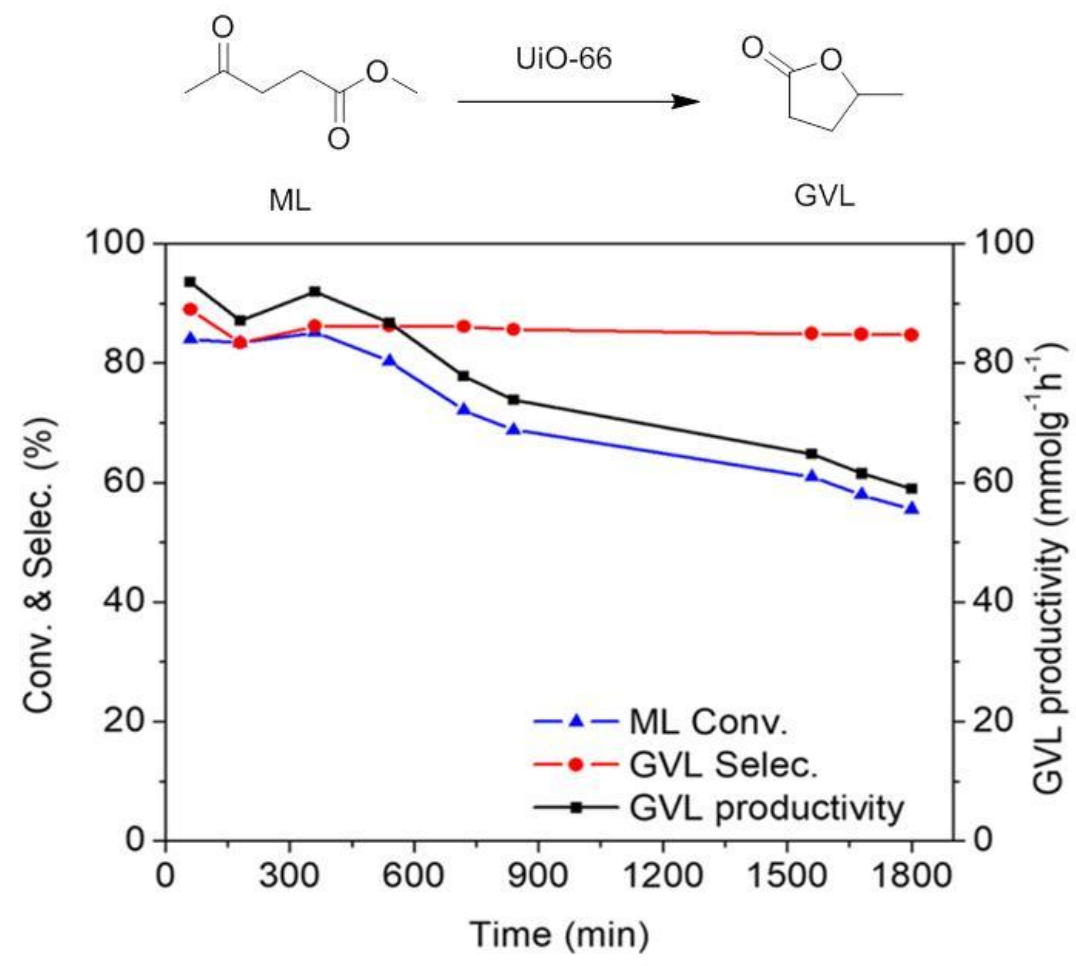

Figure 17. Continuous flow cyclization of ML to GVL catalyzed by UiO-66(Zr). Reproduced with permission from ref. ${ }^{88}$

\section{4. $\mathrm{C}-\mathrm{N}$ bond formation}


Powder $\mathrm{Cu}_{3}(\mathrm{BTC})_{2}$ of large sized grains around $20 \mu \mathrm{m}$ has been reported as heterogeneous catalyst for a wide range of organic reactions under batch conditions. A continuous flow process in a fixed-bed reactor packed with large MOF grains has as drawback the high pressure drop throughout the reactor due to the very high resistance against flow. Deposition or in-situ growth of MOFs forming a 10-30 $\mu \mathrm{m}$ thick layer on supports such as conventional millimetric pore monoliths or non-porous alumina beads have been reported under batch conditions. ${ }^{124-126}$ Non-conventional silica monoliths offer many advantages like a hierarchical macro- and mesoporosity which is an important prerequisite for catalysis in flow to avoid mass transfer limitations between the liquid and the solid phases. Further, these non-conventional monoliths are highly promising due to their highly interconnected and isotropic network of macropores $(5 \mu \mathrm{m})$ with small internal diffusion paths $\left(3 \mu \mathrm{m}\right.$ skeleton thickness), and high surface area $\left(605 \mathrm{~m}^{2} \mathrm{~g}^{-1}\right)$. Hence, $\mathrm{Cu}_{3}(\mathrm{BTC})_{2}$ was synthesized in-situ as NPs within the mesopores of these silica monoliths to be used for continuous flow in the liquid phase Friedlander condensation. ${ }^{89}$ The in-situ synthesis of $\mathrm{Cu}_{3}(\mathrm{BTC})_{2} \mathrm{NPs}$ was evidenced by powder XRD and TEM images. Also, a control $\mathrm{Cu}_{3}(\mathrm{BTC})_{2}$ catalyst was prepared with $1 \mu \mathrm{m}$ size crystals. Gas adsorption isotherm measurements of bulk $\mathrm{Cu}_{3}(\mathrm{BTC})_{2}$ showed BET surface area of $1812 \mathrm{~m}^{2} \mathrm{~g}^{-1}$ and a micropore volume of $0.71 \mathrm{~mL} \mathrm{~g}^{-1}$. In addition, the in-situ synthesis of $\mathrm{Cu}_{3}(\mathrm{BTC})_{2}$ on the silica monolith $\left(\mathrm{Cu}_{3}(\mathrm{BTC})_{2}\right.$-MonoSil $)$ was supported by EDX analysis. SEM images did not show any growth of $\mathrm{Cu}_{3}(\mathrm{BTC})_{2}$ crystals on the monolith macropores and TEM images showed the formation of 7-12 nm nanocrystals located inside the monolith structure and few $50 \mathrm{~nm}$ NPs at the rims of the monolith. In addition, gas sorption measurements provide a convincing evidence in support of the existence of $\mathrm{Cu}_{3}(\mathrm{BTC})_{2}$ NPs inside the mesopores of the silica monolith by decreasing the mesopore volume from 1.24 to $0.77 \mathrm{~mL} \mathrm{~g}^{-1}$ and concomitantly showing an increase in the microporosity from 0.04 to $0.23 \mathrm{~mL} \mathrm{~g}^{-1}$ as well as showing higher BET surface area from 605 
to $971 \mathrm{~m}^{2} \mathrm{~g}^{-1}$ compared to the parent silica monolith. The catalytic performance of $\mathrm{Cu}_{3}(\mathrm{BTC})_{2}$-MonoSil was tested in the Friedlander reaction as shown in Figure 18 under continuous flow conditions as shown in Figure 19. The $\mathrm{Cu}_{3}(\mathrm{BTC})_{2}$-MonoSil was covered with a heat shrinkable clad and placed in a chamber heated at $80{ }^{\circ} \mathrm{C}$. The solution of reactants, 2-aminobenzophenone and acetylacetone, was passed through the monolith at a flow rate of $0.5 \mathrm{~mL} \mathrm{~min}^{-1}$. The experimental results showed that the initial activity reaches 90 $\%$ conversion and a steady-state value of $85 \%$ was attained after $4 \mathrm{~h}$ on flow and maintained for $24 \mathrm{~h}$. The productivity at the steady-state was $0.5 \mathrm{mmol} \mathrm{min}^{-1} \mathrm{~g}_{\text {Monolith }}{ }^{-1}$ or $2.2 \mathrm{mmol} \mathrm{min}^{-}$ ${ }^{1} \mathrm{~g}_{\mathrm{Cu} 3(\mathrm{BTC}) 2}{ }^{-1}$. This value is about 2.5 times superior than the activity reported for commercial $\mathrm{Cu}_{3}(\mathrm{BTC})_{2}$ powder $(10-20 \mu \mathrm{m})$ in a batch reactor that reaches a conversion rate of $0.86 \mathrm{mmol}$ $\min ^{-1} \mathrm{~g}_{\mathrm{CuBTC}^{-1}}{ }^{127}$ In another report, the Friedlander reaction between 2-aminobenzophenone and acetylacetone condensation was almost quantitative after $1.5 \mathrm{~h}$ with $\mathrm{Cu}_{3}(\mathrm{BTC})_{2}$, while 75 and $52 \%$ yields $^{128}$ were obtained with $\mathrm{H}$-BEA and Cu-BEA catalysts, respectively. The enhanced activity of $\mathrm{Cu}_{3}(\mathrm{BTC})_{2}$ was attributed to its low energy barrier for the annulation step and the favourable geometry of reaction precursors adsorbed on two adjacent $\mathrm{Cu}^{2+}$ sites in $\mathrm{Cu}_{3}(\mathrm{BTC})_{2}$. On the other hand, $\mathrm{Cu}_{3}(\mathrm{BTC})_{2}$ possessed high population of active sites together with the concerted effect of adjacent active sites. These two factors are much less important in the case of $\mathrm{H}$-BEA or $\mathrm{Cu}-\mathrm{BEA}$ catalysts. ${ }^{128}$ A continuous flow process operated successfully with $\mathrm{Cu}_{3}(\mathrm{BTC})_{2}$-MonoSil as catalyst to produce $826 \mathrm{~g}$ of the desired product per $\mathrm{g}$ of $\mathrm{Cu}_{3}(\mathrm{BTC})_{2}$ per day. These results clearly establish the superior activity of $\mathrm{Cu}_{3}(\mathrm{BTC})_{2}$ under continuous flow operation provided that the active MOF is suitably deposited on the reactor. 


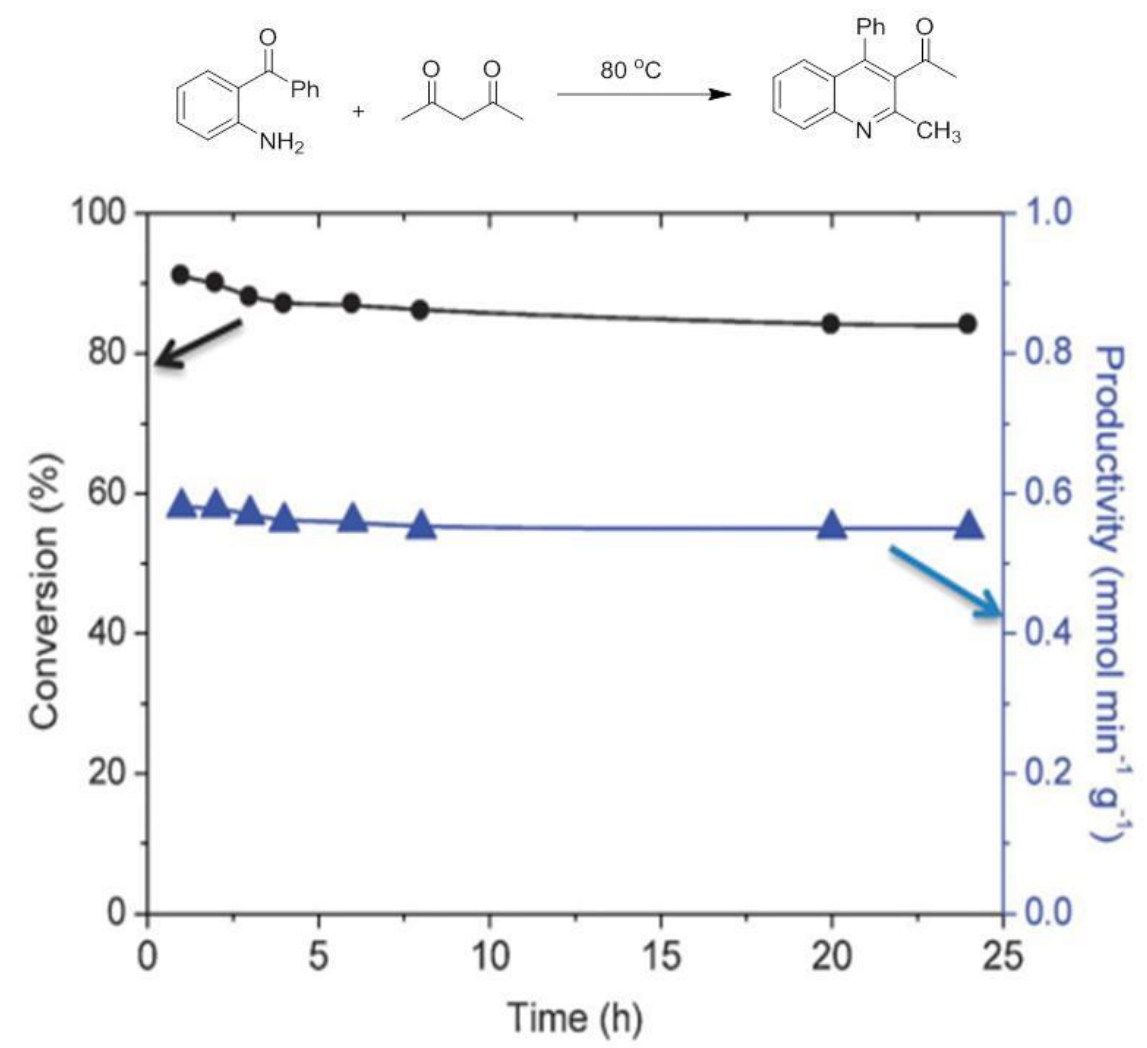

Figure 18. Conversion and productivity for the Friedlander reaction between 2aminobenzophenone and acetylacetone as a function of time on $\mathrm{Cu}_{3}(\mathrm{BTC})_{2}$-MonoSil under continuous flow conditions. Reproduced with permission from ref. ${ }^{89}$

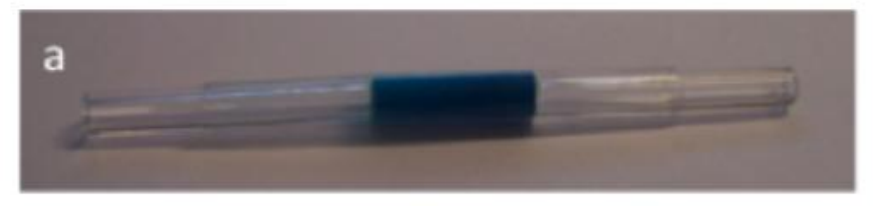

b

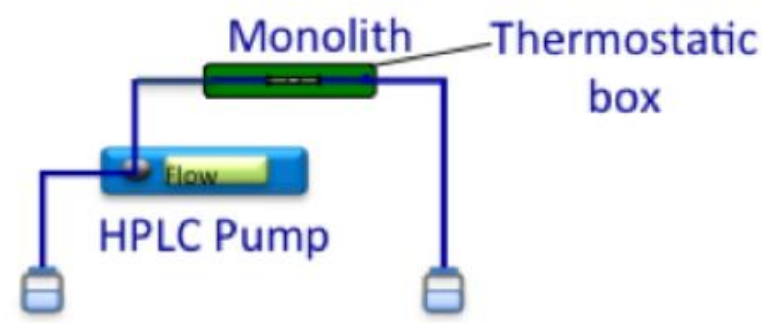

Reactants

\section{Products}

Figure 19. The experimental set up for the Friedlander reaction with cladded $\mathrm{Cu}_{3}(\mathrm{BTC})_{2}$ MonoSil of $2 \mathrm{~cm}$ length and $6 \mathrm{~mm}$ diameter (a) and flow reactor design for in-flow catalysis (b). 


\section{Oxidation reactions}

Aerobic oxidations using molecular oxygen at quasi ambient conditions as the terminal oxidant are gaining considerable importance due to the greenness of the process, but require of highly selective catalysts. Noble metals such as Pd are typically active centres for this type of oxidation.

In this context, Pd NPs were encapsulated within the pores of MIL-88B- $\mathrm{NH}_{2}$ to achieve Pd@MIL-88B-NH $\mathrm{NH}_{2}$ (8 wt \% Pd). This was later protected by $\mathrm{SiO}_{2} \mathrm{NPs}$ to obtain Pd@MIL-88B-NH $\mathrm{N}_{2} @$ nano-SiO $2(\mathrm{Scheme} 4)^{90}$ with the purpose to increase catalyst stability. The activity of this solid was tested in the oxidation of alcohols using air as the oxidant at ambient pressure under batch as well as continuous flow conditions. Powder XRD ascertained no changes in the structural integrity of MIL-88B- $\mathrm{NH}_{2}$ during $\mathrm{Pd} \mathrm{NP}$ encapsulation. The average particle size of Pd NPs was 2-3 nm and they were uniformly distributed in the MOF matrix as shown by TEM images. Gas adsorption measurements indicated that the BET surface area and pore volume for Pd@MIL-88B- $\mathrm{NH}_{2} @$ nano-SiO 2 are $603 \mathrm{~m}^{2} / \mathrm{g}$ and $1.82 \mathrm{~cm}^{3} / \mathrm{g}$, respectively. The activity of Pd@MIL-88B-NH $\mathrm{N}_{2} @$ nano- $\mathrm{SiO}_{2}$ for the oxidation of 1-phenylethanol using air as oxidant in p-xylene was tested at $150{ }^{\circ} \mathrm{C}$, reaching $98 \%$ yield. Interestingly, a wide range of secondary alcohols could also be oxidized to their respective ketones in high yields $(68-97 \%)$ under identical conditions. The superior stability of Pd@MIL-88B-NH $\mathrm{NH}_{2} @$ nano-SiO 2 was established by performing comparative reusability experiments with $\mathrm{Pd} @ \mathrm{MIL}-88 \mathrm{~B}-\mathrm{NH}_{2}$, without silica protecting shell. Due to the small particle size and the tedious recovery through centrifugation, a tea-bag system was developed by taking 200 mg of 0.51 Pd wt \% Pd@MIL-88B-NH $\mathrm{N}_{2} @$ nano-SiO 2 (1 mol\% respect to the substrate) tied with a teflon wire and dipped into 1-phenylethanol in p-xylene solution. The catalyst introduced inside the tea-bag was pulled out and subsequently immersed in a fresh reaction batch. This batch process was repeated for four recycles 
observing a significant catalyst deactivation from 85 to $38 \%$. One of the main causes for catalyst deactivation was Pd leaching. 1-Phenylethanol was selected as substrate to measure the oxidation activity in a continuous flow process using synthetic air $\left(20.9 \pm 1 \%\right.$ pure $\left.\mathrm{O}_{2}\right)$ as oxidizing agent. The packed-bed reactor was assembled in a fritted-glass chromatography column loaded with 0.51 wt \% Pd@MIL-88B-NH $\mathrm{N}_{2} @$ nano-SiO 2 (800 mg, 0.0385 mmol of $\mathrm{Pd}$, ca. $40 \mathrm{~mm}$ bed height) thermostated at $110{ }^{\circ} \mathrm{C}$ (Figure 20) with the residence time of around $10 \mathrm{~min}$. After $6 \mathrm{~h}$, the conversion was almost stable at around $80 \%$ until the experiment was stopped after 7 days (168 h) (Figure 21). Selectivity was also constant during the run forming acetophenone and ethylbenzene in 75 and $5 \%$ yield, respectively. These results are, certainly, remarkable and show the possibility to develop industrial processes using MOFs as catalysts. Although metal NPs have been frequently used as catalysts for continuous flow benzylic alcohol oxidation, ${ }^{129}$ including metal NPs supported on various MOFs, ${ }^{130}$ the activity of Pd@MIL-88B-NH $\mathrm{NH}_{2} @$ nano- $\mathrm{SiO}_{2}$ is an exclusive example of efficient aerobic oxidation of 1-phenylethanol under continuous flow conditions using Pd NPs. On other hand, Au/MIL-101(Cr) $\left(29300 \mathrm{~h}^{-1}\right)^{131}$ and Au/MIL-101(Cr)-NH $2\left(10^{3} \mathrm{~h}^{-1}\right)^{132}$ have also shown to be effective solid catalysts in promoting alcohol oxidation under batch conditions. Among the probable reasons for the enhanced activity of Pd@MIL-88B-NH $\mathrm{N}_{2} @$ nano-SiO 2 under continuous flow conditions those that have been proposed include Pd NP stabilization by amino groups and the silica coating protecting effect minimizing Pd leaching/deactivation.

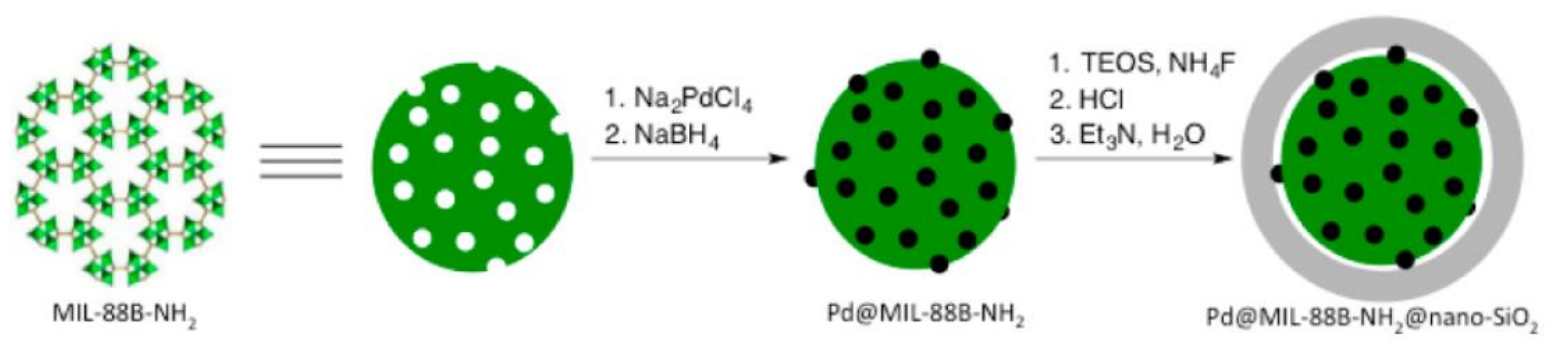

Scheme 4. Synthetic procedure for Pd@MIL-88B-NH $\mathrm{N}_{2} @$ nano-SiO 2. Reproduced with permission from ref. ${ }^{90}$ 


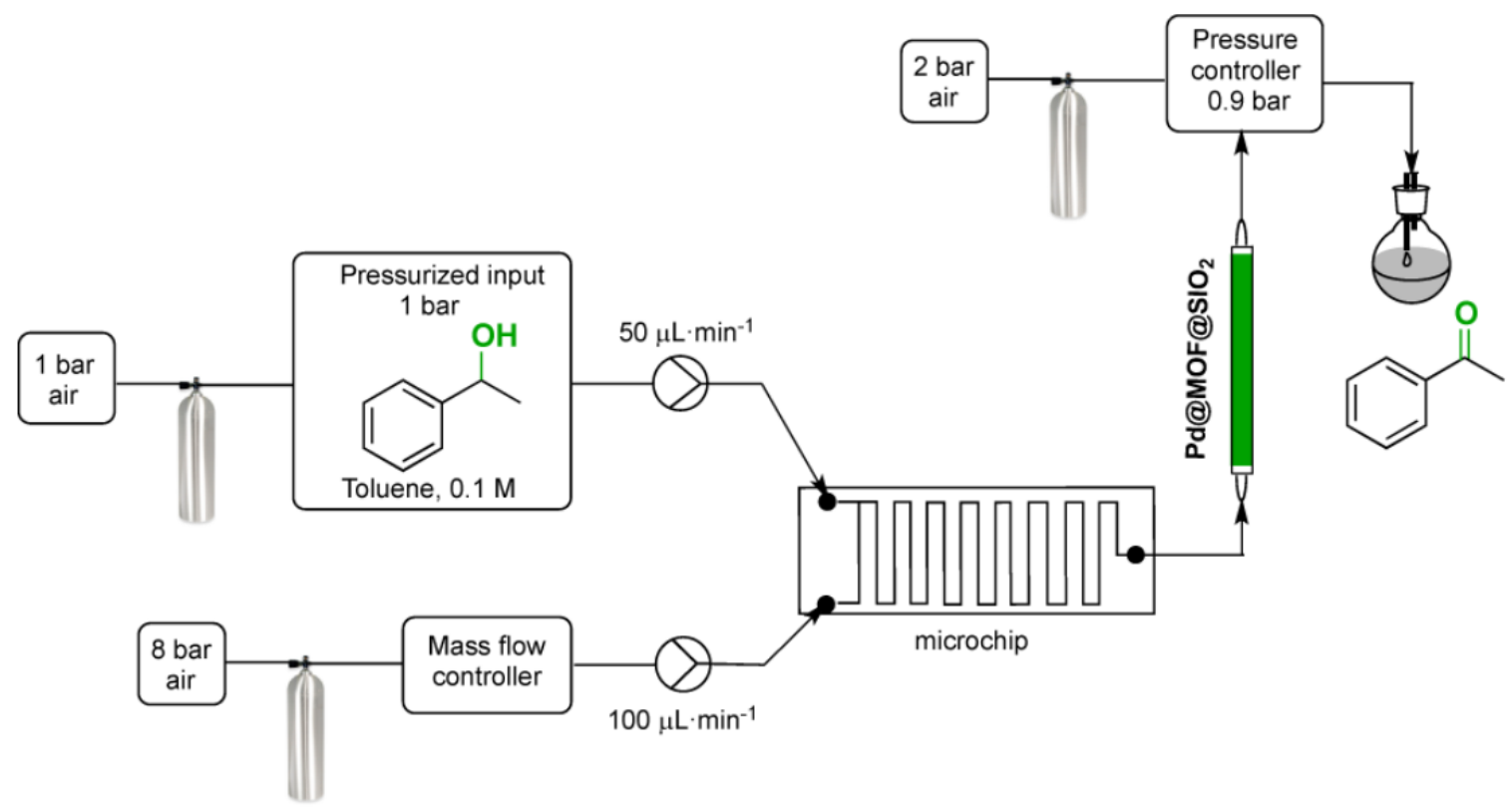

Figure 20. Process for the aerobic oxidation of 1-phenylethanol under continuous flow. Reproduced with permission from ref. ${ }^{90}$

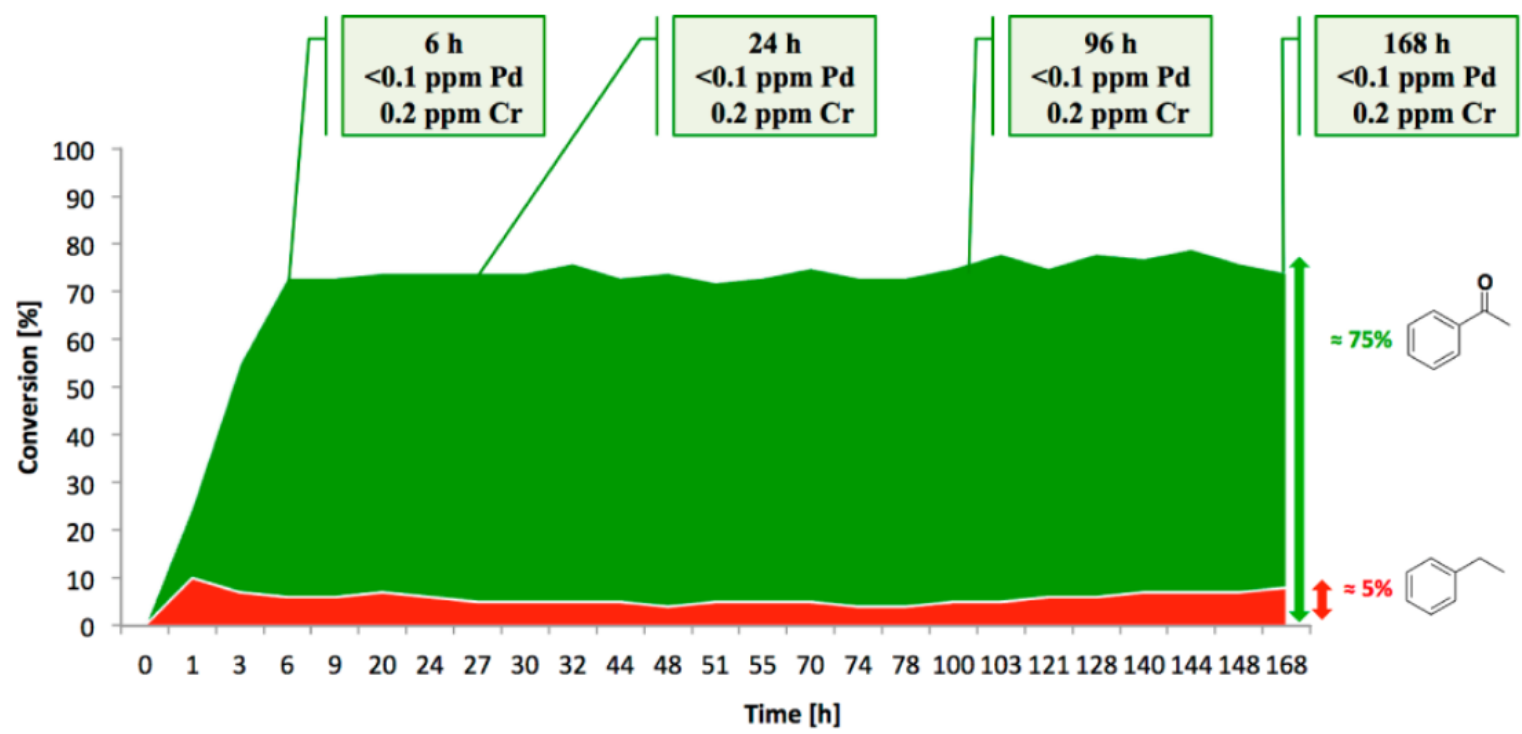

Figure 21. Conversion and metallic leaching in the aerobic oxidation of 1-phenylethanol catalyzed by $\mathrm{Pd} @$ MIL-88B-NH $2 @ \mathrm{SiO}_{2}$ for 7 days. Reproduced with permission from ref. ${ }^{90}$

Very recently, a crystalline UiO-66 solid was functionalized with Ti to obtain UiO$66(\mathrm{Zr}, \mathrm{Ti})$ that was tested in the oxidative desulfurization (ODS) of diesel. ${ }^{91}$ The parent UiO- 
66 was prepared using $\mathrm{HCl}$ as crystallization agent without any modulator. $\mathrm{Ti}^{\mathrm{IV}}$ was anchored to the $\mu_{3}$ hydroxyl groups located on the faces of the octahedral UiO-66 nodes to provide UiO-66(Zr, Ti) (Figure 22) without altering the structural integrity of UiO-66 as evidenced by powder XRD. The introduction of $\mathrm{Ti}$ at the nodes of UiO-66 slightly reduced BET surface area of the parent $\mathrm{UiO}-66(\mathrm{Zr})$ from 1328 to $1229 \mathrm{~m}^{2} / \mathrm{g}$. The activity of UiO-66(Zr) and UiO$66(\mathrm{Zr}, \mathrm{Ti})$ was established in the ODS of a solution of dibenzothiophene (Scheme 5) in dodecane $(1 \mathrm{~mL} ; 1,000 \mathrm{ppm}$ of sulphur) with $1 \mathrm{~mL}$ of $9: 1$ mixture of acetonitrile/30\% aqueous $\mathrm{H}_{2} \mathrm{O}_{2}$ at $60{ }^{\circ} \mathrm{C}$ (Figure 23). Analysis of the mixture showed that the model fuel still contained after the treatment $82 \mathrm{ppm}$ of residual sulphur with UiO-66(Zr), while the sulphur content was 75 ppm with UiO-66(Zr, Ti). Under continuous flow conditions, the suphur content in the ODS process of dibenzothiophene using UiO-66( $\mathrm{Zr})$ and $\mathrm{UiO}-66(\mathrm{Zr}$, Ti) was 535 and 276 ppm, respectively. These results imply that there is no much difference in the sulphur removal efficiency between batch versus continuous flow processes. One of the probable reasons for these results would be the limited diffusion of dibenzothiophene to the active sites. In order to confirm this hypothesis, a smaller size sulphur molecule like thioanisole (Scheme 5) was selected as sulphide source. UiO-66(Zr) as catalyst gave $21 \mathrm{ppm}$ of residual sulphur, a value close to the specification for ULSD $(<10 \mathrm{ppm})$. Interestingly, UiO-66(Zr, Ti) as catalyst showed complete desulfurization with $<1 \mathrm{ppm}$ of sulphur in the model fuel under identical continuous flow conditions. These results clearly indicate the remarkable beneficial impact of the $\mathrm{Ti}$ atoms on the catalytic process under continuous flow conditions, in agreement with the well-known activity of $\mathrm{Ti}$ as Lewis acid to activate $\mathrm{H}_{2} \mathrm{O}_{2} \cdot{ }^{133,134}$ 


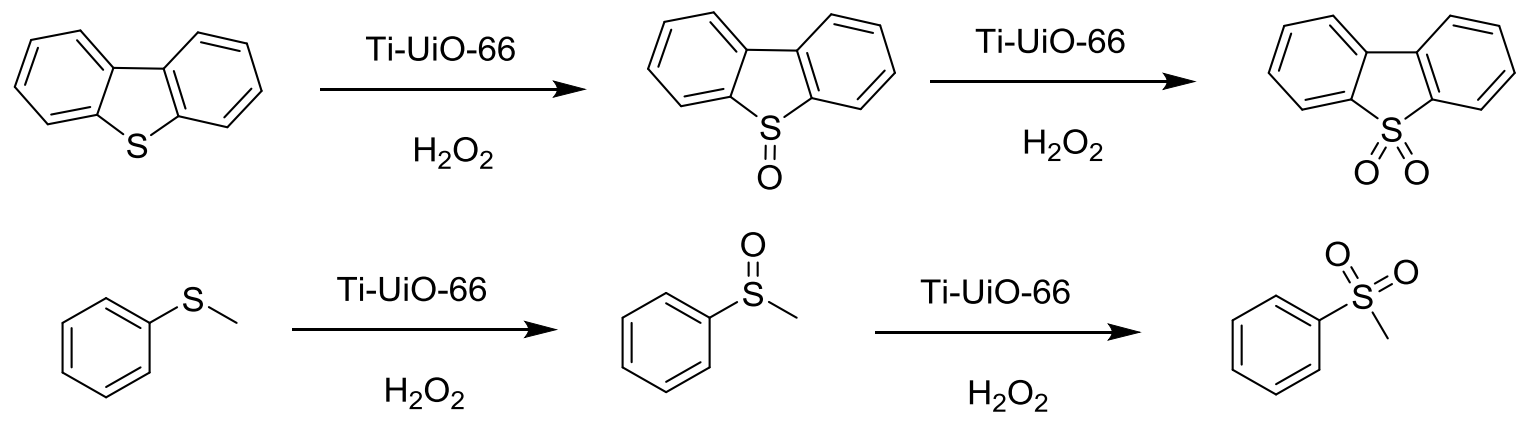

Scheme 5. ODS of dibenzothiophene and thioanisole catalyzed by UiO-66(Zr, Ti).

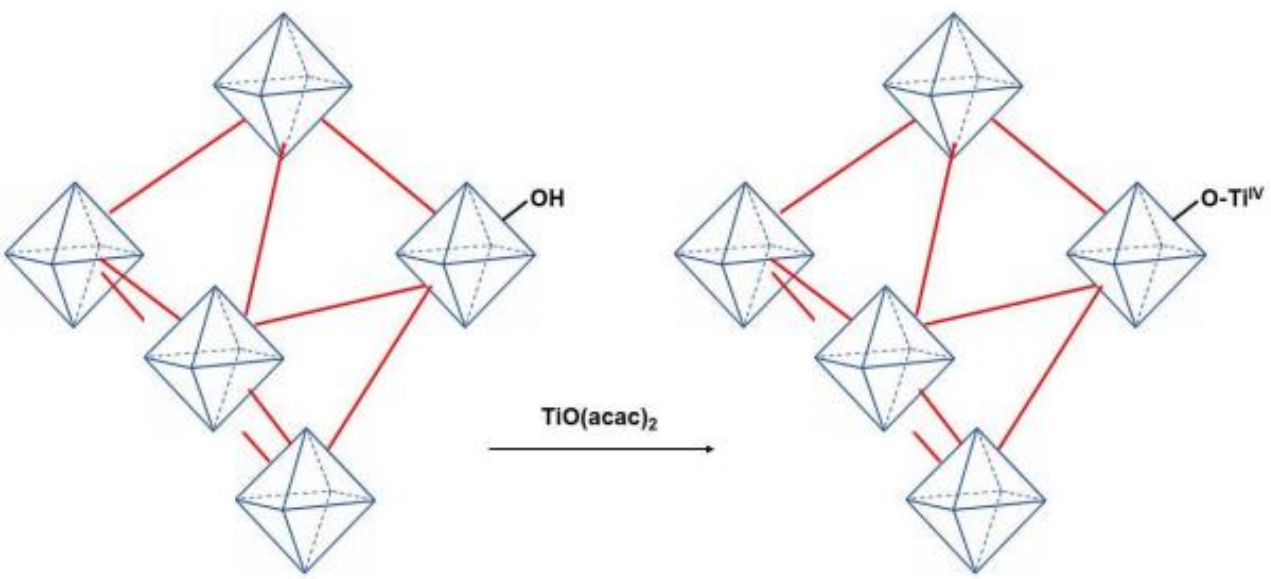

Figure 22. Synthesis of $\mathrm{UiO}-66(\mathrm{Zr}, \mathrm{Ti})$ from $\mathrm{UiO}-66(\mathrm{Zr})$ using $\mathrm{TiO}(\mathrm{acac})_{2}$ as $\mathrm{Ti}$ precursor. Reproduced with permission from ref. ${ }^{91}$

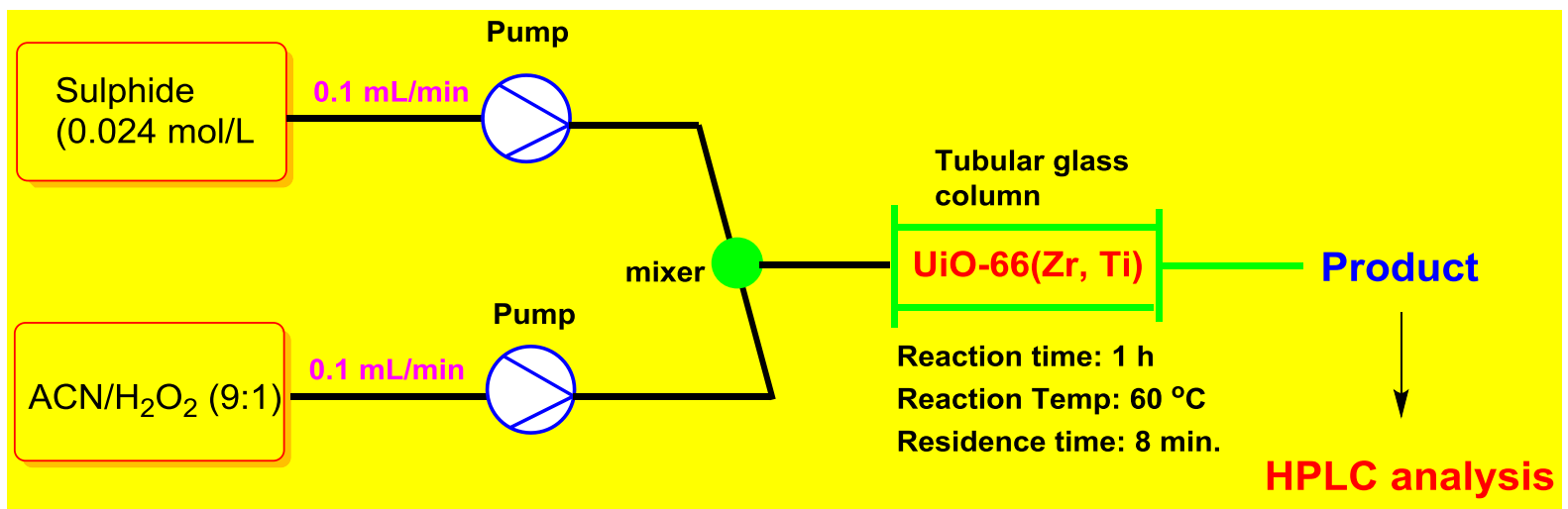

Figure 23. Continuous flow set up for the ODS reaction using UiO-66(Zr,Ti) as catalyst.

\section{Reduction reactions}


Recently, organophosphorous hydrolase (OPH) was encapsulated within the framework of MIL-100(Fe) to obtain an integrated nanocatalyst denoted as OPH@MIL$100(\mathrm{Fe})$ and its activity was tested in the cascade degradation of organophosphate nerve agents to 4 -aminophenol. ${ }^{92} \mathrm{OPH}$ is responsible for the hydrolysis of organophosphate nerve agents into 4-nitrophenol, while MIL-100(Fe) provides active sites for the reduction of 4nitrophenol to 4-aminophenol (Scheme 6). Fluorescence experiments and acid treatment clearly confirmed that $\mathrm{OPH}$ is covalently attached to MIL-100(Fe) rather than adsorbed as physical mixture. The optimal OPH loading was found to be $53 \mathrm{mg} \mathrm{g}_{\mathrm{MIL}-100(\mathrm{Fe})}{ }^{-1}$. The activity of OPH@MIL-100(Fe) was studied by constructing a simple plug-flow reactor by dispersing 20 mg of OPH@MIL-100(Fe) in Tris-HCl solution and loaded onto a commercial polymer membrane by filtration as shown in Figure 24. The solid catalyst OPH@MIL-100(Fe) retained more than $50 \%$ of the initial degradation activity after nine cycles for four organophosphate nerve agents (Figure 25). Furthermore, the crystalline structure of OPH@MIL-100(Fe) remained unchanged after nine cycles compared to the fresh solid. A total leaching of $0.55 \mathrm{wt} \%$ of the initial $\mathrm{Fe}$ content was detected. Furthermore, $\mathrm{OPH}$ maintained approximately 96 and $95 \%$ of its original activity after being incubated, respectively, in a solution of 4-nitrophenol and 4-aminophenol for $90 \mathrm{~min}$. Figure 26 clearly indicates that the hydrolytic activity of OPH and the hydrogenation activity of MIL-100(Fe) were reduced after nine catalytic cycles to $53 \%$ and $95 \%$ of the original activity, respectively. These results suggest that the decrease in the degradation activity of this integrated catalyst was mainly due to the effect of $\mathrm{NaBH}_{4}$ on the hydrolytic activity of OPH. On other hand, the degradation performance of OPH@MIL-100(Fe) was improved by reducing the contact time between the solid and $\mathrm{NaBH}_{4}$. Hence, $\mathrm{NaBH}_{4}$ was added to the reaction after the hydrolysis step. A complete degradation of methyl parathion to 4aminophenol was observed in 45 min, which was higher activity than $85 \%$ degradation at 90 
min, when $\mathrm{NaBH}_{4}$ was added at the beginning of the cascade reaction. Similarly, other three tested parathions were completely degraded by this procedure.

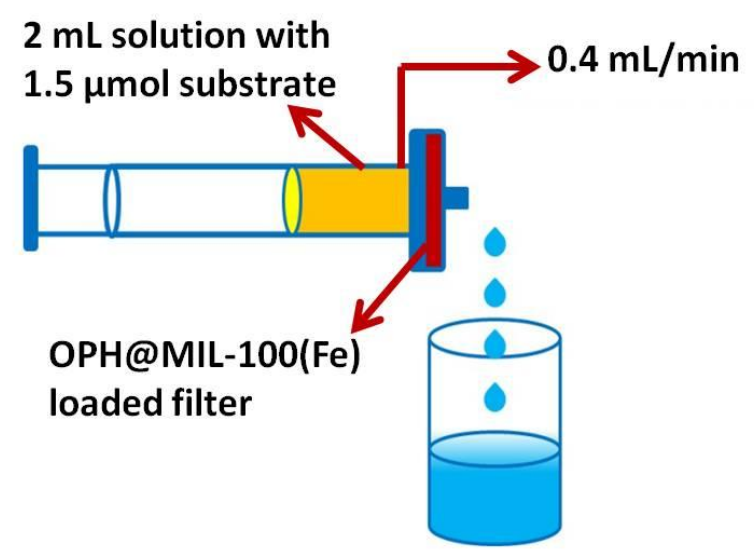

(a)

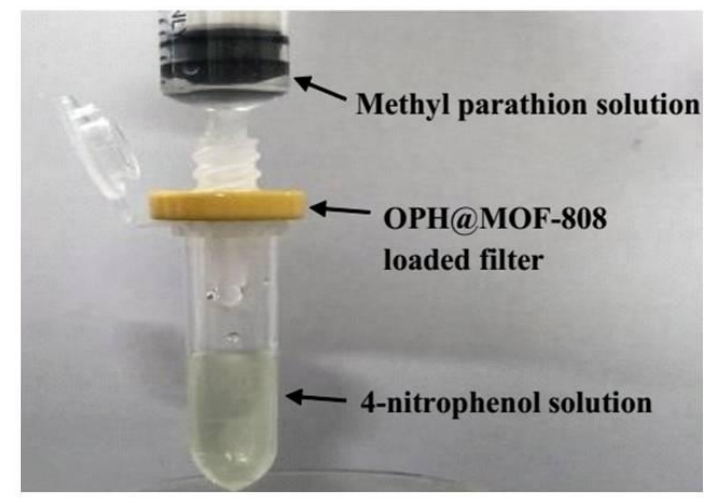

(b)

Figure 24 (a) Schematic representation of the OPH@MIL-100(Fe) plug-flow reactor and (b) OPH@MOF-808-based plug-flow reactor for hydrolysis of methyl parathion into 4nitrophenol.

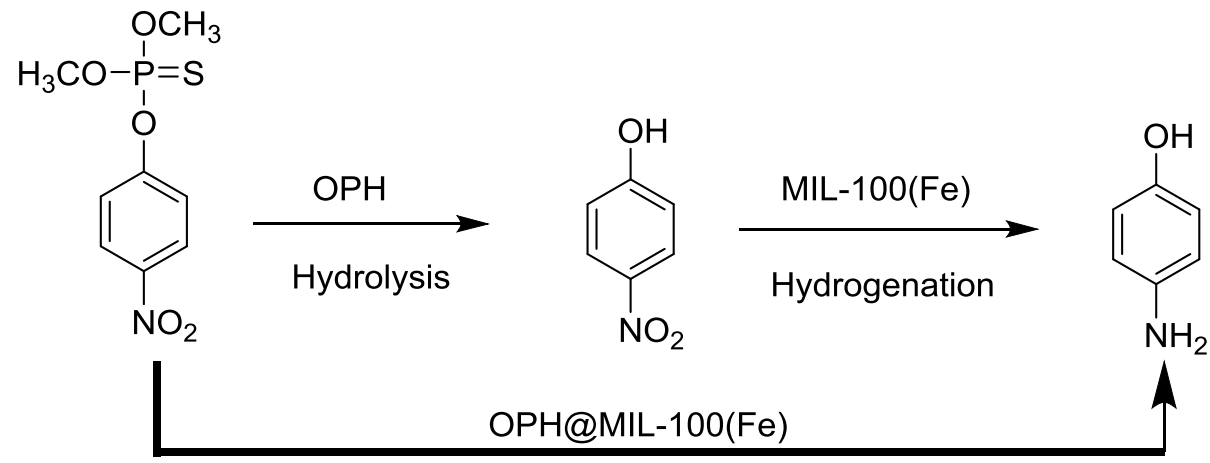

Degradation

Scheme 6. The schematic illustration of a cascade methyl parathion degradation using OPH@MIL-100(Fe) as catalyst. 


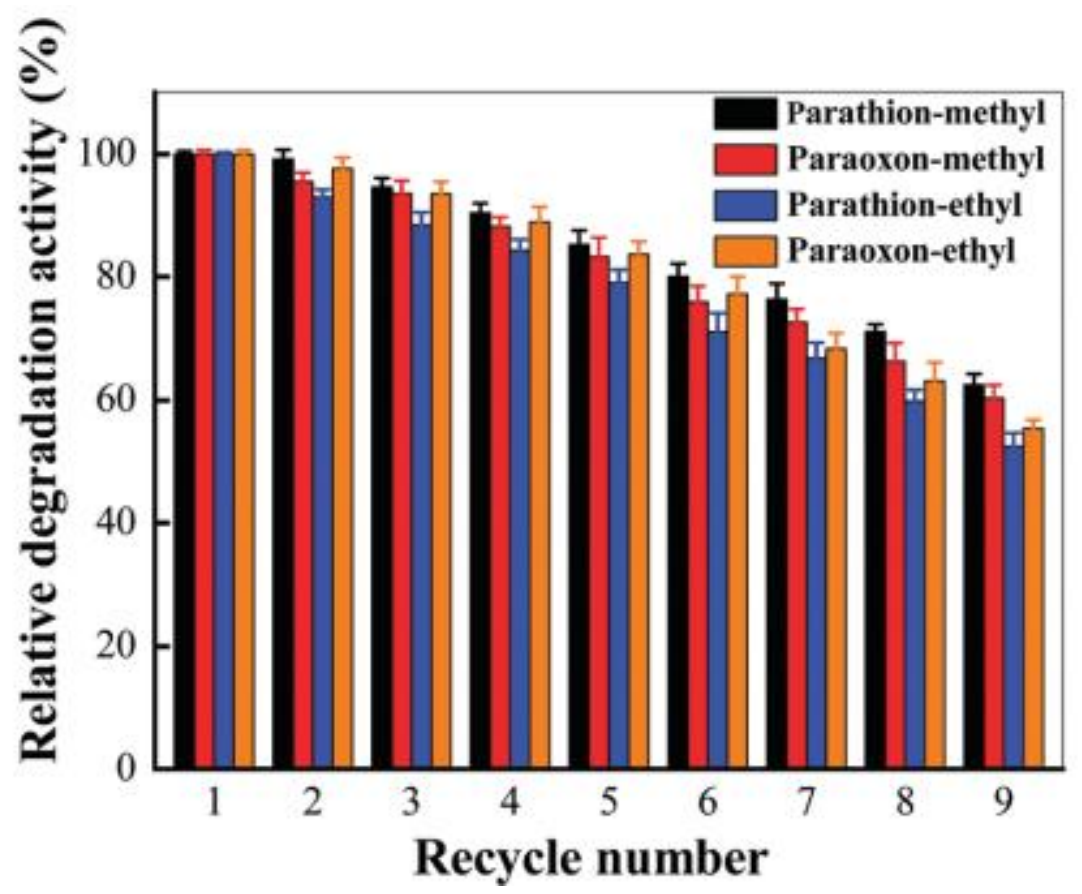

Figure 25. Relative degradation activity of OPH@MIL-100(Fe) with four substrates after multiple degradation cycles through a plug-flow reactor. Reproduced with permission from ref. $^{92}$

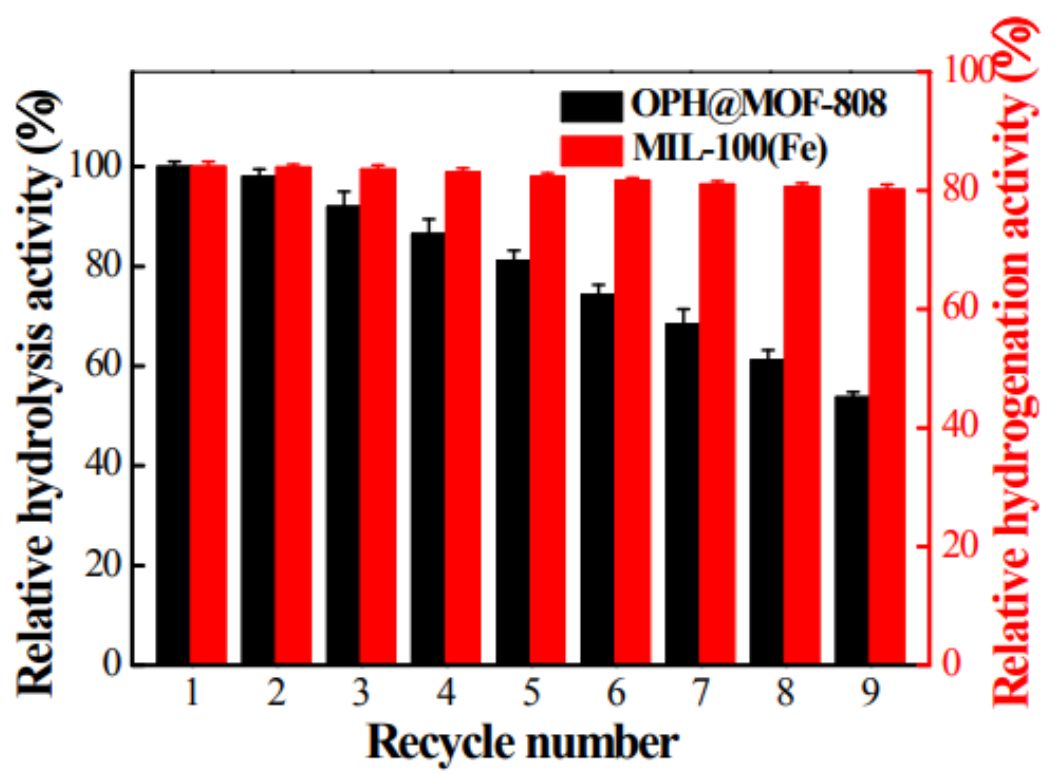

Figure 26. Relative hydrolysis activity of OPH and relative hydrogenation activity of MIL$100(\mathrm{Fe})$ after multiple degradation cycles. Reproduced with permission from ref. ${ }^{92}$ 


\section{Summary and outlook}

As commented in the introduction, MOFs are intensively studied as solid catalysts for liquid phase reactions, but scarce attention has been paid to their use under continuous flow reactions. Continuous flow operation requires of stable catalysts that do not undergo deactivation under reaction conditions. Since this operation mode represents a higher level of process intensification compared to batch-like processes, they are widely used in industrial processes. The purpose of the present review was to spur the interest of researchers in the area for performing continuous flow reactions using MOFs as catalysts, by showing that there are certain reaction types in where the stability has allowed the use of MOF as catalysts. The reactions include acetalizations, $\mathrm{CO}_{2}$ insertion, carbonylations, aerobic oxidations, reductions and even enantioselective Michael additions. It is remarkable that several of the examples reported use $\mathrm{Cu}_{3}(\mathrm{BTC})_{2}$ as catalyst. This $\mathrm{Cu} \mathrm{MOF}$ exhibits certainly a wide range of catalytic activity as Lewis acid and oxidation catalyst, but it is not the most stable material. On one hand, the reports on the use of $\mathrm{Cu}_{3}(\mathrm{BTC})_{2}$ under continuous flow illustrate that even those MOFs that are less robust can enjoy stability in a window of experimental conditions that could permit continuous flow operation. On the other hand, the current prevalence of studies using $\mathrm{Cu}_{3}(\mathrm{BTC})_{2}$ as catalyst is, in our opinion, a reflection of the lack of maturity of this field and it can be predicted that the area will be finally dominated by structurally robust MOFs.

The long term goal is the implementation of MOFs as catalysts for industrial processes, probably replacing metal salts. Compared to metal salts, MOFs offer much higher activity of the fresh material due to the high surface area and porosity that makes the metals accessible to substrates and reagents. Towards this objective of commercial preparation of fine chemicals in the liquid phase using MOFs as catalysts, a possible way to proceed is the scaling up of processes carried out at smaller scale under continuous flow. Thus, it can be 
predicted that considering the proven activity under batch conditions, there will be in the near future an increasing interest in developing continuous flow reactions using MOFs.

\section{Acknowledgements}

A.D. thanks the University Grants Commission, New Delhi, for the award of an Assistant Professorship under its Faculty Recharge Programme. A.D. also thanks the Department of Science and Technology, India, for the financial support through Extramural Research Funding (EMR/2016/006500). Financial support by the Spanish Ministry of Economy and Competitiveness (Severo Ochoa and RTI2018-890237-CO2-R1) and Generalitat Valenciana (Prometeo 2017-083) is gratefully acknowledged.

\section{References}

1. D. Farrusseng, S. Aguado and C. Pinel, Angew. Chem. Int. Ed., 2009, 48, 7502-7513.

2. A. H. Chughtai, N. Ahmad, H. A. Younus, A. Laypkov and F. Verpoort, Chem. Soc. Rev., 2015, 44, 6804-6849.

3. A. Dhakshinamoorthy and H. Garcia, Chem. Soc. Rev., 2012, 41, 5262-5284.

4. L. Zhu, X.-Q. Liu, H.-L. Jiang and L.-B. Sun, Chem. Rev., 2017, 117, 8129-8176.

5. P. Silva, S. M. F. Vilela, J. P. C. Tomé and F. A. Almeida Paz, Chem. Soc. Rev., 2015, 44, 67746803.

6. O. K. Farha, I. Eryazici, N. C. Jeong, B. G. Hauser, C. E. Wilmer, A. A. Sarjeant, R. Q. Snurr, S. T. Nguyen, A. O. Yazaydın and J. T. Hupp, J. Am. Chem. Soc., 2012134 15016-15021.

7. R. L. Martin and M. Haranczyk, Chem. Sci., 2013, 4, 1781-1785.

8. Y. He, B. Li, M. O'Keeffe and B. Chen, Chem. Soc. Rev., 2014, 43, 5618-5656.

9. S. Yuan, L. Feng, K. Wang, J. Pang, M. Bosch, C. Lollar, Y. Sun, J. Qin, X. Yang, P. Zhang, Q. Wang, L. Zou, Y. Zhang, L. Zhang, Y. Fang, J. Li and H.-C. Zhou, Adv. Mater. , 2018, 30, 1704303.

10. J. Park, H. Kim, S. S. Han and Y. Jung, J. Phys. Chem. Lett., 2012, 37, 826-829.

11. J. G. Vitillo, L. Regli, S. Chavan, G. Ricchiardi, G. Spoto, P. D. C. Dietzel, S. Bordiga and A. Zecchina, J. Am. Chem. Soc., 2008, 130, 8386-8396.

12. Z. Hu and D. Zhao, CrystEngComm, 2017, 19, 4066-4081.

13. D. S. Sholl and R. P. Lively, J. Phys. Chem. Lett., 2015, 6, 3437-3444.

14. Z. Fang, B. Bueken, D. E. De Vos and R. A. Fischer, Angew. Chem. Int. Ed., 2015, 54, 72347254.

15. A. Dhakshinamoorthy, Z. Li and H. Garcia, Chem. Soc. Rev., 2018, 47, 8134-8172.

16. S. Dissegna, K. Epp, W. R. Heinz, G. Kieslich and R. A. Fischer, Adv. Mater., 2018, 30, 1704501.

17. C. Perego and R. Millini, Chem. Soc. Rev., 2013, 42, 3956-3976.

18. X. S. Zhao, X. Y. Bao, W. Guo and F. Y. Lee, Mater. Today, 2006, 9, 32-39.

19. J. Liang, Z. Liang, R. Zou and Y. Zhao, Adv. Mater., 2017, 29, 1701139.

20. M. Dusselier and M. E. Davis, Chem. Rev., 2018, 118, 5265-5329.

21. S. M. Csicsery, Zeolites, 1984, 4, 202-213. 
22. C.-D. Wu and M. Zhao, Adv. Mater., 2017, 29, 1605446.

23. Z.-J. Lin, J. Lü, M. Hong and R. Cao, Chem. Soc. Rev., 2014, 43, 5867-5895.

24. B. Li, H.-M. Wen, W. Zhou, J. Q. Xu and B. Chen, Chem, 2016, 1, 557-580.

25. M. C. Das, S. Xiang, Z. Zhang and B. Chen, Angew. Chem. Int. Ed., 2011, 50, 10510-10520.

26. H.-Y. Guan, R. J. LeBlanc, S.-Y. Xie and Y. Yue, Coord. Chem. Rev., 2018, 369, 76-90.

27. L. M. Aguirre-Díaz, D. Reinares-Fisac, M. Iglesias, E. Gutiérrez-Puebla, F. Gándara, N. Snejko and M. Ángeles Monge, Coord. Chem. Rev., 2017, 335, 1-27.

28. C. K. Brozek and M. Dincă, Chem. Sci., 2012, 3, 2110-2113.

29. W. Lu, Z. Wei, Z.-Y. Gu, T.-F. Liu, J. Park, J. Park, J. Tian, M. Zhang, Q. Zhang, T. Gentle III, M. Bosch and H.-C. Zhou, Chem. Soc. Rev., 2014, 43, 5561-5593.

30. M. Zhang, M. Bosch, T. Gentle III and H.-C. Zhou, CrystEngComm, 2014, 16, 4069-4083.

31. M. Eddaoudi, H. Li and O. M. Yaghi, J. Am. Chem. Soc., 2000, 122, 1391-1397.

32. H. Li, M. Eddaoudi, M. O'Keeffe and O. M. Yaghi, Nature, 1999, 402, 276-279.

33. J. C. van der Waal, P. J. Kunkelera, K. Tan and H. van Bekkum, J. Catal., 1998, 173, 74-83.

34. J. F. Haw, Phys. Chem. Chem. Phys., 2002, 4, 5431-5441.

35. B. Yan, L.-Z. Tao, A. Mahmood, Y. Liang and B.-Q. Xu, ACS Catal., 2017, 7, 538-550.

36. A. Herbst and C. Janiak, CrystEngComm, 2017, 19, 4092-4117.

37. A. Dhakshinamoorthy, M. Opanasenko, J. Čejka and H. Garcia, Catal. Sci. Technol., 2013, 3, 2509-2540.

38. A. Dhakshinamoorthy, M. Alvaro, A. Corma and H. Garcia, Dalton Trans., 2011, 40, 63446360.

39. J. B. DeCoste, G. W. Peterson, H. Jasuja, T. G. Glover, Y.-G. Huang and K. S. Walton, J. Mater. Chem. A, 2013, 1, 5642-5650.

40. N. C. Burtch, H. Jasuja and K. S. Walton, Chem. Rev., 2014 114, 10575-10612.

41. K. Nita, S. Nakai, S. Hidaka, T. Mibuchi, H. Shimakawa, K.-I. Ii and K. Inamura, Studies Surf. Sci.Catal. , 1987, 34, 501-511.

42. A. R. Sujan, D.-Y. Koh, G. Zhu, V. P. Babu, N. Stephenson, A. Rosinski, H. Du, Y. Luo, W. J. Koros and R. P. Lively, Ind. Eng. Chem. Res., 2018, 57, 11757-11766.

43. A. Dhakshinamoorthy, M. Alvaro, P. Concepcion and H. Garcia, Catal. Commun., 2011, 12, 1018-1021.

44. G. Ferey, C. Mellot-Draznieks, C. Serre, F. Millange, J. Dutour, S. Surble and I. Margiolaki, Science, 2005, 3092040.

45. Y. K. Hwang, D.-Y. Hong, J.-S. Chang, S. H. Jhung, Y.-K. Seo, J. Kim, A. Vimont, M. Daturi, C. Serre and G. Férey, Angew. Chem., Int. Ed., 2008, 47, 4144.

46. B. Wang, X.-L. Lv, D. Feng, L.-H. Xie, J. Zhang, M. Li, Y. Xie, J.-R. Li and H.-C. Zhou, J. Am. Chem. Soc., 2016138 6204-6216.

47. A. Dhakshinamoorthy, A. Santiago-Portillo, A. M. Asiri and H. Garcia, ChemCatChem, 2019, 11, 899-923.

48. J. H. Cavka, S. Jakobsen, U. Olsbye, N. Guillou, C. Lamberti, S. Bordiga and K. P. Lillerud, J. Am. Chem. Soc., 2008, 130, 13850-13851.

49. F. Vermoortele, B. Bueken, G. Le Bars, B. van de Voorde, M. Vandichel, K. Houthoofd, A. Vimont, M. Daturi, M. Waroquier and V. van Speybroeck, J. Am. Chem. Soc., 2013, 135, 11465-11468.

50. M. Taddei, R. J. Wakeham, A. Koutsianos, E. Andreoli and A. R. Barron, Angew. Chem. Int. Ed., 2018, 57, 11706-11710.

51. M. Taddei, Coord. Chem. Rev., 2017, 343, 1-24.

52. K. K. Tanabe and S. M. Cohen, Chem. Soc. Rev., 2011, 40, 498-519.

53. F. X. Llabrés i Xamena, A. Abad, A. Corma and H. Garcia, J. Catal., 2007, 250, 294-298.

54. X. Liu, B. Ünal and K. F. Jensen, Catal. Sci. Technol., 2012, 2, 2134-2138.

55. R. Porta, M. Benaglia and A. Puglisi, Org. Process Res. Dev. , 2016, 20, 2-25.

56. P. Plouffe, A. Macchi and D. M. Roberge, Org. Process Res. Dev., 2014, 18, 1286-1294. 
57. J. Wegner, S. Ceylan and A. Kirschning, Chem. Commun., 2011, 47, 4583-4592.

58. M. Irfan, T. N. Glasnov and C. O. Kappe, ChemSusChem 2011, 4, 300-316.

59. U. Hintermair, G. Francio and W. Leitner, Chem. Commun., 2011, 47, 3691-3701.

60. J.-I. Yoshida, H. Kim and A. Nagaki, ChemSusChem, 2011, 4, 331-340.

61. D. Webb and T. F. Jamison, Chem. Sci., 2010, 1, 675-680.

62. S. Marre and K. F. Jensen, Chem. Soc. Rev., 2010, 39, 1183-1202.

63. C. G. Frost and L. Mutton, Green Chem., 2010, 12, 1687-1703.

64. G. M. Whitesides, Nature, 2006, 442, 368-373.

65. B. P. Mason, K. E. Price, J. L. Steinbacher, A. R. Bogdan and D. T. McQuade, Chem. Rev., 2007, 107, 2300-2318.

66. B. K. Singh, N. Kaval, S. Tomar, E. Van der Eycken and V. S. Parmar, Org. Process Res. Dev., 2008, 12, 468-474.

67. D. Mark, S. Haeberle, G. Roth, F. von Stetten and R. Zengerle, Chem. Soc. Rev., 2010, 39, 1153-1182.

68. T. Noel and S. L. Buchwald, Chem. Soc. Rev., 2011, 40, 5010-5029.

69. Y. Monguchi, T. Ichikawa, T. Yamada, Y. Sawama and H. Sajiki, Chem. Rec., 2019, 19, 3-14.

70. C. Moreno-Marrodan, F. Liguori and P. Barbaro, Beilstein J. Org. Chem., 2017, 13, 734-754.

71. C. A. Hone and C. O. Kappe, Top. Curr. Chem., 2019, 377, 2.

72. V. Pascanu, P. R. Hansen, A. B. Gomez, C. Ayats, A. E. Platero-Prats, M. J. Johansson, M. A. Pericas and B. Martin-Matute, ChemSusChem, 2015, 8, 123-130.

73. F. M. Akwi and P. Watts, Chem. Commun., 2018, 54, 13894-13928.

74. J. Zhang, J. Chen, S. Peng, S. Peng, Z. Zhang, Y. Tong, P. W. Miller and X.-P. Yan, Chem. Soc. Rev., 2019, 48, 2566-2595.

75. H. G. Jolliffe and D. I. Gerogiorgis, Chem. Eng. Res. Des., 2016, 112 310-325.

76. P. D. Morse, R. L. Beingessner and T. F. Jamison, Isr. J. Chem., 2017, 57 218-227.

77. I. Rossetti, Catal. Today, 2018, 308, 20-31.

78. D. K. B. Mohamed, X. Yu, J. Li and J. Wu, Tetrahedron Lett., 2016, 57, 3965-3977.

79. L. Shi, X. Wang, C. A. Sandoval, Z. Wang, H. Li, J. Wu, L. Yu and K. Ding, Chem. A Eur. J, 2009, 15, 9855-9867.

80. C. Wang, B. An and W. Lin, ACS Catal., 2019, 9, 130-146.

81. X. Chen, H. Jiang, B. Hou, W. Gong, Y. Liu and Y. Cui, J. Am. Chem. Soc. , 2017, 139, 1347613482.

82. Y. Chen, S. Zhang, F. Chen, S. Cao, Y. Cai, S. Li, H. Ma, X. Ma, P. Li, X. Huang and B. Wang, J. Mater. Chem. A, 2018, 6, 342-348.

83. J. Hou, Y. Luan, X. Huang, H. Gao, M. Yang and Y. Lu, New J. Chem., 2017, 41, 9123-9129.

84. C. G. Piscopo, M. Schwarzer, M. Herrmann, A. Affini, P. Pelagatti, G. Maestri, R. Maggi and S. Loebbecke, Chem CatChem, 2016, 8, 1293-1297.

85. H. Gao, Y. Luan, K. Chaikittikul, W. Dong, J. Li, X. Zhang, D. Jia, M. Yang and G. Wang, ACS Appl. Mater. Interfaces, 2015, 7, 4667-4674.

86. B. R. James, J. A. Boissonnault, A. G. Wong-Foy, A. J. Matzger and M. S. Sanford, RSC Adv., 2018, 8, 2132-2137.

87. H. D. Park, M. Dinca and Y. Roman-Leshkov, J. Am. Chem. Soc., 2018, 140, 10669-10672.

88. W. Ouyang, D. Zhao, Y. Wang, A. M. Balu, C. Len and R. Luque, ACS Sustainable Chem. Eng., 2018, 6, 6746-6752.

89. A. Sachse, R. Ameloot, B. Coq, F. Fajula, B. Coasne, D. De Vos and A. Galarneau, Chem. Commun., 2012, 48, 4749-4751.

90. V. Pascanu, A. B. Gomez, C. Ayats, A. E. Platero-Prats, F. Carson, J. Su, Q. Yao, M. A. Pericas, X. Zou and B. Martín-Matute, ACS Catal., 2015, 5, 472-479.

91. C. G. Piscopo, L. Voellinger, M. Schwarzer, A. Polyzoidis, D. Bošković and S. Loebbecke, ChemistrySelect 2019, 4, 2806 -2809. 
92. H. Li, L. Ma, L. Zhou, J. Gao, Z. Huang, Y. He and Y. Jiang, Chem. Commun., 2018, 54, 1075410757.

93. D. S. Kundu, J. Schmidt, C. Bleschke, A. Thomas and S. Blechert, Angew. Chem., Int. Ed., 2012, 51, 5456.

94. H. S. Ozdemir, E. Sahin and M. Cakici, Tetrahedron, 2015, 71, 2882.

95. F. Guo, D. Chang, G. Lai, T. Zhu, S. Xiong, S. Wang and Z. Wang, Chem. -Eur. J. , 2011, 17, 11127.

96. Y.-F. Sheng, Q. Gu, A.-J. Zhang and S.-L. You, J. Org. Chem., 2009, 74, 6899.

97. I. Fechete, Y. Wang and J. C. Vedrine, Catal. Today 2012, 189, 2.

98. T. Tsuruoka, S. Furukawa, Y. Takashima, K. Yoshida, S. Isoda and S. Kitagawa, Angew. Chem., Int. Ed., 2009, 48, 4739-4743.

99. J. Cravillon, R. Nayuk, S. Springer, A. Feldhoff, K. Huber and M. Wiebcke, Chem. Mater., 2011, 23, 2130-2141.

100. E. Angeletti, C. Canepa, G. Martinetti and P. Venturello, Journal of the Chemical Society, Perkin Transactions 1, 1989, 105-107.

101. A. Sachse, A. Galarneau, F. Di Renzo, F. Fajula and B. Coq, Chemistry of Materials, 2010, 22, 4123-4125.

102. D.-Z. Xu, S. Shi and Y. Wang, RSC Advances, 2013, 3, 23075-23079.

103. T. Jackson, J. H. Clark, D. J. Macquarrie and J. H. Brophy, Green Chemistry, 2004, 6, 193-195.

104. E. A. Feijani, H. Mandavi and A. Tavasoli, Chem. Eng. Res. Des., 2015, 96, 87-102.

105. S. L. Qiu, M. Xue and G. S. Zhu, Chem. Soc. Rev., 2014, 43, 6116-6140.

106. B. Seoane, J. Coronas, I. Gascon, M. E. Benavides, O. Karvan, J. Caro, F. Kapteijn and J. Gascon, Chem. Soc. Rev., 2015, 44, 2421-2454.

107. S. Furukawa, J. Reboul, S. Diring, K. Sumida and S. Kitagawa, Chem. Soc. Rev., 2014, 43, 57005734.

108. L. Wu, T. Moteki, Amit A. Gokhale, David W. Flaherty and F. D. Toste, Chem, 2016, 1, 32-58.

109. N. Alonso-Fagúndez, V. Laserna, A. Alba-Rubio, M. Mengibar, A. Heras, R. Mariscal and M. L. Granados, Catalysis Today, 2014, 234, 285-294.

110. J. D. Lewis, S. Van de Vyver, A. J. Crisci, W. R. Gunther, V. K. Michaelis, R. G. Griffin and Y. Román-Leshkov, ChemSusChem, 2014, 7, 2255-2265.

111. K.-i. Shimizu, E. Hayashi, T. Hatamachi, T. Kodama, T. Higuchi, A. Satsuma and Y. Kitayama, Journal of Catalysis, 2005, 231, 131-138.

112. T. Sakakura and K. Kohno, Chem. Commun., 2009, 1312-1330.

113. A.-A. G. Shaikh and S. Sivaram, Chem. Rev., 1996, 96, 951-976.

114. M. North, R. Pasquale and C. Young, Green Chem., 2010, 12, 1514.

115. K. Kasuga, T. Kato, N. Kabata and M. Handa, Bull. Chem. Soc. Jpn., 1996, 69, 2885-2888.

116. D. Y. Hong, Y. K. Hwang, C. Serre, G. Ferey and J. S. Chang, Adv. Funct. Mater., 2009, 19, 1537.

117. Y. D. Y. L. Getzler, V. Kundnani, E. B. Lobkovsky and G. W. Coates, J. Am. Chem. Soc. , 2004, 126, 6842.

118. M. L. A. Jansen and W. M. van Gulik, Curr. Opin. Biotechnol. , 2014, 30, 190.

119. H. Li, Z. Fang and S. Yang, ACS Sustainable Chem. Eng., 2016, 4, 236-246.

120. A. H. Valekar, K.-H. Cho, S. K. Chitale, D.-Y. Hong, G.-Y. Cha, U.-H. Lee, D. W. Hwang, C. Serre, J.-S. Chang and Y. K. Hwang, Green Chem. , 2016, 18 4542-4552.

121. Y. Kuwahara, H. Kango and H. Yamashita, ACS Sustainable Chem. Eng., 2017, 5, 1141-1152.

122. J. He, H. Li, Y. Lu, Y. Liu, Z. Wu, D. Hu and S. Yang, Appl. Catal., A Gen., 2016, 510, 11-19.

123. X. Tang, H. Chen, L. Hu, W. Hao, Y. Sun, X. Zeng, L. Lin and S. Liu, Appl. Catal., B Environ., 2014, 147, 827-834.

124. J. Gascon and F. Kapteijn, Angew. Chem., Int. Ed., 2010, 49, 1530.

125. S. Aguado, J. Canivet and D. Farrusseng, J. Mater. Chem., 2011, 21, 7582. 
126. E. V. Ramos-Fernandez, M. Garcia-Domingos, J. Juan-Alcaniz, J. Gascon and F. Kapteijn, Appl. Catal., A, 2011, 391, 261.

127. E. Perez-Mayoral and J. Cejka, ChemCatChem, 2011, 3, 157.

128. E. Pérez-Mayoral, Z. Musilová, B. Gil, B. Marszalek, M. Položij, P. Nachtigall and J. Čejka, Dalton Trans., 2012, 41, 4036-4044.

129. N. Zotova, K. Hellgardt, G. H. Kelsall, A. S. Jessiman and K. K. M. Hii, Green Chemistry, 2010, 12, 2157-2163.

130. A. Dhakshinamoorthy, A. M. Asiri and H. Garcia, Chem. Commun., 2017, 53, 10851-10869.

131. H. Liu, Y. Liu, Y. Li, Z. Tang and H. Jiang, J. Phys. Chem. C, 2010, 114, 13362-13369.

132. A. Santiago-Portillo, M. Cabrero-Antonino, M. Alvaro, S. Navalon and H. Garcia, Chem. Eur. J., 2019, 25, 9280-9286.

133. C. W. Yoon, K. F. Hirsekorn, M. L. Neidig, X. Yang and T. Don Tilley, ACS Catal., 2011, 1, 16651678.

134. C. Hammond and G. Tarantino, Catalysts, 2015, 5, 2309-2323. 